\title{
THE CYCLICALITY OF SALES, REGULAR AND EFFECTIVE PRICES: BUSINESS CYCLE AND POLICY IMPLICATIONS
}

\author{
Olivier Coibion \\ Yuriy Gorodnichenko \\ Gee Hee Hong \\ Working Paper 18273 \\ http://www.nber.org/papers/w18273 \\ NATIONAL BUREAU OF ECONOMIC RESEARCH \\ 1050 Massachusetts Avenue \\ Cambridge, MA 02138 \\ August 2012
}

We are grateful to Yury Yatsynovich for excellent research assistance, Martin Eichenbaum and seminar participants at UC Berkeley, NBER Summer Institute, New Economic School, Zurich University, and Central European University for helpful comments. This Working Paper should not be reported as representing the views of the IMF. The views expressed in this Working Paper are those of the author(s) and do not necessarily represent those of the IMF, IMF policy, or the National Bureau of Economic Research. Gorodnichenko thanks NSF for financial support.

NBER working papers are circulated for discussion and comment purposes. They have not been peerreviewed or been subject to the review by the NBER Board of Directors that accompanies official NBER publications.

(C) 2012 by Olivier Coibion, Yuriy Gorodnichenko, and Gee Hee Hong. All rights reserved. Short sections of text, not to exceed two paragraphs, may be quoted without explicit permission provided that full credit, including $(\subset$ notice, is given to the source. 
The Cyclicality of Sales, Regular and Effective Prices: Business Cycle and Policy Implications Olivier Coibion, Yuriy Gorodnichenko, and Gee Hee Hong

NBER Working Paper No. 18273

August 2012

JEL No. E3,E4,E5

\begin{abstract}
$\underline{\text { ABSTRACT }}$
We study the cyclical properties of sales, regular price changes and average prices paid by consumers ("effective" prices) in a dataset containing prices and quantities sold for numerous retailers across a variety of U.S. metropolitan areas. Both the frequency and size of sales fall when local unemployment rates rise and yet the inflation rate for effective prices paid by consumers declines significantly with higher unemployment. This discrepancy can be reconciled by consumers reallocating their expenditures across retailers, a feature of the data which we document and quantify. We propose a simple model with household shopping effort and store-switching consistent with these stylized facts and document its implications for business cycles and policymakers.
\end{abstract}

Olivier Coibion

University of Texas, Austin

and NBER

ocoibion@gmail.com

Yuriy Gorodnichenko

Department of Economics

508-1 Evans Hall \#3880

University of California, Berkeley

Berkeley, CA 94720-3880

and NBER

ygorodni@econ.berkeley.edu
Gee Hee Hong

University of California, Berkeley

ghhong@econ.berkeley.edu 


\section{Introduction}

Explaining the apparent non-neutrality of money has led macroeconomists to study a variety of frictions, such as nominal and real wage rigidities or information rigidities. But the most commonly emphasized potential source of monetary non-neutrality remains “sticky prices” as epitomized by Woodford (2003). In part, this likely reflects the ubiquitousness of sticky prices in daily life. For example, Starbucks has raised its brewed coffee prices only once per year since the 2007-2009 recession began, despite the fact that the spot price of (Robusta) coffee bean rose 50\% between February of 2007 and February of 2008, then fell 33\% from February of 2008 to February 2010, before again rising 50\% by February 2011. ${ }^{1}$ This annual frequency of updating prices is not uncommon, and the notion that many prices change only infrequently has been well-documented in the literature. ${ }^{2}$

Yet while firms may choose to change their prices only infrequently, this need not imply that the “effective” prices actually paid by households are themselves sticky. Chevalier and Kashyap (2011), for example, argue that if households respond strongly to sales, then "effective" price flexibility due to consumers reallocating their expenditures across goods or time could potentially undo much of the macroeconomic effects of the underlying price rigidities commonly observed in regular prices. While a significant body of work now exists which quantifies how the treatment of sales affects the degree of price rigidity (e.g. Bils and Klenow 2004, Nakamura and Steinsson 2008, Eichenbaum, Jaimovic and Rebelo 2011, and Kehoe and Midrigan 2011), evidence on the extent to which sales prices affect the effective prices paid by households remains limited. In large part, this shortcoming reflects data limitations: measuring effective prices paid by households requires data on both quantities and prices, whereas most data-sets include only the latter.

Using a panel dataset of both prices and quantities sold at the universal product code (UPC) level across different stores in 50 U.S. metropolitan areas from 2001 to 2007, we build on this literature by studying the cyclicality in both the prices posted by retailers as well as the effective prices actually paid by consumers. Consistent with Gali and Gertler (1999), Williams (2006), Roberts (2006) and others documenting the lack of a strong negative relationship between inflation and unemployment in U.S. macroeconomic data, we find little cyclical sensitivity in the inflation rate of prices posted by retailers. In contrast, and consistent with the notion of significant consumer reallocation of expenditures in response to economic conditions, we document that effective price inflation is indeed more cyclically sensitive than inflation in posted prices. Furthermore, the difference is quantitatively large: a $2 \%$ point increase in the local unemployment rate lowers the local inflation rate in effective prices by $0.5 \%$ relative to the inflation rate in posted prices for a given UPC.

\footnotetext{
${ }^{1}$ See "Starbucks to Raise Prices" in the January $4^{\text {th }}, 2012$ edition of the Wall Street Journal.

${ }^{2}$ See e.g. Carlton (1986), Cecchetti (1986), and Kashyap (1995).
} 
To assess whether this sensitivity of effective prices paid by households is driven by sales, we also measure the cyclicality of regular and sales price changes, as well as the proportion of a given good bought on sale. While regular price changes exhibit little cyclical sensitivity, we find that the frequency and size of sales, as well as the share of goods bought on sale, decline when unemployment rates rise. Thus, the greater flexibility in prices paid by households relative to the prices charged by firms does not stem from the cyclical response of sales. Indeed, the cyclical behavior of sales is precisely the opposite of what one would expect if sales were used in the same manner as regular price changes: for sales to undo the effects of price rigidities in terms of monetary non-neutrality, we would expect them to be systematically more frequent when local unemployment rates rise. Thus, these results provide new evidence consistent with Eichenbaum et al. (2011), Kehoe and Midrigan (2010) and Guimaraes and Sheedy (2011) that sales are fundamentally different from regular price changes.

If sales are not the source of the observed flexibility in the prices actually paid by households for a given good in a given metropolitan area, what is? We argue that both the counter-intuitive cyclical behavior of sales prices and the discrepancy between the cyclical changes in posted and paid prices can be accounted for by consumers switching across stores in response to economic conditions. Intuitively, given considerable dispersion of prices across stores in any given time period, a deterioration in local economic conditions should lead some price-sensitive consumers to reallocate some of their consumption expenditures toward low-price retailers, thereby lowering the average price paid for any given good. At the same time, this store-switching behavior on the part of price-sensitive consumers should reduce the incentive of high-price stores to attract these price-sensitive consumers through sales, which could account for the counter-intuitive cyclical behavior of sales prices that we identify.

We document two pieces of evidence consistent with this mechanism. First, because we have data for a variety of identical goods sold across different stores within a given geographic area, we can quantify the extent to which some stores are systematically more expensive than others. High-price stores experience larger a decline in the importance of sales than low-price stores when local unemployment rates rise, consistent with the mechanisms described above. We also show that, when the unemployment rate increases, the growth rate of revenues in high-price stores declines more than in low-price stores, consistent with significant expenditure reallocation across retailers by households. Second, we exploit a detailed panel dataset tracking individual households' expenditures at the UPC level for each store. Given that we can characterize the degree to which some stores are more expensive than others, these data allow us to quantify the extent to which individual households reallocate their expenditures across different retailers in response to economic conditions. We find robust evidence that individual households do indeed reallocate their consumption expenditures toward low-price retailers when local 
economic conditions deteriorate and that this reallocation is most pronounced for households near the middle of the income distribution.

In short, our empirical results point to significantly more flexibility in the prices paid by households relative to the prices charged by firms, but this flexibility appears to be driven by the reallocation of household expenditures across retailers rather than by sales. While previous work has considered the macroeconomic consequences of effective price flexibility due to sale pricing by retailers, the potential implications of retail-switching remain unexplored. As a result, we build on the effective price literature by integrating store-switching by households into a basic New Keynesian model. In this model, two retailers each purchase intermediate goods from monopolistic competitors, who are subject to sticky-prices, and convert these goods into an identical final good. One "local" retailer charges a premium over the "discount" retailer. However, household expenditures at the latter are subject to iceberg costs which can be reduced by time-intensive shopping on the part of households. When the return to shopping effort is diminishing, shopping effort on the part of households will be countercyclical. As a result, periods of low employment are also periods of high shopping effort activity. This effort leads to lower effective prices at the "discount" retailer and households therefore reallocate more of their expenditures toward this retailer when employment is low. We show that time-intensive shopping effort and expenditure reallocation lead to three testable predictions: 1) effective prices are high relative to posted prices when the level of economic activity is high, 2) high-price retailers of otherwise identical goods account for a larger share of total retail revenues when the level of economic activity is high, and 3) the unconditional Phillips curve relationship between inflation and economic activity is steeper when measured in terms of effective rather than posted prices. Consistent with household expenditurereallocation, we find that all three predictions hold in our data even when aggregated across all categories and regions.

In the model, the effective prices paid by households are much more flexible than the underlying posted prices, as suggested by Chevalier and Kashyap (2011). However, this effective price flexibility stems not from the presence of sales, as in Chevalier and Kashyap (2011), but from the reallocation of household expenditures across retailers and the time-variation in shopping effort. In response to monetary policy shocks, for example, nearly $50 \%$ of the total adjustment in the price of the final consumption good paid by households occurs in the first quarter, while only this ratio is less than $20 \%$ for underlying posted prices. As a result, the contemporaneous effect of monetary policy shocks on output is smaller, i.e. there is less monetary non-neutrality than one would expect based on the frequency of posted price changes. However, the effect is relatively small on impact and most importantly does not qualitatively affect the persistence of the response of the output gap to monetary policy shocks. Hence, the response of output to a monetary policy shock looks much more like that of a typical New Keynesian 
model with high levels of price stickiness than one with low levels of price-stickiness. In short, despite significant flexibility in the effective prices faced by households, the dynamics of the model are dominated by the underlying level of price-stickiness in posted prices. In this sense, our results are similar in spirit to those of Eichenbaum et al. (2011), Guimaraes and Sheedy (2011) and Kehoe and Midrigan (2011) but whereas they focus on effective price flexibility due to sales, we emphasize the role of the reallocation of expenditures across stores by households as the source of effective price flexibility.

Despite the fact that the quantitative implications of store-switching are limited in terms of the degree of monetary neutrality, the presence of shopping effort and store-switching does have several novel business cycle and policy implications. For example, the presence of shopping effort and storeswitching alters the effective Frisch labor supply elasticity and the effective elasticity of the output gap with respect to real interest rates, when the latter are expressed in terms of input prices rather than final consumption goods prices. For the labor supply elasticity, when the utility return to labor is high, then the return to shopping effort must also be high since the marginal disutilities of labor and shopping effort are identical. High returns to shopping effort require low shopping intensity under diminishing returns. But if less time is spent on shopping, then the marginal disutility of labor is low so households will be willing to supply more labor. For the sensitivity of the output gap to real interest rate changes expressed in terms of posted prices, if real interest rates rise, then output will fall but be expected to rise via the dynamic IS curve. With countercyclical shopping effort, the time spent on shopping will therefore be expected to rise thereby lowering expected inflation in final goods prices. The latter will lead to relatively more consumption and output, thereby mitigating the initial decline in output.

The presence of store-switching and shopping effort also leads to new insights into some traditional measurement issues regarding inflation. For example, the Boskin Commission report (1996) and Shapiro and Wilcox (1996) discussed the potential for store-substitution to cause biased estimates of inflation. Reinsdorf (1993), Hausman and Leibtag (2007) and Diewart, Greenlees and Hulten (2009) try to assess the average inflation bias in the U.S. from store-switching, but focus primarily on the entry of new potentially low-price outlets and the fact that these entrants will only gradually be included in the CPI sample of stores. Triplett (2003) also highlights retail-switching behavior on the part of households as well as the related costs faced by households due to shopping effort. As emphasized in Triplett (2003), the difference in our model between the final consumption price index faced by households and a fixedexpenditure weight index will reflect two sources: the reallocation of expenditures by households across retailers as well as the time-varying intensity of shopping effort on the part of households. One contribution of the paper is to show that the "effective" price index in our model, which uses time-varying expenditure weights across retailers, will generally track the final consumption price index despite not directly including the household costs stemming from shopping effort. Another contribution to the 
inflation measurement literature is documenting how store-switching also leads to a cyclical mismeasurement of inflation both in the data and in the model. We further document that substitution across similar goods within stores also varies with business cycle conditions, so that the well-known "substitution bias" will occur not just in the long-run but also over the course of the business cycle. These two forms of cyclical biases suggest that to more precisely measure the cost-of-living, statistical agencies would be well-served by tracking actual prices paid by consumers rather than prices charged by retail outlets, as emphasized in Triplett (2003).

We also show that shopping effort and store-switching have policy implications above and beyond that for the measurement of inflation. First, the loss function derived from the household's expected utility over consumption and leisure displays a larger relative weight on output gap stabilization. This primarily reflects a reduced welfare cost of inflation volatility in the presence of shopping effort. Inflation volatility implies higher price dispersion which requires more labor, and therefore less leisure, due to the convexity of labor supply. However, countercyclical shopping effort implies reduced shopping intensity when hours worked are high, thereby mitigating the decrease in leisure and therefore the welfare costs of inflation volatility. Finally, we consider whether welfare would be enhanced if central banks responded to effective price measures rather than posted prices. The results vary with the regime: an inflation-targeting central bank is generally well-served by responding to posted price inflation rather than measures of effective price inflation, but in price-level targeting regimes, significantly higher welfare can be obtained by targeting deviations of effective prices from a target level than from targeting traditional posted price gaps. This again suggests that devoting more resources to constructing aggregate measures of effective prices paid by households could potentially lead to improved policy rules and therefore greater economic stability and welfare.

The structure of the paper is as follows. Section 2 discusses the dataset used for the empirical analysis. Section 3 presents baseline empirical results on the cyclicality of regular, sales and effective prices while section 4 documents evidence supporting the cyclicality of store-switching by consumers. Section 5 presents equivalent results for the cyclicality of within-store cross-good substitution. Section 6 develops the model with store-switching and household shopping effort and derives policy and business cycle implications. Section 7 concludes.

\section{Data Description}

We use a very extensive data set assembled by Symphony IRI, a marketing and market research agency, ${ }^{3}$ and discussed in more detail in Bronnenberg, Kruger and Mela (2008). This data set contains weekly

\footnotetext{
${ }^{3}$ Information Resources, Inc. ("IRI”) has changed its name to SymphonyIRI Group, Inc. All estimates and analyses in this paper based on SymphonyIRI Group, Inc. data are by the author(s) and not by SymphonyIRI Group, Inc.
} 
scanner price and quantity data covering a panel of stores in 50 metropolitan areas and 31 product categories from January 2001 and December 2007. Importantly, the date set covers multiple chains of retailers for each market. In addition, the data includes a panel of households in two of the metropolitan areas in which households provided detailed information on their characteristics and purchases. This household dimension can be linked to the store-level information of the data set.

The metropolitan areas are typically defined at the Metropolitan Statistical Area (MSA) level. In four cases (West Texas/New Mexico, South Carolina, New England, and Mississippi), the areas identified in the data set offer a greater coverage than a city. Two of the metropolitan areas are smaller than typical (Eau Claire, WI and Pittsfield, MA) but the household panel data were constructed only for these two areas. Within each metropolitan area, the data includes price and quantity data from a panel of stores, defined either as drug stores or grocery stores. Grocery stores outnumber drug stores within each metropolitan area. For example, data from San Francisco in 2005 cover 44 grocery stores and 14 drug stores. Each outlet has an identifier which is constant over time so one can track the prices and revenues at each retailer over time. However, retailers (or chains of retailers) are deliberately not identified by name.

For each retail outlet, weekly data are available at the UPC (universal product code) level. Goods are classified into 31 general product categories (e.g., Beer, Coffee, Deodorant) as well as more refined categories. Brand information is included (e.g., Budweiser, Heineken, Coors) but all private-label UPC's have the same brand identification so that the identity of the retailer cannot be recovered from the labeling information. Detailed information about each good is included, such as whether a product is low-fat, as is information about the volume of the product (e.g., 6-packs vs. 12-packs, volume per container). Unfortunately, no data on costs are available.

Retailers report the total dollar value of weekly sales (TR) for each UPC code, as well as total units sold (TQ). The combination of the two yields the average retail price during that week which is computed as follows:

$$
P_{m s c t j}=\frac{T R_{m s c t j}}{T Q_{m s c t} j}
$$

where $m, s, c, t$, and $j$ index markets, stores, product categories, time, and UPC. This retail price includes retail features, displays and retailer coupons, but does not incorporate manufacturer coupons. In addition, retailers flag goods on sale. Thus, the dataset provides the average price of a good paid by consumers at a given store during the course of the week, as well as whether this price is identified as a sales price.

Because we are interested in differentiating between regular price changes and those due to sales, we adopt the following conventions. First, any change in prices between two periods when neither period has a sales flag is defined as a "regular" price change if the price difference exceeds $1 \%$ in value. Second, when a sales flag is listed and the price after the sale expires is the same as prior to the sale, we assume no 
change in regular prices in intermittent periods. Third, in addition to the sales flag provided in the data set, we apply an additional filter similar to the filter in Nakamura and Steinsson (2008). Specifically, we consider a good on sale if a price reduction is followed by a price increase of the same magnitude within four weeks. ${ }^{4}$

Table 1 presents basic statistics about the weekly frequency and size (in log-percentage terms) of both sales price changes and regular price changes across goods and for each of the main categories. We also present data on the average share of goods bought on sale. ${ }^{5}$ The frequency of sales and regular price changes are computed at the individual UPC level in a given month, then averaged across all UPC labels within a category in a given city and month, and finally averaged across time and cities. To aggregate across the individual UPCs within each product category, we use several weighting schemes: $i$ ) equal weights; ii) expenditure shares for a given city and year (“city specific”); iii) cross-city expenditure shares for a given year (“common”). ${ }^{6}$

The average size of sales is approximately $25 \%$ across all goods. While less than $20 \%$ of goods are on sale in any given week, more than $30 \%$ of all goods purchased are done so when goods are on sale. Frozen dinners and frozen pizzas are the goods which are proportionally most bought on sale, while cigarettes are the least frequently bought on sale (Appendix Table A1). It is also the case that frozen dinners and pizzas are among the goods which are most frequently on sale while cigarettes are only rarely on sale. Cigarettes and beer are the goods for which sales, when they do occur, tend to be smallest while frozen dinners and pizzas are, again, at the other extreme. Panel A of Figure 1 documents that there is a strong positive correlation between the frequency and size of sales across categories, while Panel C illustrates the fact that categories of goods with a higher frequency of sales also have a larger fraction of goods bought on sale.

Rows (4) through (9) in Table 1 focus on the properties of regular price changes. Across all goods, increases in regular prices are more frequent than price decreases. The average size of price changes is $3.5 \%$ and the average size of absolute price changes is $12 \%$. The average weekly frequency of regular price changes is $5 \%$, so that the average duration between regular price changes is approximately 5 months. While lower than the frequency found by Nakamura and Steinsson (2008), our data is sampled at the weekly frequency which can lead to higher estimates of the frequency of price changes than when data is sampled at the monthly frequency, as documented in Kehoe and Midrigan (2010). Panel B of

\footnotetext{
${ }^{4}$ Results are similar when we do not use this filter because the vast majority of sales are picked by the flag provided in the dataset. See Appendix D for more details.

${ }^{5}$ This share for each UPC is calculated as follows. The denominator is the total number of units of a UPC sold across all stores in a given city and month. The numerator is the number of units of the same UPC sold on sale (i.e., when a flag indicates that a store had a sale of this UPC in a given week) across all stores in a given city and month.

${ }^{6}$ See Appendix D for more details on how weights are constructed.
} 
Figure 1 illustrates that, in contrast to sales, categories of goods with more frequent regular price changes tend to have smaller price changes.

Figure 1 also examines whether there is any systematic link between the properties of regular price changes and sales across categories. Panel D, for example, shows that there is little link between the frequencies of sales and regular price changes across categories, while Panel E documents instead a positive relationship between the average size of sales (in percentage terms) and the average change in regular prices across categories. Finally, Panel F illustrates a weak positive relationship between the frequency of sales and the average size of regular price changes across categories.

\section{The Cyclicality of Effective, Regular and Sales Price Changes}

While a significant literature now exists on measuring and quantifying different forms of price changes, our primary interest is in examining the cyclicality of different prices in the data. In particular, we distinguish between two forms of prices: posted prices are those provided at the store-level and consist of both regular and sales prices, and "effective" prices are the average (weighted by quantities) prices paid by households across retailers for a given good.

\subsection{The Cyclicality of Posted and Effective Prices}

To first characterize whether the prices that households pay differ in a systematic manner from the prices charged by retailers, we examine the cyclicality of the two. Measuring the effective prices paid by households exploits the fact that our data includes quantities sold as well as prices. It further exploits the fact that we have data for a large number of retailers within each metropolitan area. Specifically, we first construct the quantity-weighted average "effective" price of a specific good $j$ in category c across stores in geographic area $m$ as

$$
\bar{P}_{m c j t}^{e f f}=\frac{\sum_{s \in m} T R_{m s c t j}}{\sum_{s \in m} T Q_{m s c t j}} .
$$

This measure can change because individual prices change or because consumers reallocate their consumption of the good across stores. For each good $j$ in category $c$ and market $m$, we then compute the monthly inflation rate $\log \left(\bar{P}_{m c j, t}^{e f f} / \bar{P}_{m c j, t-1}^{e f f}\right)$. Then, using weights $\omega_{m c j t}$ for UPCs, we aggregate across all goods $j$ within a category $c$ to get the average category-level inflation rate across stores. In aggregating across goods, we consider the use of equal weights, city-specific weights, and common weights across UPC's within each product category. Because these weights are held fixed within each calendar year, our measure of "effective" price inflation does not include substitution across goods, a question to which we return in section 5. Finally, we cumulate monthly inflation rates into the annual inflation rate $\bar{\pi}_{m c t}^{\text {eff }}$. which we refer to as the "across-store effective inflation rate". Using prices 
constructed in (2.1), we also construct posted inflation price measures $\bar{\pi}_{m c t}^{\text {post }}$ in an equivalent manner, except for the fact that weighting across retailers is based on fixed-expenditure weights rather than timevarying expenditure-weights. $^{7}$

To assess the cyclicality of price changes with respect to economic conditions, we adopt the following baseline empirical specification:

$$
Y_{m c t}=\beta U R_{m c t}+\lambda_{t}+\theta_{m, c}+\text { error }
$$

where $m, c$, and $t$ index markets (e.g., Atlanta, Detroit), the category of the good (e.g., beer, yogurt), calendar time (i.e., month); $Y_{m c t}$ is a variable of interest (e.g., effective inflation rate); $U R_{m c t}$ is the local seasonally-adjusted unemployment rate; ${ }^{8} \theta_{m, c}$ denotes the fixed effect for each market and category of good while $\lambda_{t}$ denotes time fixed effects. Because the unemployment rate at the metropolitan level is only available at the monthly frequency, we estimate specification (3.2) at the monthly frequency as well. Since the error term in specification (3.2) is likely to be serially and cross-sectionally correlated, we use the Driscoll and Kraay (1998) method to construct standard errors. ${ }^{9}$

Estimates of $\beta$ in specification (3.2) show the strength of correlations between local business conditions and various pricing moments and thus are informative about cyclical properties of these moments. One may, however, entertain a causal interpretation of the estimates. Because most goods sold in stores are not produced locally, specification (3.2) should not suffer from endogeneity issues typically associated with regressions of prices on real economic activity. For example, unobserved productivity innovations for a specific product, like razors, are unlikely to be correlated with local unemployment rates. While aggregate shocks could lead to simultaneous movements in prices of goods and local economic conditions, controlling for time fixed-effects should eliminate this endogeneity issue. Hence, the causal interpretation of $\beta$ in specification (3.2) can stem from the fact that almost all products sold at a given retailer will be produced in other geographic areas so that local variation in unemployment rates will serve as proxies for shocks to the local demand for consumer goods.

Given these measures of posted price and effective price inflation rates at the category/market level, we estimate their cyclical sensitivity to local economic conditions using equation (3.2). The results

\footnotetext{
${ }^{7}$ In constructing fixed expenditure-weights across stores for a given UPC, we use the average share of revenues for each store over the course of that calendar year. Thus, our measure of posted price inflation updates weights applied to each retailer for each UPC at the annual frequency. In contrast, the BLS updates retailer weights once every five years. This implies our estimates will actually understate the difference between posted and effective price measures relative to BLS procedures.

${ }^{8}$ We find similar results when we use alternative measures of local business conditions, e.g., local employment statistics constructed by the Bureau of Labor Statistics.

${ }^{9}$ Driscoll-Kraay standard errors tend to be conservative. Appendix Table 3 presents alternative estimates of standard errors.
} 
are presented in Table 2. Focusing on the results with both city-category and time fixed-effects, we find little cyclical sensitivity of posted price inflation measures to local economic conditions. While the coefficients on unemployment rates are mostly negative, we cannot reject the null of zero response. This acyclicality in posted price inflation to economic conditions is consistent with Gali and Gertler (1999), Williams (2006), Roberts (2006) and others documenting the lack of a strong negative relationship between inflation and real economic activity in U.S. macroeconomic data, albeit that our results obtain at a microeconomic level. However, the results for inflation in effective prices are quite different: the inflation rate of prices actually paid by consumers drops significantly when local economic conditions worsen. Furthermore, the difference between the two sets of coefficients is economically large: a $2 \%$ point increase in the local unemployment rate lowers the effective price inflation rate by $0.5 \%$ at an annual rate below the inflation rate of posted prices. Hence, the key finding is that effective prices paid by households are significantly more flexible and sensitive to economic conditions than the underlying prices charged by retailers. ${ }^{10}$

\subsection{The Cyclicality of Sales and Regular Price Changes}

The greater flexibility in the effective prices paid by households relative to those charged by firms is consistent with the logic of Chevalier and Kashyap (2011) in which the reallocation of consumer expenditures leads not just to greater effective price flexibility for households but ultimately to diminished monetary non-neutralities. To investigate the source of this flexibility, we now consider whether sales are the key driver of this behavior. Thus, we again estimate (3.2) but now use the frequency and size of sales for each UPC aggregated to the category/market level, as well as the share of monthly expenditures for each UPC done on sale, again aggregated to the category/market level. For comparison, we also assess the cyclicality of regular price changes, both in terms of their frequency and size. Note that since posted price inflation rates depend on both the frequency and size of price changes, this can be interpreted as a decomposition of the results for inflation rates.

The first column of Table 2 documents results from estimating specification (3.2) at the category/market level using a simple average across all UPC products within a category, excluding all fixed effects in specification (3.2). The results indicate that a higher local unemployment rate is associated with more frequent sales and a larger share of goods on sales. However, it is unclear whether this larger role played by sales reflects the fact that sales become more prevalent within a market when $i$ )

\footnotetext{
${ }^{10}$ Appendix Table 4 confirms this finding at the category level: the point estimates of the effect of unemployment on effective price inflation are stronger than those on posted price inflation for 25 out of 31 categories. Likewise, Appendix Table 4 documents that the same result obtains for the majority of individual categories for posted prices: for 19 out of 31 categories, the point estimates of local unemployment on posted inflation rates are insignificantly different from zero.
} 
the unemployment rises (i.e. business cycle effects), ii) regions with higher unemployment rates on average also experience more frequent sales for other reasons (i.e. systematically more depressed areas may have on average more frequent sales), or iii) there is a comovement of trends in unemployment and properties of sales. As a result, columns (2) and (3) present equivalent results controlling for geographic/category specific effects and time fixed effects to address ii) and iii). Introducing geographic/category level fixed effects eliminates much of the positive effect of unemployment on sales found in the previous specification, leaving little evidence of cyclical sensitivity of pricing behavior to economic conditions. However, this lack of sensitivity to economic conditions could also reflect macroeconomic shocks (or other omitted variables) which induce variation in both unemployment rates and the dependent variables and thus lead to potentially spurious correlations. As a result, our preferred specification includes both geographic/category fixed effects and time fixed effects. As illustrated in column (3), controlling for time fixed effects alters the results: higher unemployment rates within an area become associated with significantly less frequent sales and those sales which do occur are smaller in size (the positive coefficient points to smaller sales since these are measured as negative values). Although consumers may time their purchases to exploit scarcer sales and thus offset some of the decline by purchasing more goods on sale whenever there is a sale, we find no support for this channel. Specifically, the share of goods bought on sale declines with increases in the rate of unemployment. ${ }^{11}$ Hence, these results indicate that once one controls for aggregate conditions, a worsening in local economic conditions reduces the size, frequency, and relative importance of sales. ${ }^{12}$

In addition, column (3) documents the cyclicality of regular price changes. These results point to a slightly reduced frequency in regular price changes. This reduced frequency of price changes obtains for both price increases and price decreases, although the results are only marginally statistically significant for the former. However, when we measure category averages using expenditure weights, either city-specific (column (4)) or common across cities (column (5)), cyclical changes in the frequency of regular price changes are no longer significantly different from zero. Furthermore, we find little evidence that the size of regular price changes varies with local economic conditions, regardless of the category aggregation method. The cyclicality of sales behavior, on the other hand, is very robust to the

\footnotetext{
${ }^{11}$ Glandon (2011) also estimates the sensitivity of sales prices and shares of goods sold on sale to unemployment rates using the IRI data but finds that higher unemployment rates are associated with larger discounts for consumers. However, he estimates a specification similar to (1) at the annual frequency and without explicit controls for geographic areas or categories of goods. Hence, his estimates point to the same conclusion as our pooled OLS estimates. The results in Table 2 suggest, however, that controlling for time and regional/product dummies is key to identifying the pro-cyclicality of sales.

${ }^{12}$ Using another data set, Anderson et al. (2012) find that sales are unresponsive to macroeconomic shocks such as changes in oil prices.
} 
aggregation method. The frequency and average size of sales, as well as the share of goods bought on sale, are robustly lower when local unemployment rates are higher. ${ }^{13}$

In short, these results suggest that the properties of regular price changes are close to acyclical: neither the frequency nor size of these types of price changes vary in a systematic manner with local economic conditions. Similarly, we find little evidence that category-level inflation rates are significantly reduced by higher local unemployment rates. In contrast, sales prices appear to be much more cyclical: sales are smaller and less frequent when local unemployment rates are high, and the share of goods bought on sale declines with worsening local economic conditions. This counter-intuitive cyclical behavior of sales strongly suggests that sales prices are unlikely to have the same macroeconomic implications as regular price changes since one would then expect more frequent and larger sales in the face of economic downturns accounting for the decline in aggregate inflation. Thus, the pro-cyclicality of sales suggests that the relevant degree of price stickiness is closer to that of Nakamura and Steinsson (2008) than Bils and Klenow (2004), consistent with Eichenbaum et al. (2011), Kehoe and Midrigan (2010) and Sheedy and Guimaraes (2011).

\subsection{Implications of Sales and Effective Price Cyclicality}

The pro-cyclicality of both sales and effective prices identified in the previous two sections raises two questions. The first is whether the two are related phenomena. The pro-cyclicality of effective prices means that when local economic conditions deteriorate, households pay lower prices (or price increases are smaller) for a given good. The acyclicality of regular price changes means that the regular prices of the goods do not change, on average, when local economic conditions deteriorate while the pro-cyclicality of sales means that goods are less frequently on sale and that sales are smaller on average. One way to reconcile these sets of facts is through the reallocation of expenditures by households across retailers: when local economic conditions worsen, households purchase relatively more of their expenditures at low-price retailers, thereby lowering effective prices paid even in the absence of decreases in prices charged by retailers.

While the pro-cyclicality of sales may seem counterintuitive when these are viewed primarily as just another form of price changes, interpreting it in the context of a setting in which consumers can switch across retailers delivers a natural link between the two. Intuitively, a deterioration in local economic conditions should lead more price-sensitive consumers to reallocate some of their consumption

\footnotetext{
${ }^{13}$ Appendix Table 4 presents disaggregated results from estimating (3.2) by category. The results support the notion that the pro-cyclicality of sales is quite common and is not driven by just a few categories. For example, 22 out of 31 categories are characterized by higher unemployment rates being associated with less frequent sales, and these effects are statistically significant for 15 of the categories. Only for two categories are the effects reversed and statistically significant: diapers and tooth-brushes.
} 
expenditures toward low-price retailers, thereby lowering the average price paid for any given good. At the same time, this store-switching behavior on the part of price-sensitive consumers should reduce the incentive of high-price stores to attract these price-sensitive consumers through sales, which could account for the counter-intuitive cyclical behavior of sales prices that we identify. In addition, these two effects should reinforce each other. To the extent that high-price stores reduce the frequency and size of sales, then this should induce additional store-switching behavior on the part of price-sensitive consumers, which in turn should again reduce the incentive of high-price stores to do sales, etc.

In Appendix B, we present a simple model building on Lal and Rao (1997) which illustrates this mechanism and the multiplier effect of store-switching on sales and vice-versa. There are two retailers in the model. One sets "everyday low prices” (EDLP) and does no sales while the other retailer, referred to as "HiLo", follows a pricing strategy that incorporates intermittent sales. The coexistence of the two types of retailers is a unique Nash equilibrium and ensures a segmentation of the market. The two stores compete over two different types of consumers: "bargain hunters" and "loyal" consumers. These consumers differ in their transportation costs and in whether they observe sales prices. Bargain hunters have low transportation costs and always observe all prices, hence they purchase from the store that offers the lowest cost that period (including transportation cost). Loyal consumers have higher transportation costs and do not observe current prices. As a result, they buy a single unit from the retailer which offers the lowest price (net of transportation costs) in expectation. An increase in the share of bargain hunters (which we interpret as similar to an increase in local unemployment rate) leads to relatively more consumers buying from the low-price EDLP retailer. This reduces the incentive of the HiLo retailer to do sales thereby increasing the relative price of HiLo stores by decreasing the optimal size of sales. This simple model illustrates how variation in local economic conditions can, in the presence of storeswitching on the part of households, naturally account for the pro-cyclicality of sales observed in the data. In section 4, we provide additional empirical evidence in support of this mechanism.

The second question which follows from store-switching by households is whether the flexibility that it implies for effective prices paid by households matters for macroeconomic dynamics. Chevalier and Kashyap (2011) argue that effective price flexibility due to sales could potentially undo the monetary non-neutralities typically associated with rigid prices. Our evidence suggests that while the prices paid by households are indeed significantly more flexible than implied by changes in posted prices, this flexibility stems from the reallocation of household expenditures across retailers rather than from counter-cyclical sales. An important question, therefore, is quantifying the extent to which effective price flexibility due to store-switching affects the degree of monetary non-neutrality as well as assessing other business cycle and policy implications of store-switching. To this end, we build a model in section 6 with shopping 
effort and store-switching on the part of households which allows us to quantify the implications of storeswitching behavior for macroeconomic dynamics.

\section{Household Store-Switching}

To provide more direct evidence on whether consumers reallocate their expenditures across retailers as their incomes change, we pursue two complimentary approaches. The first approach establishes that the pro-cyclicality of sales is particularly pronounced for high-price retailers. The second approach employs household panel data and documents that households do indeed reallocate their consumption expenditures toward low-price retailers when local economic conditions worsen.

\subsection{Cross-sectional variation in the sensitivity of pricing to business conditions}

To quantify expenditure switching across retailers, we construct a time-varying ranking of stores' relative prices as follows. First, for each UPC-level good $j$ in category $c$ and market $m$, we rank each store $s$ in a given market and period $t$ by the price charged for that good. The rank $R$ is 1 when a store has the lowest price, $R=2$ for the second lowest price, and so on. We normalize the rank by $\left(R_{\max }+1\right)$, i.e., the number of stores selling this good plus one, so that the resulting rank $R_{m c s t j} \in(0,1) .{ }^{14}$ Second, we compute the average rank for a store across the set of UPC products $\Omega$. We consider several versions of $\Omega$ because different stores sell different goods: i) $\Omega$ includes all UPCs that are sold in every store in a given market $\left(\Omega_{\max }\right)$; ii) $\Omega$ includes UPCs sold in $90 \%$ of stores in a market $\left(\Omega_{90}\right)$; iii) $\Omega$ includes UPCs sold in $75 \%$ of stores $\left(\Omega_{75}\right){ }^{15}$ The average rank of a store for a given $\Omega$ is $R_{m s t, \Omega}=\sum_{c} \sum_{j \in \Omega} \omega_{m c s t j} R_{m c s t j}$ where $\omega$ is a weight (equal, city-specific, or common). Finally, we rank stores based on $R_{m s t, \Omega}$ to determine stores with consistently low and high prices. To make ranks comparable across cities, we normalize $R_{m s t, \Omega}$ by the number of stores in a city plus one to have the resulting rank $\bar{R}_{m s t, \Omega} \in(0,1)$, where 0 is the lowest-price and 1 is the highest-price store. A store's price ranking tends to be highly persistent over time, with an autocorrelation parameter of 0.90 at the annual frequency. ${ }^{16}$

To quantify how the cyclicality of price changes varies with the relative price rank of the store, we perform the analysis at the store-level using the following empirical specification

$$
Y_{m s t}=q_{s m}+a_{1} U R_{m t}+a_{2} U R_{m t} \times \bar{R}_{m s t, \Omega}+\lambda_{t}+\text { error }
$$

\footnotetext{
${ }^{14}$ In this normalization, we use $\left(R_{\max }+1\right)$ instead of $R_{\max }$ to ensure that the average rank is centered at 0.5 .

${ }^{15}$ We do not consider $\Omega$ which includes goods sold in at least one store, which includes private labels specific to a retail chain. In this case, when only one store sells a given UPC, it is automatically ranked as the lowest priced store $(\mathrm{R}=1)$. Consequently, stores with a significant share of private labels may appear cheap even when they are not. Thus, using the universe of goods to rank stores can lead to distorted rankings of stores.

${ }^{16}$ We find similar results when we use alternative measures to rank stores (e.g., percent deviation from median price of a UPC in a given city and month). See Appendix Tables 6 and 7.
} 
where $Y_{m s t}$ is a price moment considered for store $s$ in market $m$ at time $t, q_{s m}$ is the store $s$ fixed effect in market $m$, and $\lambda_{t}$ is the time fixed effect. The aggregation of the price measures across goods is done via expenditure shares of each UPC product across all stores.

In Table 3, we present results using the three different definitions of $\Omega$ applied to the size and frequency of sales, the share of goods bought on sale, and the size and frequency of regular price changes. The results are consistent with the notion that a store's price rank has significant effects on the cyclicality of price changes. Specifically, more expensive stores (those with a higher rank) exhibit much more pronounced declines in the frequency of sales. This is accompanied by a significant decline in the share of goods bought on sale in more expensive stores. The size of sales in more expensive stores and the size of sales in less expensive stores have similar reactions to the unemployment rate. Finally, when the unemployment rate increases, the growth rate of revenues declines more strongly in expensive stores than in cheap stores. In fact, the least expensive stores may experience an increase in the growth rate of revenue when unemployment increases. These results hold for all definitions of $\Omega$ and are therefore consistent with the notion that higher unemployment leads to store-switching by price-sensitive consumers and a reduction in the incentive of high-price stores to offer discounts and sales to attract them.

\subsection{Households' choices of shopping outlets as a function of business conditions}

We also consider an alternative and more direct approach to quantifying the extent of consumers' reallocation of their expenditures across stores. The household panel data developed by IRI Symphony tracks between 5,000 and 10,000 households in Eau Claire, WI and Pittsfield, MA from 2001 to 2007. About 2,000 households are continuously present between 2001 and 2007. During this time, households' expenditures on each UPC product were tracked, including the location of each purchase. Hence, these detailed data allow us to directly measure the extent of the store-switching phenomenon at the level of individual households in light of changing economic conditions.

To do so, we first construct a household-specific time-varying measure of the pricing rank of the stores in which each household does its shopping. Specifically, we construct an average rank of stores at which household $h$ shopped in month $t$ and market $m$ (either Eau Claire, WI or Pittsfield, MA)

$$
\tilde{R}_{h m t}=\sum_{s \in m} \psi_{m h s t} \bar{R}_{m s t, \Omega}
$$

where $\bar{R}_{m s t, \Omega}$ is the average price rank of store $s$ in market $m$ at time $t$ across the set of goods $\Omega$ as defined before and $\psi_{m h s t}$ denotes the share of the household's expenditures spent at store $s$ in market $m$ and month $t$. A low (high) value of $\widetilde{R}_{h m t}$ means that household $h$ made purchases in low (high) price stores in

month $t$. Using $\tilde{R}_{h m t}$ therefore provides a way to quantify the extent to which each household is allocating their expenditures across retailers of different average price levels. 
To assess whether individual households reallocate their expenditures across stores as local economic conditions change, we estimate the following specification across households in the two markets

$$
\tilde{R}_{h m t}=q_{h m}+a_{1} U R_{m t}+\lambda_{t}+\text { error }
$$

where $q_{h m}$ is a household $h$ in city $m$ fixed effect and $\lambda_{t}$ is a time fixed effect. The results are presented in Table 4 using both a simple average across all UPC's consumed by a household as well as using a household's average expenditure-weights across UPCs. Because store price ranks can vary with the set of UPC's used in their construction, we produce these results for each of the definitions of $\Omega$ considered before. The results are similar regardless of the choice for $\Omega$ or weights used to construct each household's average expenditure-rank: the coefficient on unemployment is negative and statistically significantly different from zero at standard levels. Thus, higher local unemployment rates are associated with households substituting more of their expenditures towards low-price retailers. In addition, the estimated magnitudes are relatively large: a $1 \%$ point increase in the local unemployment rate is associated with a decrease in the average rank at which households shop of between 0.05 and 0.13 depending on the specific measures used. ${ }^{17}$

The household data also includes detailed characteristics of each household for that year, such as age of the head of household, income, and the number of household members. As a result, we can also investigate which types of households are most likely to engage in store-switching behavior. Specifically, we focus on the relationship between household income and store-switching via the following empirical specification:

$$
\tilde{R}_{h m t}=q_{h m}+a_{1} U R_{m t}+\sum_{g} a_{g} U R_{m t} \times D_{h m}^{g}+\lambda_{t}+\text { error }
$$

where $D_{\mathrm{hm}}^{g}$ is the dummy variable equal to one if the average annual income of household $h$ in market $m$ falls into $g^{\text {th }}$ quintile of the income distribution we have in the IRI sample of households. ${ }^{18}$ Hence, $a_{1}$ indicates the degree of store switching for the lowest-income quintile. Using $a_{1}$ as the benchmark, we explore how the degree of store-switching varies with income quintile. The results are presented in Table 5 for different measures of $\Omega$ and using both equal and expenditure-share weighting of different goods. In each case, the strongest store switching is observed for households in the second and third income quintiles (annual income between $\$ 22,600$ and $\$ 50,000$ ). This seems intuitive: most low-income

\footnotetext{
${ }^{17}$ An alternative way to assess store-switching by households is to construct the fraction of each household's expenditures going to high-price versus low-price retailers (defining low-price as rank less than 0.5), then regress these time-varying expenditure shares for each household on local economic conditions using (4.3). The results are qualitatively similar as those found using time-varying rank of stores at which households do their shopping: higher local unemployment leads to a larger share of household expenditures being spent at low-price retailers. We are grateful to Martin Eichenbaum for suggesting this alternative approach.

${ }^{18}$ The income ranges for each quintile are: $1^{\text {th }}$ quintile ranges from $\$ 5000$ to $\$ 22,500 ; 2^{\text {nd }}$ quintile ranges from $\$ 22,600$ to $\$ 31,600 ; 3^{\text {rd }}$ quintile ranges from $\$ 31,700$ to $\$ 50,000 ; 4^{\text {th }}$ quintile ranges from $\$ 50,100$ to $\$ 70,000 ; 5^{\text {th }}$ quintile ranges from $\$ 70,100$ to $\$ 120,000$.
} 
households are likely to shop in less expensive stores most of the time, while high-income households are more likely to consistently shop in the most expensive stores. Hence, sales by high-price stores are likely to be designed to attract the middle of the income distribution, and it is these consumers whose switching behavior is most significant over the course of the business cycle.

\section{Cross-Good Substitution}

While we have so far limited our attention to expenditure-switching across stores by households for a given UPC product, the literature on price measurement has long emphasized another margin of substitution, namely across goods. Our primary motivation for focusing on switching across stores for a given good is that, as in the construction of the CPI, it is helpful to consider the cost of a fixed basket of goods for welfare purposes. The substitution bias long emphasized in the literature, in which CPI inflation will be overstated because it ignores the possibility of consumers switching to substitute goods when relative prices change, instead involves a change in the composition of the basket which will have implications for welfare. Nonetheless, we also consider this additional margin here for two reasons. First, the substitution bias has primarily been considered as a source of a long-run bias in inflation measurements, while the cyclical properties of this margin have been ignored. Second, comparing the degree of store-switching to the amount of across-goods substitution provides one metric to quantify the relative importance of store-switching for the measurement of inflation.

To quantify the degree of substitution across goods, we first construct the quantity-weighted average "effective" price across all goods $j$ within category $c$ in store $s$ and geographic area $m$ as

$$
\bar{P}_{m c t s}^{e q}=\frac{\sum_{j \in c} T R_{m s c t j}}{\sum_{j \in c} T Q_{m s c t} \times E Q_{j}} .
$$

where $E Q_{j}$ is the quantity equivalent of good $j$. Hence, in calculating $\bar{P}_{m c t s}^{e q}$, all prices are converted into quantity-equivalent measures so that e.g. the price of a 6-pack of beer is comparable to a 12-pack. $\bar{P}_{m c t s}^{e q}$ can change because individual prices change or because consumers reallocate their consumption of goods within a given category. For category $c$, store $s$ and market $m$, we compute the monthly inflation rate $\log \left(\bar{P}_{m c s t}^{e q} / \bar{P}_{m c s, t-1}^{e q}\right)$. Then, we aggregate across all stores in market $m$ to get the average category-level inflation rate. Similar to the aggregation above, we consider the use of equal weights or expenditureweights to aggregate across stores. ${ }^{19}$ Finally, we cumulate monthly inflation rates into annual inflation rate $\bar{\pi}_{m c t}^{e q}$ which we refer to as the "within-category effective inflation rate".

Because some categories include much more heterogeneity in goods than others, we consider two classification schemes for measuring the substitution of goods within categories. The first (and broadest)

\footnotetext{
${ }^{19}$ Because quantity equivalents are not available or are not comparable for some categories, we exclude the following categories from this analysis: deodorant; frozen dinner; photo; soup.
} 
includes all UPCs within a category. The second allows substitution only within subcategories which approximately corresponds to adding another digit to the level of disaggregation. For example, we use all types of milk when we calculate $\bar{P}_{m c t s}^{e q}$ for the first classification. In contrast, the second classification considers separately such subcategories as whole milk, skimmed milk, $2 \%$ milk, etc. Inflation rates for subcategories are aggregated to the category level using equal or expenditure-based weights.

The sensitivity of these inflation rates to local unemployment is then assessed using

$$
\bar{\pi}_{m c t}^{e q}=\beta U R_{m t}+\lambda_{t}+\theta_{m, c}+\text { error }
$$

which is equivalent to the specification used to measure the sensitivity of effective across-store inflation rates to economic conditions. The results, presented in Table 6, point to a statistically significantly negative relationship between unemployment rates and cross-good inflation rates. Thus, as in our baseline results, this indicates that there is significant substitution of expenditures by households in response to changing local economic conditions, but along a different margin, namely substituting across different goods within a category. Not surprisingly, the effect is stronger when we allow a larger set of goods within each category. Importantly, the quantitative magnitudes are of the same order as those identified for across-store substitution.

\section{Aggregate Implications of Store-Switching}

The key message from our empirical results is that while significant flexibility is present in the prices paid by households relative to those charged by retailers, this flexibility is driven primarily by store-switching on the part of households rather than sales. To what extent should macroeconomists care about storeswitching behavior? In this section, we present a stylized New Keynesian model in which households can reallocate their expenditures across stores in light of changing economic conditions. The model delivers testable predictions which are confirmed in the data. We then present and discuss some business cycle and policy implications of the model.

\subsection{New Keynesian Model with Consumer-Expenditure Reallocation across Retailers}

To assess the implications of the reallocation of expenditures across stores, we incorporate a decision on the part of households over how much to purchase from different retailers into an otherwise standard New Keynesian model as in Clarida, Gali and Gertler (1999) and Woodford (2003). Retailers sell identical composite goods but at potentially different prices. The "local" retailer charges a higher price to consumers, but purchases at the "discount” retailer come with an iceberg cost. This cost can be reduced by households via time-intensive shopping effort. Thus, households can reduce the effective price of their aggregate consumption at the expense of leisure time. Intermediate goods are produced under monopolistic competition subject to infrequent price adjustment. We abstract from sales in the model and 
focus primarily on the expenditure reallocation decision of households, but including sales would tend to strengthen the expenditure reallocation process given the cyclical properties of sales documented in sections 3 and 4 .

\subsubsection{Household Problem}

The representative household maximizes lifetime utility over consumption and leisure

$$
E_{0} \sum_{t=0}^{\infty} \beta^{t}\left\{\log C_{t}+\log \left(1-L_{t}-S_{t}\right)\right\}
$$

where $C_{t}$ is the consumption bundle of goods, $L_{t}$ is labor supply, $S_{t}$ is the shopping effort or time spent searching for better prices, and $\beta$ is the discount factor. Labor is freely mobile across employers. Households live in location $A$ and can purchase consumption goods $C_{A, t}$ from the "local" retailer and purchase $C_{B, t}$ from the "discount" retailer in location $B$. We assume that the total consumption bundle $C_{t}$ is given by

$$
C_{t}=\left(C_{A, t}^{\frac{\gamma-1}{\gamma}}+C_{B, t}^{\frac{\gamma-1}{\gamma}}\right)^{\gamma /(\gamma-1)}
$$

where $\gamma$ measures the elasticity of substitution across stores (or rather locations). The imperfect substitution among retailers guarantees positive purchases at each retailer and will be used to calibrate the degree of store-switching to what we observe in the data. The budget constraint of the household is

$$
P_{A, t} C_{A, t}+\tau_{t} P_{B, t} C_{B, t}+H_{t}=\left(1+i_{t-1}\right) H_{t-1}+W_{t} L_{t}+\Pi_{t}
$$

where $\tau_{t}$ is the iceberg cost of traveling to another location (or searching another location), $H_{t}$ is the bond holding, $W_{t}$ is wages, and $\Pi_{t}$ represents profits from ownership of all firms.

We will assume that the iceberg cost is a function of $S_{t}$

$$
\tau_{t}=\tau\left(S_{t}\right), \quad \tau \geq 1, \tau(0)>1, \tau^{\prime}<0 .
$$

To simplify algebra, we will assume that $\tau\left(S_{t}\right)$ has constant elasticity $\phi$

$$
\left(\frac{S_{t}}{\tau_{t}} \frac{\partial \tau_{t}}{\partial S_{t}}\right)=\phi \leq 0
$$

Intuitively, one can think of $\tau$ as e.g. an information cost associated with shopping at the "discount" retailer which is reduced as the household devotes more time to search at this retailer. For example, households typically do their shopping in one primary retailer at which they may accumulate substantial store-specific knowledge, such as the location of different goods (Rhee and Bell 2002). Shopping at other retailers will require more time and effort in the absence of this information, which is captured by $\tau$. However, households can reduce this additional cost via the time-intensive shopping process in which information about other retailers is acquired.

Both retailers face the same marginal cost over consumption goods given by $P_{t}$. The "discount" retailer sells at cost $P_{B, t}=P_{t}$, whereas the price at the "local" retailer is assumed to be a constant markup 
over this input price $P_{A, t}=\mu P_{t}$, possibly reflecting higher local taxes, high-quality service, the use of an additional scarce input (such as more expensive local real estate), or a lower level of productivity. Thus, the relative posted prices of the two retailers are assumed to be constant $\left(\frac{P_{A, t}}{P_{B, t}}=\mu\right)$, but the relative expenditure costs faced by households will vary with $\tau_{t}: \frac{P_{A, t}}{\tau_{t} P_{B, t}}=\mu / \tau_{t}$. The efficient allocation of consumption by the household across retailers implies

$$
\frac{C_{A, t}}{C_{B, t}}=\left(\frac{\tau_{t} P_{B, t}}{P_{A, t}}\right)^{\gamma}=\left\{\frac{\tau_{t}}{\mu}\right\}^{\gamma}
$$

such that the demand for goods from the "local" retailer at location $A$ relative to the demand for goods from the "discount" retailer at location $B$ will fall when the iceberg costs associated with the "discount" store are low. With iceberg costs a function of shopping effort, time variation in shopping intensity will affect the relative prices at the two stores faced by households and will therefore underlie the reallocation of household expenditures across retailers. The efficient allocation of consumption expenditures on the part of the household also implies that the price of the final consumption bundle $P_{t}^{C}$ is

$$
P_{t}^{C}=\left(\left\{P_{A, t}\right\}^{1-\gamma}+\left\{\tau_{t} P_{B, t}\right\}^{1-\gamma}\right)^{1 /(1-\gamma)}=\mu P_{t}\left(1+\left\{\frac{C_{A, t}}{C_{B, t}}\right\}^{\frac{1-\gamma}{\gamma}}\right)^{1 /(1-\gamma)} .
$$

Because the final goods sold at the two retailers are identical, log changes in $P_{t}$ will be equivalent to those of a fixed-expenditure-weighted price index like the CPI. Changes in the price of the final consumption good (i.e. “cost-of-living” index), however, will systematically differ from changes in $P_{t}$ for two reasons. First, as emphasized by Triplett (2003), the price of final consumption good depends on the time-varying effort devoted to shopping, which is a relevant cost from the household's point of view but is clearly not captured in standard price indexes. Second, the price of the final consumption good will vary with the reallocation of expenditures across the two retailers on the part of the household, even when the household buys identical individual goods at the two retailers, as long as prices differ across retailers.

Note also that the household budget constraint can be rewritten more simply in terms of the price of the final consumption good as

$$
P_{t}^{C} C_{t}+H_{t}=\left(1+i_{t-1}\right) H_{t-1}+W_{t} L_{t}+\Pi_{t} .
$$

As a result, the first-order conditions with respect to aggregate consumption and bond holdings will be standard conditional on being expressed in terms of the final consumption good and its price index $P_{t}^{C}$ :

$$
\begin{array}{lll}
\text { Consumption: } & C_{t}^{-1}=q_{t} P_{t}^{C} & \Rightarrow \check{q}_{t}=-\check{C}_{t}-\breve{P}_{t}^{C} \\
\text { Bonds: } & q_{t}=E_{t} q_{t+1} \beta\left(1+i_{t}\right) & \Rightarrow \check{q}_{t}=E_{t} \check{q}_{t+1}+i_{t}
\end{array}
$$

where "checks" denote log-linearized deviations from steady-state values. The optimality condition for labor is 


$$
\text { Labor: } \quad\left(1-L_{t}-S_{t}\right)^{-1}=W_{t} q_{t} \Rightarrow \eta_{L} \check{L}_{t}+\eta_{S} \check{S}_{t}=\breve{W}_{t}+\check{q}_{t}
$$

where

$$
\eta_{L} \equiv \frac{\bar{L}}{1-\bar{L}-\bar{S}} \text { and } \eta_{S} \equiv \frac{\bar{S}}{1-\bar{L}-\bar{S}}
$$

is the steady-state ratio of labor supply to leisure and equivalently for $\eta_{S}$, and bars indicate steady-state levels of variables. Note that $\eta_{L}$ and $\eta_{S}$ are the steady-state elasticities of the marginal disutility of reducing leisure hours with respect to labor and shopping hours respectively. The first-order condition for labor includes shopping effort $S_{t}$ since the latter also affects the marginal disutility of labor.

The optimality condition with respect to shopping effort is

$$
\begin{gathered}
\text { Shopping Effort: } \quad \quad\left(1-L_{t}-S_{t}\right)^{-1}=-\phi\left(\frac{\tau_{t}^{1-\gamma}}{\mu^{1-\gamma}+\tau_{t}^{1-\gamma}}\right) \frac{1}{S_{t}} \\
\Rightarrow\left\{\eta_{L} \check{L}_{t}+\eta_{S} \check{S}_{t}\right\}=\omega_{S} \check{S}_{t}
\end{gathered}
$$

where

$$
\omega_{S} \equiv \phi(1-\gamma)\left(\frac{\mu^{1-\gamma}}{\mu^{1-\gamma}+\bar{\tau}^{1-\gamma}}\right)-1
$$

and $\bar{\tau}$ is the steady-state level of iceberg costs. This optimality condition states that the marginal disutility of shopping effort (the LHS) must equal the marginal benefit of shopping time (the RHS), which is the utility flow from the reduction in expenditures associated with lower effective prices at the "discount" retailer. The parameter $\omega_{S}$ denotes the steady-state elasticity of this utility flow with respect to shopping. A steady state with an interior solution for shopping requires the marginal return to shopping effort to be diminishing in the hours spent shopping, i.e. $\omega_{S}<0$ which, as we document later, is consistent with the data.

Because the marginal disutility of labor and shopping effort are equal, an optimizing household will therefore also equalize the marginal returns to labor and shopping hours:

$$
\breve{W}_{t}+\check{q}_{t}=\omega_{s} \check{S}_{t}
$$

so that with diminishing returns to shopping effort, hours spent shopping will tend to be low when the utility return to labor is high. A direct relationship between hours worked and hours spent shopping also follows directly from the first-order condition with respect to shopping:

$$
\eta_{L} \check{L}_{t}=\varepsilon_{s} \check{S}_{t}
$$

where, given $\eta_{S}=-\phi \frac{\bar{\tau}^{1-\gamma}}{\mu^{1-\gamma}+\bar{\tau}^{1-\gamma}}$,

$$
\varepsilon_{S} \equiv \omega_{S}-\eta_{S}=\phi-\gamma \phi \frac{\mu^{1-\gamma}}{\mu^{1-\gamma}+\bar{\tau}^{1-\gamma}}-1
$$

The parameter $\varepsilon_{S}$ represents the steady-state elasticity of the net utility cost from higher shopping effort, combining the fact that shopping hours above the steady-state both increase the marginal disutility of hours worked or spent shopping and lead to lower marginal expenditure reductions from shopping effort. Note 
that diminishing marginal return to shopping $\left(\omega_{S}<0\right)$ is sufficient (but not necessary) for this net utility elasticity to be negative, so that shopping intensity will be countercyclical with respect to hours: $\varepsilon_{S}<0$. $^{20}$ Intuitively, if labor hours are low, the marginal disutility to shopping is low, so the household will increase shopping effort which will both increase the disutility of shopping and lower its marginal return.

One can use this relationship between hours worked and shopping time to eliminate shopping effort from the first-order condition with respect to labor, yielding

$$
\eta_{L}\left(1+\frac{\eta_{s}}{\varepsilon_{S}}\right) \check{L}_{t}=\breve{W}_{t}+\check{q}_{t} .
$$

Shopping effort being countercyclical with respect to labor increases the effective Frisch labor supply elasticity. ${ }^{21}$ This reflects the fact that when the utility return to labor is high, shopping intensity will tend to be low so that the return to shopping is also high. But if the household spends fewer hours shopping, then the marginal disutility of labor will be lower, and the household will therefore be willing to supply more labor than it would in the absence of a time-varying shopping effort.

\subsubsection{Firms}

Retailer $j$ for $j \in\{A, B\}$ purchases intermediate goods along a continuum of mass one and assembles them into a consumption good:

$$
C_{j, t}=\left(\int_{0}^{1} y_{j, t}(i)^{\frac{\sigma-1}{\sigma}} d i\right)^{\sigma /(\sigma-1)}
$$

where $y_{j, t}(i)$ is an individual good $i$ (think of this as a UPC) bought by the retailer in location $j$, and $\sigma$ is the elasticity of substitution across individual goods (varieties). Note that because the aggregator is the same across locations, the composition of goods in the basket is exactly the same across locations and buyers. Cost minimization implies that the marginal cost paid by both retailers for producing one consumption good is given by

$$
P_{t}=\left(\int_{0}^{1} p_{t}(i)^{1-\sigma} d i\right)^{1 /(1-\sigma)} .
$$

Intermediate goods are produced by a continuum of monopolistic competitors, each of which sells to both retailers. Producer $i$ therefore faces the following total demand:

$$
y_{t}(i)=y_{A, t}(i)+y_{B, t}(i)=\left(\frac{p_{t}(i)}{P_{t}}\right)^{-\sigma} C_{A, t}+\left(\frac{p_{t}(i)}{P_{t}}\right)^{-\sigma} C_{B, t}=\left(\frac{p_{t}(i)}{P_{t}}\right)^{-\sigma} Y_{t}
$$

\footnotetext{
${ }^{20}$ Diminishing marginal return to shopping also ensures that leisure is countercyclical with respect to labor since log-deviations of leisure are equal to $-\frac{\omega_{s}}{\varepsilon_{s}} \eta_{L} \check{L}_{t}$.

${ }^{21}$ The steady-state ratio of labor to leisure is given by $\eta_{L}=\frac{\sigma-1}{\sigma}\left(\frac{\alpha}{\mu}\right)$ which is independent of shopping effort in the model.
} 
where $Y_{t}=C_{A, t}+C_{B, t}$. The production function for each intermediate goods producer $i$ is given by

$$
y_{t}(i)=Z_{t} N_{t}(i)^{\alpha}, \quad \alpha \in(0,1)
$$

where $y_{t}(i)$ is the output of variety $i, Z_{t}$ is the aggregate level of technology, and $N_{t}(i)$ is employment of firm $i$. Technology follows a stationary AR(1) process in logs with i.i.d. innovations denoted by $\epsilon_{t}^{z}$ and persistence $\rho_{z}$ :

$$
\check{Z}_{t}=\rho_{z} \check{Z}_{t-1}+\epsilon_{t}^{Z} \text {. }
$$

Workers are hired from a common labor market at nominal wage $W_{t}$. Firms can reset prices as in Calvo (1983) with the probability of being able to reset their price denoted by $1-\theta$. When able to reset prices, firm $i$ therefore choose a reset price $P_{t}^{*}(i)$ to maximize profits

$$
\max _{P_{t}^{*}} E_{t} \sum_{k=0}^{\infty} \theta^{k}\left\{\Xi_{t, t+k}\left(P_{t}^{*}(i) y_{t+k \mid k}(i)-W_{t+k} N_{t+k \mid k}(i)\right)\right\}
$$

where $y_{t+k \mid k}(i)$ is the level of output in period $t+k$ of the firm that reset its price in period $t, \Xi_{t, t+k}$ is the stochastic discount factor, subject to their demand curve and the production function. Combined with the evolution of the intermediate goods price level $P_{t}$

$$
P_{t}=\left(\theta P_{t-1}^{1-\sigma}+(1-\theta) P_{t}^{* 1-\sigma}\right)^{\frac{1}{1-\sigma}}
$$

this yields the log-linearized New Keynesian Phillips Curve in terms of input prices $P_{t}$ for retailers

$$
\pi_{t}=\beta E_{t} \pi_{t+1}+\kappa \overline{M C}_{t}
$$

where $\kappa=\frac{(1-\theta)(1-\beta \theta)}{\theta} \Theta, \Theta=\frac{1-\alpha}{1-\alpha+\alpha \sigma}, \pi_{t}=\breve{P}_{t}-\breve{P}_{t-1}$, and real marginal costs are given by $\breve{M C}_{t}=\breve{W}_{t}-$ $\breve{P}_{t}-\breve{Y}_{t}+\breve{N}_{t}$. In the absence of sticky-prices, output in the model would simply track technology, so the log-linearized output gap is defined as $\check{X}_{t} \equiv \check{Y}_{t}-\breve{Y}_{t}^{n}=\check{Y}_{t}-\check{Z}_{t}$.

\subsubsection{The Central Bank}

Monetary policy follows an interest rate rule in which interest rates respond to inflation, output growth and the output gap such that, after-log-linearization,

$$
i_{t}=\rho_{r} i_{t-1}+\left(1-\rho_{r}\right)\left[\chi_{\pi} \pi_{t}+\chi_{x} \check{X}_{t}+\chi_{\Delta y} \Delta \check{Y}_{t}\right]+\epsilon_{t}^{r}
$$

where $\rho_{r}$ is the degree of interest-smoothing, $\chi_{\pi}$ is the long-run response to inflation, $\chi_{x}$ is the long-run response to the output gap, $\chi_{\Delta y}$ is the long-run response to output growth, $\epsilon_{t}^{r}$ is an i.i.d. monetary policy shock.

\subsubsection{Parameter Values}

To the extent possible, we rely on typical values of parameters in the model. For example, we set $\beta=0.99$ and $\theta$, the degree of price rigidity, to 0.70 such that firms update their prices every 10 months 
on average, as in Nakamura and Steinsson (2008). This rate of price-stickiness obtains empirically from focusing only on regular price changes. This is consistent with our empirical results documenting the pro-cyclicality of sales prices. However, we subsequently experiment with lower values of $\theta$ to explore the quantitative importance of store-switching relative to the effects of not treating sales as regular price changes. We set $\alpha$ to be 0.66 and $\sigma$, the elasticity of substitution across intermediate goods, to be 10 . Coefficients for the interest rate rule follow Coibion and Gorodnichenko (2011), such that long-run responses to inflation $\left(\chi_{\pi}\right)$, output growth $\left(\chi_{\Delta y}\right)$ and the output gap $\left(\chi_{x}\right)$ are equal to $1.5,0.5$, and 0.1 respectively while the degree of interest smoothing $\rho_{r}$ is 0.9 . The persistence of technology shocks is 0.95. Following Coibion, Gorodnichenko and Wieland (2011), the standard deviation of technology shocks is set to 0.0090 while that of monetary policy shocks is 0.0024 .

With respect to the parameters governing store-switching and shopping effort, we first normalize the iceberg cost such that $\bar{\tau} \equiv \tau(\bar{S})=\mu$. As a result, steady-state consumption of "local” versus “discount” stores is equalized. This appears to be in line with data since the 1990s. For example, in the 2002 Economic Census, discount stores and supercenters accounted for $73 \%$ of sales at general merchandise stores and $41 \%$ of sales at both general merchandise and food stores (Annual Benchmark Report for Retail Trade and Food Services (2005)). Discount stores and supercenters are also significantly cheaper on average. Cleeren et al. (2010) report that discount stores often charge up to $60 \%$ less than regular grocery stores for leading brands. Hausman and Leibtag (2007) report that supercenters are on average $27 \%$ cheaper than other grocery stores for selected food products. We set a slightly higher value of $\mu=1.5$, such that "discount" stores in the model are $33 \%$ cheaper on average, because the ability of superstores and discount stores to achieve price discounts is likely to be even larger for nongrocery products (which are more durable and hence more amenable to bulk purchases) than for the grocery goods which Hausman and Leibtag (2007) focus on. These parameters imply a steady-state labor-leisure ratio of 0.4. The 2005 American Time Use Survey reports that the average American age 15 and older worked 3.7 hours a day while spending 5.7 hours on leisure and 8.6 hours on sleep. These values imply average labor-leisure ratios of 0.65 (not counting sleep as leisure) or 0.26 (counting sleep as leisure).

Evidence on the elasticity of substitution across stores is limited. Walters (1991) examined both within and across-store substitution and found relatively low rates for the latter relative to the former. Kumar and Leone (1988) found cross-store elasticities of substitution to be two to three times smaller than within-store elasticities for narrow product categories. Rhee and Bell (2002) similarly document limited switching by households in terms of their primary store of choice. As a result, we set $\gamma=4$, less than half the elasticity of substitution across varieties. For the elasticity of iceberg costs to shopping effort, Aguiar and Hurst (2005) report that retired households spend 42\% more time shopping than pre- 
retired households, leading to a $17 \%$ decline in total food expenditures (with no change in food consumption). We use a slightly lower elasticity of $\phi=-0.3$ (rather than $\phi=-0.4=-17 \% / 42 \%$ ) since some of the reduction in expenditures documented in Aguiar and Hurst also reflects a rise in time spent preparing food. Note that with $\gamma=4$ and $\bar{\tau}=\mu$, diminishing marginal return to shopping effort will obtain for $-2 / 3>\phi>0$, so our baseline value of $\phi$ is squarely in the middle of the admissible range.

While there is only limited evidence on empirical values for $\gamma$ and $\phi$, we can use our estimates of household-switching to assess how well our baseline parameter values conform to our empirical estimates. For example, Table 4 indicates that a 1\% point increase in the unemployment rate is associated with a decrease in the average rank at which households shop of approximately 0.13 when counting goods sold at all stores, with a standard error of almost 0.04. Using Okun's Law such that a 1\% point increase in the unemployment rate is associated with a $2 \%$ decline in the output gap as in Knotek (2007), this delivers a semi-elasticity of the average rank at which households shop with respect to the output gap of approximately 0.065 with a 95\% confidence interval of [0.028 0.102]. In our model with two retailers, the average price rank at which the household shops is

$$
R_{t}^{C}=\left(\frac{C_{A, t} P_{A, t}}{C_{A, t} P_{A, t}+C_{B, t} P_{B, t}}\right) \times \frac{2}{3}+\left(\frac{C_{B, t} P_{B, t}}{C_{A, t} P_{A, t}+C_{B, t} P_{B, t}}\right) \times \frac{1}{3}
$$

where the $2 / 3$ and $1 / 3$ values reflect our ranking algorithm of section 4 . It follows that the steady-state semi-elasticity of the average price rank at which the household shops with respect to the output gap can be expressed as

$$
d R^{C}=\frac{1}{3} S_{A}\left(1-s_{A}\right) \gamma \phi \zeta \check{X}_{t}
$$

where $\zeta \equiv\left(\frac{\sigma-1}{\sigma \mu}\right) \frac{1}{\varepsilon_{S}}<0$ is the steady-state elasticity of shopping effort with respect to the output gap and $s_{A}=\frac{\mu}{1+\mu}$ is the steady-state share of household expenditures at high-price retailers. Our baseline parameter values then imply an elasticity of the average price rank at which households shop relative to the output gap of approximately 0.082, which is close to the empirical estimate and well within the confidence interval. Hence, our baseline parameter choices for $\gamma$ and $\phi$ yield a rate of expenditure reallocation across retailers which is in line with our empirical estimates of actual household behavior.

\subsubsection{The Simplified Log-Linearized Model}

A convenient property of the model is that it can be reduced to the same three equations typical of New Keynesian models. The assumption that $\bar{\tau}=\mu$, which is not out of line with current expenditure shares in the U.S., is particularly convenient in simplifying expressions in the model. Under this condition, the standard New Keynesian Phillips Curve for input prices can be expressed in terms of the output gap 


$$
\pi_{t}=\beta E_{t} \pi_{t+1}+\tilde{\kappa} \check{X}_{t}
$$

where $\tilde{\kappa} \equiv \frac{(1-\theta)(1-\beta \theta)}{\theta}\left(\frac{1-\alpha}{1-\alpha+\alpha \sigma}\right)\left\{\left(\frac{\sigma-1}{\sigma \mu}\right)+\frac{1}{\alpha}\right\}$. The policy rule is unchanged. The Euler equation for the output gap is

$$
\check{X}_{t}=E_{t} \check{X}_{t+1}-\frac{1}{1+\frac{1}{2} \phi \zeta}\left(i_{t}-E_{t} \pi_{t+1}-r_{t}^{n}\right)
$$

where $\zeta<0$ whenever shopping effort is countercyclical with respect to hours $\left(\varepsilon_{s}<0\right)$. Furthermore, one can verify that $\phi \zeta$ is increasing in $\phi$ as long as $\sigma>1$. Thus, larger elasticities of iceberg costs to shopping effort (more negative $\phi$ ) effectively decrease the elasticity of the output gap, holding future gaps constant, to contemporaneous real interest rates. This effect reflects the countercyclicality of the shopping effort: if consumption prices are expected to rise, then the output gap should be high but falling and therefore the shopping intensity should be low but expected to rise. The expected increase in shopping time will therefore offset part of the increase in the rise in consumption prices which reduces the expected decline in gaps. As a result, when the Euler equation is expressed in terms of input prices, the sensitivity of the output gap to changes in real interest rates is diminished.

\subsection{Testable Predictions of the New Keynesian Model with Store-Switching}

In this section, we focus on the empirical validity of the key mechanism of the model with store-switching that underlies the subsequent business cycle and policy implications of the model. Specifically, low economic activity is associated with more shopping activity and therefore lower relative consumption prices, as illustrated by:

$$
\check{P}_{t}^{C}-\check{P}_{t}=\frac{\phi}{2} \check{S}_{t}=\frac{\phi}{2} \zeta \check{X}_{t} .
$$

When the output gap is low, shopping effort will be high $(\zeta<0)$, thereby reducing the relative price of the final consumption good relative to input prices. Because the price of the final consumption good, rather than intermediate prices, is what matters ultimately for household welfare, the novel channel in this model is how the ratio of the two evolves with economic conditions. $\check{P}_{t}$ in the model is equivalent, when log-linearized, to the CPI price index in the data. Unfortunately, there is no direct empirical equivalent to the effective price of the final consumption good $\breve{P}_{t}^{C}$ since it incorporates both the iceberg cost, which is unobservable, as well as the reallocation of expenditures across retailers.

However, we can construct an alternative effective price index $P_{t}^{E}$ equivalent to that considered in sections 3 and 4, which incorporates the reallocation of expenditures across stores:

$$
P_{t}^{E} \equiv \frac{\left(P_{A, t} C_{A, t}+P_{B, t} C_{B, t}\right)}{\left(C_{A, t}+C_{B, t}\right)} .
$$

After log-linearization, this price index evolves according to: 


$$
\breve{P}_{t}^{E}-\breve{P}_{t}=\frac{(\mu-1)}{(\mu+1)} \gamma \frac{\phi}{2} \zeta \check{X}_{t}=\frac{(\mu-1)}{(\mu+1)} \gamma\left(\breve{P}_{t}^{C}-\check{P}_{t}\right) .
$$

Thus, our alternative measure of effective prices $\breve{P}_{t}^{E}$ should be high relative to the CPI price index $\breve{P}_{t}$ when the level of economic activity is high $\left(\check{X}_{t}>0\right)$, exactly as would be the case with the measurable final consumption price index $\breve{P}_{t}^{C}$. Only the magnitude of the elasticity of relative price movements with respect to economic conditions will differ. Given our calibration of the model, $\frac{(\mu-1)}{(\mu+1)} \gamma=0.8$ so $\breve{P}_{t}^{E}$ will capture $80 \%$ of the movements in the final consumption price index, despite the fact that iceberg costs are not directly observable. Thus, our "effective" price measure $\breve{P}_{t}^{E}$ which reflects the prices consumers actually pay will, at least in our calibration, closely track the final consumption price index $\breve{P}_{t}^{C}$.

We can assess the validity of this prediction in our dataset by constructing a measure of the gap between the average effective price level and the average posted price level. The average effective price level is based on the average price paid by households for a given UPC in a metropolitan area, then aggregated across UPCs and geographic areas using constant expenditure weights. Changes in this index therefore reflect both changes in the individual prices as well as consumer reallocation of expenditures across retailers. The posted price index is constructed using fixed expenditure-weights over all individual UPC products and geographic areas. Panel A of Figure 2 plots the difference between these two series and the aggregate unemployment rate. As predicted by the theory, the average effective price index declines sharply relative to the posted price index when the U.S. unemployment rate rises, while the reverse happens when the unemployment rate declines. Hence, this figure illustrates how, even after aggregating across all regions and product categories, the effects of consumer reallocation across retailers leads to a non-trivial mis-measurement of the household consumption price index.

Furthermore, the quantitative magnitudes implied by the series shown in the figure are in line with the predictions of the model. At our baseline parameters, the elasticity of the difference between effective prices and posted prices $\left(\breve{P}_{t}^{E}-\breve{P}_{t}\right)$ with respect to the output gap is approximately 0.15. Between 2001 and 2003, the U.S. unemployment rate rose by approximately 2 percentage points, which via Okun's Law, translates to an approximate 4 percentage point decline in the output gap. The theory predicts that such a decline in the gap would be associated with a decline in the effective price index of 0.60 percentage points relative to the posted price index. The figure points to a decline in this price differential which is very close to this value. Thus, both the qualitative and quantitative implications of this dimension of the model appear to be consistent with the data.

The potential for mismeasurement by fixed-expenditure-weight prices indexes of the effective prices paid by households due to store-switching has long been recognized by the literature on inflation measurement (e.g. Boskin Commission Report 1996, Shapiro and Wilcox 1996, Reinsdorf 1993, Triplett 2003, Hausman and Leibtag 2007) but little progress has been made in quantifying it. Our model and 
empirical estimates suggest that the cyclical mismeasurement is relatively large. Because it would be difficult for statistical agencies to construct time-varying expenditure weights across retailers in real-time, one implication of these results is that better measurement of the "cost-of-living” should focus on tracking the prices paid by households rather than those charged by specific retailers, as suggested in Triplett (2003).

A second approach to assessing the store-switching channel and its effect on relative prices is to focus on quantities purchased rather than prices. In our model, the relative quantities purchased at "local" retailers versus “discount” retailers follow

$$
\check{C}_{t}^{A}-\check{C}_{t}^{B}=\gamma \phi \zeta \check{X}_{t}
$$

such that when the output gap is low, households will tend to purchase relatively more goods from lowprice stores than high-price stores. Again, this reallocation of expenditures will reflect the higher degree of shopping effort when economic activity is low. Given that the relative posted prices at the two stores are constant in the model, the cyclical reallocation in goods purchased will be mirrored in terms of relative dollar expenditures across the two retailers. Specifically, defining the share of total revenues going to "local" retailers as $s_{A, t} \equiv\left(C_{A, t} P_{A, t}\right) /\left(C_{A, t} P_{A, t}+C_{B, t} P_{B, t}\right)$, the cyclicality of the revenue share of high-price retailer is

$$
\check{s}_{A, t}=\left(\frac{2}{5}\right) \gamma \phi \zeta \check{X}_{t} .
$$

To evaluate this additional prediction, we construct the share of total retailer revenues going to "highprice” retailers in our data-set, where "high-price” retailers are defined as in section 4.1 and have the rank above 0.5. Panel B of Figure 2 plots the time series for this share, aggregated across all metropolitan areas, as well as the unemployment rate. Consistent with the prediction of the model, the revenue share of "highprice” retailers declined sharply during the 2001-2003 recession, before gradually recovering. Thus, the cyclical behavior of relative revenues of "high-price" and "low-price" retailers in the data is also consistent with the predictions of the model with time-varying shopping effort and store-switching. One caveat is that the figure also illustrates how the revenue share of "high-price" retailers never recovers fully after the 2001-2003 recession, which reflects the trend growth of discount retail stores in the U.S. during this time period.

The third approach is with respect to the slope of the Phillips curve, i.e. the relationship between inflation and real economic activity. While the New Keynesian Phillips curve (NKPC) is unchanged in the presence of endogenous shopping effort when expressed in terms of input prices, the relevant measure from households' point of view is the price of the final consumption bundle. We can rewrite the NKPC in terms of consumption price inflation as

$$
\pi_{t}^{C}=\beta E_{t} \pi_{t+1}^{C}+\left(\tilde{\kappa}+\frac{1}{2} \phi \zeta(1+\beta)\right) \check{X}_{t}-\frac{1}{2} \phi \beta \zeta E_{t} \check{X}_{t+1}-\frac{1}{2} \phi \zeta \check{X}_{t-1} .
$$


such that consumption price inflation depends on expected inflation in the next quarter, the current output gap, as well as the previous period's gap and the next quarter's expected gap. The presence of shopping effort increases the coefficient on the contemporaneous output gap, which suggests a steeper short-run Phillips curve relationship between effective price inflation and real economic activity. This seems intuitive since the ability of households to reallocate their expenditures across stores suggests that the effective price of consumption goods paid by consumers should be more flexible than that of input prices.

To assess the manner in which the relationship between inflation and real economic activity is affected by store-switching, we first simulate the model with time-varying shopping effort. We then plot the unconditional relationship between CPI inflation $\pi_{t}$ and employment, as well as that between measured effective price inflation $\pi_{t}^{E}$, in Panel A of Figure 3. The lines show the slopes of the average relationship between employment and each measure of inflation in the model: as suggested by the coefficients on the output gap in the NKPC, the slope is steeper when using effective consumption prices rather than CPI measures.

Panel B of Figure 3 shows the equivalent unconditional correlations between each form of inflation and unemployment from aggregating our monthly micro-level data. Specifically, Figure 3 plots

posted price inflation $\pi_{t}^{\text {post }}$ and effective price inflation $\pi_{t}^{e f f}$. In each case, the inflation measures are constructed as weighted (by expenditure shares) averages of $\bar{\pi}_{m c t}^{\text {post }}$ and $\bar{\pi}_{m c t}^{\text {eff }}$ across metropolitan areas and categories. The figure reveals that, with higher aggregate levels of unemployment, both fixedweighted inflation and effective price inflation measures are lower, but the decline is larger for effective price inflation measures as predicted by the model with store substitution, with the difference between the two being statistically significant at the $1 \%$ level.

In short, these results suggest that the key predictions of the model with store-switching and shopping effort are apparent not only in micro-data but also in more aggregate series. The countercyclicality of consumer shopping effort leads to effective prices paid by consumers that are countercyclical with respect to standard price measures such as the CPI index, reallocation of consumer expenditures toward low-price outlets during economic downturns, and steeper Phillips curves in terms of effective prices paid by consumers than typically found.

\subsection{Business Cycle and Policy Implications of Store-Switching}

In this section, we turn to the implications of shopping effort and store-switching for business cycle dynamics and policy in the model. We focus on three questions: 1) how does the presence of shopping effort and store-switching affect the degree of monetary neutrality, 2) how does it affect the relative importance of stabilizing inflation and output gap volatility for welfare, and 3) does it matter whether monetary policy-makers target traditional inflation measures or are there welfare gains from targeting 
“effective” price measures which incorporate store-switching on the part of households? We address each question in turn.

\subsubsection{Effective Price Flexibility and the Degree of Monetary Non-Neutrality}

The first question is whether, with prices being effectively more flexible than suggested by posted prices, the degree of monetary neutrality will be lower than expected from the degree of price stickiness. This logic was suggested by Chevalier and Kashyap (2011) in the context of sales, but store-switching similarly generates flexibility in the effective prices paid by households which could potentially undo the stickiness in regular price changes. To assess the implications of store-switching for the degree of monetary neutrality, we consider the dynamic effects of a contractionary monetary policy shock in our model. Panel A in Figure 4 plots the impulse responses of inflation and the output gap from our model after a contractionary monetary policy shock. The responses include those from a standard New Keynesian model without store-switching $(\phi=0)$, as well as in the case of endogenous shopping effort $(\phi=-0.3)$. These responses illustrate a key implication of endogenous shopping effort: an equivalent contractionary monetary policy shock has smaller real effects in the presence of store-switching. At our baseline parameter values, the reduction in real effects for a monetary policy shock is approximately $10 \%$ on impact. This reflects the reduced elasticity of output with respect to real interest rates in the dynamic IS equation (6.17). The higher real interest rate after a contractionary monetary policy shock contracts contemporaneous demand for consumption goods and therefore leads to a decline in labor demand and wages. Because households want to equalize the return to shopping effort and labor, the lower return to labor leads to an increase in shopping effort and a reallocation of consumption expenditures across retailers which reduces the effective prices faced by consumers. With effective prices lower than they would be in the absence of store-switching, consumption does not fall by as much as in the model without store-switching. The reduced effect on output then also implies smaller effects on inflation via the NKPC.

In addition, Panel A plots the impulse responses of inflation and the output gap in the model without store-switching and the levels of price flexibility from Bils and Klenow (2004): $\theta=0.40$ such that firms update prices every five months on average. This is a useful benchmark because it illustrates dynamics when sales are treated as regular price changes. Hence, the figures allow us to assess the relative importance of the two results from section 3: sales are not like regular price changes (so prices are less flexible than implied by average frequencies) and store-switching on the part of households is present (so effective prices are more flexible than implied by posted prices). The former implies larger real effects of monetary policy while the latter suggests smaller real effects. On balance, the results in Figure 3 suggest that incorporating both less flexible posted prices and store switching leads to approximately 
the same contemporaneous response of the output gap as in the more flexible-price model without storeswitching. However, the dynamic response of the output gap is much more persistent than with more flexible prices and no store switching. Thus, the medium-run effects of monetary policy shocks on real economic activity are much more affected by the increased price stickiness when sales are not being treated like regular price changes than by the household's store-switching/shopping-effort mechanism. $^{22,23}$

Panel B of Figure 4 illustrates how store-switching affects relative consumption across retailers in the baseline case of $\phi=-0.3$. While consumption at "local" stores falls very sharply, consumption at "discount” stores is nearly unaffected. This pattern reflects the extent of consumer reallocation of household expenditures in response to economic conditions. This pattern is also consistent with the empirical response of the growth rate of revenue in high- and low-price stores to the local unemployment rate reported in Table 3. Panel B also illustrates the response of different price and inflation measures to the contractionary monetary policy shock. The price of the final consumption bundle $\breve{P}^{C}$ declines much more sharply on impact than CPI/input prices $\breve{P}$ as a result of the increased shopping effort. Our measure of effective prices $\breve{P}^{E}$ tracks the price of final consumption bundle $\breve{P}^{C}$ closely. In terms of inflation rates, shopping-effort/store-switching leads to a dramatic difference in the behavior of inflation rates: final good inflation drops substantially on impact but is very low in subsequent periods. A simple way to gauge how much more flexible final goods prices are than posted prices is to note that, in the period of the shock, posted prices $\breve{P}$ fall by only $1 / 6^{\text {th }}$ of the cumulative decline in prices while almost $1 / 2$ of the cumulative adjustment in final goods prices $\breve{P}^{C}$ happens in the first quarter. Despite this much greater flexibility in the effective prices paid by households due to store-switching than would be expected from the underlying degree of price stickiness, the implications for monetary neutrality are limited. In this sense, our results are in the same spirit as Eichenbaum et al. (2011), Kehoe and Midrigan (2010) and Guimaraes and Sheedy (2011), but whereas they focus on sales pricing as a sources of effective price flexibility for households, our results stem from the shopping effort and store-switching margins. But the common finding is that even with high effective price flexibility for households, the degree of monetary neutrality in the models hinges primarily on the underlying degree of rigidity in regular prices.

\footnotetext{
${ }^{22}$ Appendix Figure 1 illustrates how the size of the contemporaneous response and the average response of the output gap to monetary policy shocks are increasing in the elasticity of substitution across retailers and the elasticity of iceberg costs to shopping effort.

${ }^{23}$ The similarity of impulse responses however should not mean that one can ignore endogenous variations in shopping effort. Specifically, the interpretation of estimated relationships in terms of structural parameters depends on whether consumers can re-allocate their spending across stores. For example, if one ignores store switching, one could erroneously interpret the reduced sensitivity of output gap to posted-price inflation as a low inter-temporal elasticity of substitution.
} 


\subsubsection{Welfare Objective Function with Endogenous Shopping Effort and Store-Switching}

The difference between posted and effective price movements induced by the shopping effort and storesubstitution margins also implies that standard approximations of household welfare in New Keynesian models will be affected. The most common approach to quantifying welfare is through $2^{\text {nd }}$ order approximations of utility, as in Woodford (2003), which deliver a loss function in terms of inflation and output gap volatility. But since household welfare with shopping effort depends on effective prices rather than posted prices, this suggests that the relative importance of the two forms of volatility will be affected. To formally assess this effect, we derive the $2^{\text {nd }}$ order approximation to utility in the model and express it in terms of posted inflation volatility and output gap volatility (Appendix C):

$$
\begin{aligned}
& E\left(U_{t}\right) \approx-\frac{1}{2}\left(\frac{\sigma-1}{\sigma \mu}\right)\left\{c_{\pi}(\phi) E\left(\pi_{t}^{2}\right)+c_{x}(\phi) E\left(\check{X}_{t}^{2}\right)\right\}, \\
& c_{\pi}(\phi) \equiv \frac{\sigma}{\Theta} \frac{\theta}{(1-\theta)^{2}}\left(\frac{\omega_{S}}{\varepsilon_{S}}\right), \\
& c_{x}(\phi) \equiv \frac{1}{\alpha}+\left(\frac{\sigma-1}{\sigma \mu}\right) \frac{\frac{\gamma}{4} \phi^{2}-\frac{\phi}{2}+\omega_{S}^{2}}{\varepsilon_{S}^{2}} .
\end{aligned}
$$

Panel C of Figure 4 illustrates how the coefficients on inflation and output gap volatility vary with the elasticity of costs to shopping time $\phi$. Higher elasticities systematically lower the coefficient on inflation volatility, i.e., $\frac{\partial c_{\pi}}{\partial \phi}<0$. The latter reflects the elasticity of leisure with respect to price dispersion: without shopping effort, high price dispersion requires high levels of labor supply and therefore less leisure, which reduces welfare. However, when shopping effort is present and countercyclical, higher levels of labor supply associated with price dispersion are offset by fewer hours spent shopping, so the sensitivity of leisure to inflation volatility is reduced. The coefficient on output gap volatility reflects the loss from volatility in leisure, which depends on the variance in labor supply, shopping effort, the covariance between the two, and changes in the dispersion of consumption across the two retailers. The interaction of these effects is nonlinear, such that low elasticities of shopping reduce the cost of a given level of output gap volatility but this effect is reversed at high elasticities. The overall effect is to make welfare relatively more sensitive to output gap volatility relative to inflation volatility as the steady-state level of shopping effort increases. Thus, the presence of store-switching and shopping effort suggests that stabilizing output gap volatility should play a more prominent role in the objective function of policymakers than implied by standard models omitting this channel.

\subsubsection{What Price Measure Should Policymakers Target?}

A third question of practical interest implied by the model is whether policymakers should focus on standard fixed-expenditure weight price measures or one that reflects the shopping effort, and therefore expenditurereallocation, activities of households. While household welfare is explicitly associated with the price of the 
final consumption good $P_{t}^{C}$, the fact that these prices are effectively more flexible than posted prices $P_{t}$ might suggest that responding to the latter will be welfare-improving via the logic of Aoki (2001).

To address this question, we quantify household welfare (6.23) when the central bank responds either to posted price inflation $\pi_{t}$ in the standard interest rate rule, final good price inflation $\pi_{t}^{C}$ or the closely related expenditure-weighted final goods inflation rate $\pi_{t}^{E}$ holding the other parameters in the model (including those in the policy rule) constant. The resulting inflation and output gap variances are plotted in Panel A of Figure 5 for different long-run inflation response coefficients $\phi_{\pi}$. Responding to posted price inflation $\pi_{t}$, as assumed in our baseline, leads to lower volatility in posted price inflation but higher levels of output gap volatility, with the latter effect being particularly strong when the inflation response is high. Given that inflation volatility is more heavily weighted in the loss function, these results lead to utility being higher in most cases when the central bank targets posted price inflation rather than final goods price inflation or the expenditure-weighted inflation measure. Thus, this result suggests that, even in the presence of store-switching and time-varying shopping effort, policy-makers may be better served by responding to traditional measures of inflation than to measures of effective price inflation.

However, this result appears to be specific to inflation targeting. For example, this result does not obtain if we consider price-level targeting (PLT) regimes, which-as we know from Woodford (2003), Gorodnichenko and Shapiro (2007), Coibion et al. (forthcoming), and others-are closer to replicating the optimal policy under commitment than inflation targeting. Specifically, we replace the baseline interest rate rule with one that allows for responses to deviations of price-levels from their targets:

$$
i_{t}=\rho_{r} i_{t-1}+\left(1-\rho_{r}\right)\left[\chi_{p} \breve{P}_{t}^{m}+\chi_{x} \breve{X}_{t}+\chi_{\Delta y} \Delta \breve{Y}_{t}\right]+\epsilon_{t}^{r}
$$

where $\breve{P}_{t}^{m}$ denotes the deviation of posted prices $\breve{P}_{t}$, final goods prices $\breve{P}_{t}^{C}$, or expenditure-weighted prices $\breve{P}_{t}^{E}$ from a target path. Panel B of Figure 5 plots the implied inflation and output volatilities for different response coefficient $\chi_{p}$ to each price level, as well as expected utility losses for different values of $\chi_{p}$. While output gap volatility is still higher when the central bank responds to posted prices, posted price inflation volatility is now also higher in this case. This reflects the fact that much of the price response is immediate for $\breve{P}_{t}^{C}$ and $\breve{P}_{t}^{E}$ and more delayed for $\breve{P}_{t}$. Under price level targeting, the large immediate decline in effective prices after a disinflationary shock must be reversed when the central bank targets the level of effective prices. This requires significant declines in nominal and real interest rates on the part of monetary policy-makers, which will tend to immediately raise contemporaneous output gaps via the dynamic IS curve relative to how they otherwise would have responded. This, in turn, offsets some of the initial disinflation via the New Keynesian Phillips Curve. As a result, both inflation and output gap volatility will be significantly reduced when the central bank targets the "effective" or final consumption price level. This effect does not occur under inflation-targeting because the latter does not require the 
policy-maker to undo the immediate decline in effective prices and therefore does not require the significant declines in nominal and real interest rates which serve to stabilize both inflation and output volatility under PLT. Hence, expected utility is now strictly greater when the central bank targets deviations of effective final goods price deviations rather than posted price levels.

\section{Conclusion}

A key question for macroeconomists is quantifying both the degree of price rigidities and the implications of these rigidities for macroeconomic dynamics. How to interpret temporary sales is a central ingredient in characterizing whether price-stickiness is large enough to qualitatively affect business cycle dynamics. We shed new light on this question by studying the cyclicality of sales and regular price changes using detailed micro-level data. We find that sales are pro-cyclical: higher unemployment rates lead to declines in both the frequency and absolute size of sales, as well as to declines in the share of goods bought on sale. This suggests that sales prices differ in a fundamental way from regular price changes, and are therefore unlikely to undo the high levels of price-stickiness apparent among regular price changes.

At the same time, we show that actual prices paid by households for a given good are significantly more flexible than what is implied by the behavior of posted prices. This pattern reflects store-switching on the part of households in light of changing economic conditions. In a simple model of shopping effort and store-switching, the ability of consumers to reallocate their expenditures across retailers charging different prices provides an additional force toward price flexibility which leads to smaller real effects of monetary policy shocks. Furthermore, store-switching by households can rationalize the pro-cyclicality of sales: economic downturns increase the incentive of households to search for bargains at low-price retailers, thereby reducing the incentive of high-price retailers to try and attract these households via sales. However, despite the increased flexibility in the prices that households actually pay in light of store-switching, the quantitative implications of store-switching for monetary neutrality are relatively small. Thus, our results are similar in spirit to those of Eichenbaum et al. (2011), Kehoe and Midrigan (2010), and Guimaraes and Sheedy (2011), but whereas they focus on the role of sales in generating increased flexibility in prices paid by households, we focus on the store-switching margin for effective price flexibility. Nonetheless, store-switching does have non-trivial implications for the relative importance of stabilizing output gap versus inflation variation in welfare calculations, the question of which price measures should be targeted by policymakers, and the interpretation of estimated relationships in terms of structural parameters.

Another implication of store-switching and time-varying shopping effort is that there is a cyclical mismeasurement of the price of households' final consumption basket in standard aggregate inflation measures. This points towards a need for statistical agencies to devote more resources toward measuring 
the reallocation of household expenditures, not just across goods as commonly emphasized with respect to the substitution bias, but also across retailers. While the construction of time-varying expenditure weights in real-time is unlikely to be feasible for statistical agencies, one approach would be to track the prices paid by households in real-time rather than the prices charged by a fixed set of retailers, as suggested by Triplett (2003). To this end, scanner price data, which provide prices and quantities, may be a useful tool for constructing cost-of-living indexes although a number of challenges remain to be addressed in this area (see Feenstra and Shapiro (2003)).

A related implication is that the ideal price index in the presence of time-varying shopping effort should measure not only the reallocation of expenditures across stores but also the shopping effort intensity of households, since this represents a component of the cost of the consumption basket. Further work on how this could be measured in practice would be of immediate practical relevance. One implication of our results, however, is that shopping effort and store-switching are closely related, so that a price-measure which incorporates the reallocation of expenditures across retailers will generally capture most of the missing cyclical variation in the final consumption price index.

Another fruitful extension would be to consider the impact of the rise in online retailing: the latter likely reduces shopping costs substantially and therefore facilitates the reallocation of expenditures across retailers by households. With online retailing growing rapidly, expenditure-reallocation across retailers is likely to become increasingly important. Just as Walmart reshaped the retailing industry in the U.S., the rise of Amazon.com and other online retailers will similarly transform household expenditure decisions. Our results suggests that the ways in which households reallocate their expenditures, as well as the intensity of their shopping search, will not be innocuous for macroeconomic dynamics and optimal policy responses to economic fluctuations.

One may also use this idea to shed new light on the puzzle of the missing disinflation during the 2007-2009 downturn. As documented in Ball and Mazunder (2011), the magnitude of the output gap in the recent recession would have been expected to lead to significantly more disinflation than actually occurred, based on historical Phillips curve correlations. One potential explanation is that the slope of the Phillips curve is non-linear, becoming flatter at low levels of economic activity and inflation levels. This could follow from downward wage rigidity, for example. Such a result could also follow from cyclical changes in price rigidities. For example, if prices become increasingly rigid due to store-switching as economic conditions worsen, as suggested by the results in Table 2, then this could lead to a flattening of the Phillips curve at lower levels of economic activity. Estimates of the slope of the Phillips curve during regular times would therefore lead to an over-prediction of the decline in inflation during periods of economic crisis. 


\section{References}

Aguiar, Mark and Erik Hurst, 2005. "Consumption versus Expenditure,” Journal of Political Economy, 113(5), 919-948.

Anderson, Eric, Emi Nakamura, Duncan Simester, and Jón Steinsson, 2012. "Decomposing Variation in Retail Prices," manuscript.

Aoki, Kosuke, 2001. “Optimal Monetary Policy Responses to Relative Price Changes,” Journal of Monetary Economics 48(1), 55-80.

Ball, Lawrence and Sandeep Mazumder, 2011. “Inflation Dynamics and the Great Recession,” Brookings Papers on Economic Activity (Spring), 337-381.

Bils, Mark, and Peter J. Klenow, 2004. "Some Evidence on the Importance of Sticky Prices," Journal of Political Economy 112(5), 947-985.

Boskin, Michael J., E. Dulberger, R. Gordon, Z. Griliches, and D. Jorgenson, 1996. “Toward a More Accurate Measure of the Cost of Living,” Final Report to the Senate Finance Committee, Dec. 4.

Bronnenberg, Bart J., Michael W. Kruger, and Carl F. Mela, 2008. "Database Paper: The IRI Marketing Data Set,” Marketing Science 27(4), 745-748.

Calvo, Guillermo, A. 1983. "Staggered Prices in a Utility-Maximizing Framework,” Journal of Monetary Economics 12(3), 383-398.

Carlton, Dennis W., 1986. “The Rigidity of Prices,” American Economic Review 76(4), 637-658.

Cecchetti, Stephen G., 1986. "The Frequency of Price Adjustment: A Study of the Newsstand Prices of Magazines,” Journal of Econometrics 31, 255-274.

Chevalier, Judith A., and Anil K Kashyap, 2011. “Best Prices,” NBER Working Paper 16680.

Christiano, Lawrence, Martin Eichenbaum, and Charles Evans, 1999. "Monetary Policy Shocks: What Have We Learned, and To What End,” in J. Taylor and M. Woodford, eds., Handbook of Monetary Economics.

Clarida, Richard, Jordi Gali, and Mark Gertler, 1999. "The Science of Monetary Policy: A New Keynesian Perspective,” Journal of Economic Literature 37, 1661-1707.

Cleeren, Kathleen, Frank Verboven, Marnik G. Dekimpe, and Katrijn Gielens, 2010. "Intra- and Intermarket Competition among Discounters and Supermarkets,” Marketing Science 29(3) 456-473.

Coibion, Olivier and Yuriy Gorodnichenko, 2011. "Monetary Policy, Trend Inflation, and the Great Moderation: An Alternative Interpretation,” American Economic Review 101(1), 341-70.

Coibion, Olivier, Yuriy Gorodnichenko, and Johannes Wieland, forthcoming. "The optimal inflation rate in New Keynesian models,” Review of Economic Studies.

Diewart, Erwin, John Greenlees and Charles Hulten, 2009. Price Index Concepts and Measurement. The University of Chicago Press

Driscoll, John C., and Aart C. Kraay, 1998. "Consistent Covariance Matrix Estimation With Spatially Dependent Panel Data,” Review of Economics and Statistics 80(4), 549-560.

Eichenbaum, Martin, Nir Jaimovich, and Sergio Rebelo, 2011. "Reference Prices and Nominal Rigidities," American Economic Review 101(1), 234-262.

Feenstra, Robert, and Matthew Shapiro, 2003. Scanner Data and Price Indexes. University of Chicago Press.

Gali , Jordi, and Mark Gertler, 1999. "Inflation Dynamics: A Structural Econometric Analysis,” Journal of Monetary Economics 44, 195-222.

Gali, Jordi, 2008. Monetary Policy, Inflation and the Business Cycle. Princeton University Press.

Glandon, Philip J., 2011. "Sales and the (Mis)Measurement of Price Level Fluctuations," Manuscript.

Gorodnichenko, Yuriy, and Matthew D. Shapiro, 2007. "Monetary Policy When Potential Output Is Uncertain: Understanding the Growth Gamble of the 1990s," Journal of Monetary Economics 54, 11321162.

Guimaraes, Bernardo and Kevin Sheedy, 2011. "Sales and Monetary Policy,” American Economic Review 101, 844-874.

Hausman, Jerry and Ephraim Leibtag, 2007. "Consumer Benefits from Increased Competition in Shopping Outlets: Measuring the Effect of Wal-Mart,” Journal of Applied Econometrics 22, 1157-77. 
Kashyap, Anil, 1995. "Sticky Prices: New Evidence from Retail Catalogs,” Quarterly Journal of Economics 110, 245-274.

Kehoe, Patrick J. and Virgiliu Midrigan, 2010. “Price Are Sticky After All,” Federal Reserve Bank of Minneapolis Research Department Staff Paper 413.

Knotek, Edward S. II, 2007. “How Useful Is Okun’s Law?” Federal Reserve Bank of Kansas City Economic Review, Fourth Quarter, 73-103.

Kumar, V. and Robert P. Leone, 1988. "Measuring the Effect of Retail Store Promotions on Brand and Store Substitution,” Journal of Marketing Research 25(2) 178-185.

Lal, Rajiv, and Ram Rao, 1997. "Supermarket Competition: The Case of Every Day Low Pricing," Marketing Science 16, 60-80.

Nakamura, Emi, and Jón Steinsson, 2008. "Five Facts About Prices: A Reevaluation of Menu Cost Models," Quarterly Journal of Economics 123, 1415-1464.

Reinsdorf, M. 1993. "The effect of outlet price differentials on the U.S. Consumer Price Index" in Price Measurements and Their Uses. M. Foss, M. Manser, and A. Young (eds.). NBER Studies in Income and Wealth, Vol. 57. Chicago: University of Chicago Press.

Rhee, Hongjai, and David R. Bell, 2002. “The Inter-Store Mobility of Supermarket Shoppers,” Journal of Retailing 78, 225-237.

Roberts, John M., 2006. "Monetary Policy and Inflation Dynamics," International Journal of Central Banking 2, 193-230.

Romer, Christina, and David H. Romer, 2004. "A New Measure of Monetary Shocks: Derivation and Implications,” American Economic Review 94, 1055-1084.

Shapiro, Matthew D., and David W. Wilcox, 1996. "Mismeasurement in the Consumer Price Index: An Evaluation,” in NBER Macroeconomics Annual 1996, eds. Ben S. Bernanke and Julio J. Rotemberg, MIT Press, Cambridge, MA.

Triplett, Jack E., 2003. "Using Scanner Data in Consumer Price Indexes: Some Neglected Conceptual Issues," in Scanner Data and Price Indexes, eds. Robert C. Feenstra and Matthew D. Shapiro, University of Chicago Press.

Walters, Rockney G., 1991. "Assessing the Impact of Retail Price Promotions on Product Substitution, Complementary Purchase, and Interstore Sales,” Journal of Marketing 55, 17-28.

Warner, Elizabeth J., and Robert B. Barsky, 1995. "The Timing and Magnitude of Retail Store Markdowns: Evidence from Weekends and Holidays” Quarterly Journal of Economics 110(2), 321-352.

Williams, John C., 2006, “The Phillips Curve in an Era of Well-Anchored Inflation Expectations,” Working Paper, Federal Reserve Bank of San Francisco.

Woodford, Michael, 2003. Interest and Prices: Foundations of a Theory of Monetary Policy. Princeton University Press. 
Table 1. Descriptive statistics.

\begin{tabular}{|c|c|c|c|c|}
\hline \multirow[t]{3}{*}{ Dependent variable } & & \multirow{3}{*}{$\begin{array}{c}\text { Equal weights } \\
\text { to all UPCS } \\
(1)\end{array}$} & \multicolumn{2}{|c|}{$\begin{array}{c}\text { Use expenditure shares as } \\
\text { weights to aggregate UPCs }\end{array}$} \\
\hline & & & City specific & Common \\
\hline & & & $(2)$ & (3) \\
\hline \multicolumn{5}{|l|}{$\begin{array}{l}\text { Sales } \\
\end{array}$} \\
\hline Frequency & $\begin{array}{l}\text { mean } \\
\text { s.d. }\end{array}$ & $\begin{array}{c}0.195 \\
(0.079)\end{array}$ & $\begin{array}{c}0.237 \\
(0.108)\end{array}$ & $\begin{array}{c}0.237 \\
(0.107)\end{array}$ \\
\hline Size & $\begin{array}{l}\text { mean } \\
\text { s.d. }\end{array}$ & $\begin{array}{l}-0.251 \\
(0.077)\end{array}$ & $\begin{array}{l}-0.249 \\
(0.088)\end{array}$ & $\begin{array}{l}-0.252 \\
(0.089)\end{array}$ \\
\hline Share of goods bought on sales & $\begin{array}{l}\text { mean } \\
\text { s.d. }\end{array}$ & $\begin{array}{c}0.238 \\
(0.100)\end{array}$ & $\begin{array}{c}0.319 \\
(0.146)\end{array}$ & $\begin{array}{c}0.317 \\
(0.142)\end{array}$ \\
\hline \multicolumn{5}{|l|}{$\begin{array}{l}\text { Changes of regular prices } \\
\text { Frequency }\end{array}$} \\
\hline All & $\begin{array}{l}\text { mean } \\
\text { s.d. }\end{array}$ & $\begin{array}{c}0.048 \\
(0.031)\end{array}$ & $\begin{array}{c}0.047 \\
(0.036)\end{array}$ & $\begin{array}{c}0.048 \\
(0.038)\end{array}$ \\
\hline Positive & $\begin{array}{l}\text { mean } \\
\text { s.d. }\end{array}$ & $\begin{array}{c}0.032 \\
(0.025)\end{array}$ & $\begin{array}{c}0.031 \\
(0.028)\end{array}$ & $\begin{array}{c}0.031 \\
(0.029)\end{array}$ \\
\hline Negative & $\begin{array}{l}\text { mean } \\
\text { s.d. }\end{array}$ & $\begin{array}{c}0.016 \\
(0.012)\end{array}$ & $\begin{array}{l}0.016 \\
(0.015)\end{array}$ & $\begin{array}{c}0.017 \\
(0.015)\end{array}$ \\
\hline $\begin{array}{l}\text { Size } \\
\text { All }\end{array}$ & $\begin{array}{c}\text { mean } \\
\text { s.d. }\end{array}$ & $\begin{array}{c}0.035 \\
(0.046)\end{array}$ & $\begin{array}{c}0.034 \\
(0.043)\end{array}$ & $\begin{array}{c}0.035 \\
(0.044)\end{array}$ \\
\hline Positive & $\begin{array}{l}\text { mean } \\
\text { s.d. }\end{array}$ & $\begin{array}{c}0.120 \\
(0.053)\end{array}$ & $\begin{array}{c}0.100 \\
(0.055)\end{array}$ & $\begin{array}{c}0.102 \\
(0.057)\end{array}$ \\
\hline Negative & $\begin{array}{c}\text { mean } \\
\text { s.d. }\end{array}$ & $\begin{array}{l}-0.121 \\
(0.084)\end{array}$ & $\begin{array}{l}-0.089 \\
(0.069)\end{array}$ & $\begin{array}{l}-0.091 \\
(0.071) \\
\end{array}$ \\
\hline
\end{tabular}

Notes: The table reports basic statistics about sales and regular price changes at the city/category level at the weekly frequency from 2001 to 2007. 
Table 2. Cyclical properties of selected moments of price changes.

\begin{tabular}{|c|c|c|c|c|c|}
\hline \multirow{3}{*}{ Dependent variable } & \multicolumn{3}{|c|}{ Equal weights to all UPCS } & \multicolumn{2}{|c|}{$\begin{array}{c}\text { Use expenditure shares as } \\
\text { weights to aggregate UPCs }\end{array}$} \\
\hline & & & & \multirow[b]{2}{*}{$\begin{array}{c}\text { City specific } \\
\text { City } \times \text { Category } \\
\text { Month } \\
\text { Fixed effects } \\
(4) \\
\end{array}$} & \multirow[b]{2}{*}{$\begin{array}{c}\text { Common } \\
\text { City } \times \text { Category } \\
\text { Month } \\
\text { Fixed effects } \\
\text { (5) }\end{array}$} \\
\hline & $\begin{array}{c}\text { Pooled OLS } \\
(1) \\
\end{array}$ & $\begin{array}{c}\text { City } \times \text { Category } \\
\text { Fixed effects } \\
(2) \\
\end{array}$ & $\begin{array}{c}\text { City } \times \text { Category } \\
\text { Month } \\
\text { Fixed effects } \\
\text { (3) } \\
\end{array}$ & & \\
\hline \multicolumn{6}{|l|}{ Sales } \\
\hline Frequency & $\begin{array}{l}0.785 * * * \\
(0.235)\end{array}$ & $\begin{array}{c}0.327 \\
(0.550)\end{array}$ & $\begin{array}{l}-0.365 * * * \\
(0.120)\end{array}$ & $\begin{array}{l}-0.422 * * * \\
(0.153)\end{array}$ & $\begin{array}{l}-0.475 * * * \\
(0.141)\end{array}$ \\
\hline Size & $\begin{array}{l}0.245 * * * \\
(0.086)\end{array}$ & $\begin{array}{l}0.321^{* *} \\
(0.145)\end{array}$ & $\begin{array}{l}0.256^{* *} \\
(0.120)\end{array}$ & $\begin{array}{c}0.183 \\
(0.137)\end{array}$ & $\begin{array}{c}0.224^{*} \\
(0.128)\end{array}$ \\
\hline Share of goods bought on sales & $\begin{array}{l}1.126 * * * \\
(0.237)\end{array}$ & $\begin{array}{c}0.512 \\
(0.587)\end{array}$ & $\begin{array}{l}-0.461^{* * *} \\
(0.133)\end{array}$ & $\begin{array}{l}-0.563 * * * \\
(0.171)\end{array}$ & $\begin{array}{l}-0.629 * * * \\
(0.161)\end{array}$ \\
\hline \multicolumn{6}{|l|}{$\begin{array}{l}\text { Changes of regular prices } \\
\text { Frequency }\end{array}$} \\
\hline All & $\begin{array}{c}0.083 \\
(0.097)\end{array}$ & $\begin{array}{l}-0.066 \\
(0.222)\end{array}$ & $\begin{array}{l}-0.100 * * \\
(0.044)\end{array}$ & $\begin{array}{l}-0.097 \\
(0.065)\end{array}$ & $\begin{array}{l}-0.070 \\
(0.064)\end{array}$ \\
\hline Positive & $\begin{array}{c}0.015 \\
(0.056)\end{array}$ & $\begin{array}{l}-0.126 \\
(0.128)\end{array}$ & $\begin{array}{l}-0.053 * \\
(0.032)\end{array}$ & $\begin{array}{l}-0.058 \\
(0.040)\end{array}$ & $\begin{array}{l}-0.050 \\
(0.041)\end{array}$ \\
\hline Negative & $\begin{array}{c}0.067 \\
(0.042)\end{array}$ & $\begin{array}{c}0.060 \\
(0.097)\end{array}$ & $\begin{array}{l}-0.047 * * * \\
(0.019)\end{array}$ & $\begin{array}{l}-0.040 \\
(0.029)\end{array}$ & $\begin{array}{l}-0.020 \\
(0.028)\end{array}$ \\
\hline \multicolumn{6}{|l|}{ Size } \\
\hline All & $\begin{array}{l}-0.122 \\
(0.098)\end{array}$ & $\begin{array}{l}-0.292 \\
(0.196)\end{array}$ & $\begin{array}{l}-0.095 \\
(0.062)\end{array}$ & $\begin{array}{l}-0.008 \\
(0.053)\end{array}$ & $\begin{array}{l}-0.005 \\
(0.052)\end{array}$ \\
\hline Positive & $\begin{array}{c}0.024 \\
(0.046)\end{array}$ & $\begin{array}{l}0.142 * * \\
(0.072)\end{array}$ & $\begin{array}{l}-0.155^{*} \\
(0.092)\end{array}$ & $\begin{array}{l}-0.020 \\
(0.079)\end{array}$ & $\begin{array}{l}-0.027 \\
(0.080)\end{array}$ \\
\hline Negative & $\begin{array}{c}0.051 \\
(0.092)\end{array}$ & $\begin{array}{l}-0.014 \\
(0.216)\end{array}$ & $\begin{array}{l}-0.004 \\
(0.129)\end{array}$ & $\begin{array}{l}-0.026 \\
(0.101)\end{array}$ & $\begin{array}{l}-0.023 \\
(0.101)\end{array}$ \\
\hline Inflation of posted prices & $\begin{array}{l}-0.077 * * * \\
(0.020)\end{array}$ & $\begin{array}{l}-0.081 \\
(0.054)\end{array}$ & $\begin{array}{c}0.007 \\
(0.034)\end{array}$ & $\begin{array}{l}-0.0273 \\
(0.036)\end{array}$ & $\begin{array}{l}-0.034 \\
(0.039)\end{array}$ \\
\hline Inflation of effective prices & $\begin{array}{l}-0.221 * * * \\
(0.034)\end{array}$ & $\begin{array}{l}-0.470 * * * \\
(0.076)\end{array}$ & $\begin{array}{l}-0.208 * * * \\
(0.045)\end{array}$ & $\begin{array}{l}-0.258 * * * \\
(0.064)\end{array}$ & $\begin{array}{l}-0.263^{* * *} \\
(0.060)\end{array}$ \\
\hline
\end{tabular}

Notes: The table reports estimated coefficients on local seasonally-adjusted unemployment rate in specification (3.2). Number of observation is 127,224.

Estimated specification is given by equation (1). Driscoll and Kraay (1998) standard errors are in parentheses. ***, **, * denote significance at 0.01 , 0.05, and 0.10 levels. 
Table 3. Cyclicality of pricing moments by store rank.

\begin{tabular}{|c|c|c|c|c|c|c|}
\hline \multirow[t]{2}{*}{ "Dependent variable } & \multicolumn{2}{|c|}{ 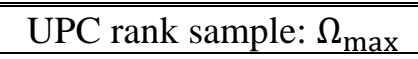 } & \multicolumn{2}{|c|}{ UPC rank sample: $\Omega_{90}$} & \multicolumn{2}{|c|}{ "UPC rank sample: $\Omega_{75}$} \\
\hline & $\begin{array}{l}\text { UR } \\
(1) \\
\end{array}$ & $\begin{array}{c}\text { UR } \times \text { rank } \\
(2) \\
\end{array}$ & $\begin{array}{l}\text { UR } \\
(3) \\
\end{array}$ & $\begin{array}{c}\text { UR } \times \text { rank } \\
(4)\end{array}$ & $\begin{array}{l}\text { UR } \\
(5) \\
\end{array}$ & $\begin{array}{c}\text { UR } \times \text { rank } \\
(6) \\
\end{array}$ \\
\hline \multicolumn{7}{|l|}{ Sales } \\
\hline Frequency & $\begin{array}{l}-0.046 \\
(0.155)\end{array}$ & $\begin{array}{l}-1.398 * * * \\
(0.177)\end{array}$ & $\begin{array}{l}0.052 \\
(0.154)\end{array}$ & $\begin{array}{l}-1.578^{* * * *} \\
(0.190)\end{array}$ & $\begin{array}{l}0.119 \\
(0.156)\end{array}$ & $\begin{array}{l}-1.709 * * * \\
(0.193)\end{array}$ \\
\hline Size & $\begin{array}{l}0.087 \\
(0.102)\end{array}$ & $\begin{array}{l}-0.181 \\
(0.150)\end{array}$ & $\begin{array}{l}0.123 \\
(0.100)\end{array}$ & $\begin{array}{l}-0.251 \\
(0.175)\end{array}$ & $\begin{array}{l}0.137 \\
(0.099)\end{array}$ & $\begin{array}{l}-0.277 \\
(0.196)\end{array}$ \\
\hline $\begin{array}{l}\text { Share of goods bought on } \\
\text { sales, } \omega_{m c t}\end{array}$ & $\begin{array}{l}0.225 \\
(0.163)\end{array}$ & $\begin{array}{l}-1.677^{* * *} \\
(0.210)\end{array}$ & $\begin{array}{l}0.332 * * \\
(0.168)\end{array}$ & $\begin{array}{l}-1.874 * * * \\
(0.227)\end{array}$ & $\begin{array}{l}0.412 * * * \\
(0.170)\end{array}$ & $\begin{array}{l}-2.030 * * * \\
(0.235)\end{array}$ \\
\hline Growth rate of revenue & $\begin{array}{l}0.266 \\
(0.231)\end{array}$ & $\begin{array}{l}-0.620 * * * \\
(0.089)\end{array}$ & $\begin{array}{l}0.432 * \\
(0.225)\end{array}$ & $\begin{array}{l}-0.919 * * * \\
(0.086)\end{array}$ & $\begin{array}{l}0.605^{* * *} \\
(0.218)\end{array}$ & $\begin{array}{l}-1.251^{* * *} \\
(0.111)\end{array}$ \\
\hline \multicolumn{7}{|l|}{ Changes of regular prices } \\
\hline All & $\begin{array}{l}0.019 \\
(0.081)\end{array}$ & $\begin{array}{l}-0.157 * * * \\
(0.052)\end{array}$ & $\begin{array}{l}0.026 \\
(0.084)\end{array}$ & $\begin{array}{l}-0.173 * * * \\
(0.061)\end{array}$ & $\begin{array}{l}0.031 \\
(0.084)\end{array}$ & $\begin{array}{l}-0.183^{* * *} \\
(0.066)\end{array}$ \\
\hline Positive & $\begin{array}{l}0.010 \\
(0.050)\end{array}$ & $\begin{array}{l}-0.067 * * \\
(0.035)\end{array}$ & $\begin{array}{l}0.016 \\
(0.052)\end{array}$ & $\begin{array}{l}-0.081 * * \\
(0.041)\end{array}$ & $\begin{array}{l}0.019 \\
(0.052)\end{array}$ & $\begin{array}{l}-0.087 * * \\
(0.043)\end{array}$ \\
\hline Negative & $\begin{array}{l}0.009 \\
(0.037)\end{array}$ & $\begin{array}{l}-0.090 * * * \\
(0.020)\end{array}$ & $\begin{array}{l}0.010 \\
(0.037)\end{array}$ & $\begin{array}{l}-0.093 * * * \\
(0.023)\end{array}$ & $\begin{array}{l}0.012 \\
(0.037)\end{array}$ & $\begin{array}{l}-0.096 * * * \\
(0.026)\end{array}$ \\
\hline \multicolumn{7}{|l|}{ Size } \\
\hline All & $\begin{array}{l}-0.121 * * \\
(0.055)\end{array}$ & $\begin{array}{l}0.034 \\
(0.034)\end{array}$ & $\begin{array}{l}-0.125^{* *} \\
(0.056)\end{array}$ & $\begin{array}{l}0.041 \\
(0.036)\end{array}$ & $\begin{array}{l}-0.123^{* *} \\
(0.057)\end{array}$ & $\begin{array}{l}0.037 \\
(0.039)\end{array}$ \\
\hline Positive & $\begin{array}{l}-0.140 \\
(0.091)\end{array}$ & $\begin{array}{l}-0.105^{* * * *} \\
(0.039)\end{array}$ & $\begin{array}{l}-0.146 \\
(0.095)\end{array}$ & $\begin{array}{l}-0.094 * * \\
(0.046)\end{array}$ & $\begin{array}{l}-0.139 \\
(0.097)\end{array}$ & $\begin{array}{l}-0.107 * * \\
(0.049)\end{array}$ \\
\hline Negative & $\begin{array}{l}0.310^{* * * *} \\
(0.079)\end{array}$ & $\begin{array}{l}-0.039 \\
(0.056)\end{array}$ & $\begin{array}{l}0.320^{* * * *} \\
(0.084)\end{array}$ & $\begin{array}{l}-0.058 \\
(0.070)\end{array}$ & $\begin{array}{l}0.308 * * * \\
(0.089)\end{array}$ & $\begin{array}{l}-0.036 \\
(0.082)\end{array}$ \\
\hline
\end{tabular}

Notes: The table reports estimates of specification (4.1). Number of observation is 144,270 . UR is the local seasonally-adjusted unemployment rate. Rank is the rank of the store in terms of level of prices $\left(\bar{R}_{m s t, \Omega}\right)$. $\Omega$ indicates what universe of goods is used to rank stores. Expenditure shares are used to aggregate ranks across UPCs. Driscoll and Kraay (1998) standard errors are in parentheses. $* * *, * *, *$ denote significance at $0.01,0.05$, and 0.10 levels. See text for further details. 
Table 4. Rank of the shore where households shop as a function of locall unemployment rate.

\begin{tabular}{ccc}
\hline \hline $\begin{array}{c}\text { Sample of UPCs } \\
\text { used in ranking } \\
\text { stores }\end{array}$ & Equal weights to all goods & $\begin{array}{c}\text { Goods are weighted by } \\
\text { expenditure shares }\end{array}$ \\
\cline { 2 - 3 }$\Omega_{\max }$ & $(1)$ & $(2)$ \\
& $-9.298^{* * *}$ & $-13.090^{* * *}$ \\
$\Omega_{90}$ & $(3.221)$ & $(3.796)$ \\
& $-9.210^{* * *}$ & $-14.237^{* * *}$ \\
& $(3.006)$ & $(3.751)$ \\
$\Omega_{75}$ & $-10.585^{* * *}$ & $-4.908^{* *}$ \\
& $(3.238)$ & $(2.382)$ \\
\hline \hline
\end{tabular}

Notes: The table reports estimates of specification (4.3). The dependent variable is the average rank of stores where a household shops in a given month. The table reports estimated coefficients on the local seasonallyadjusted unemployment rate. Each regression has 471,615 observations. Driscoll and Kraay (1998) standard errors are in parentheses. $* * *, * *, *$ denote significance at $0.01,0.05$, and 0.10 levels. 
Table 5. Rank of the shore where households shop as a function of local unemployment rate and household's income.

\begin{tabular}{|c|c|c|c|c|c|c|}
\hline $\begin{array}{c}\text { Sample of } \\
\text { UPCs used in } \\
\text { ranking stores } \\
\end{array}$ & $\begin{array}{c}\text { Weights for } \\
\text { aggregation of UPCs }\end{array}$ & $\begin{array}{c}U R_{c t} \\
(1)\end{array}$ & $\begin{array}{c}U R_{c t} \times D^{2} \\
\text { (2) }\end{array}$ & $\begin{array}{c}U R_{c t} \times D^{3} \\
\text { (3) }\end{array}$ & $\begin{array}{c}U R_{c t} \times D^{4} \\
\text { (4) }\end{array}$ & $\begin{array}{c}U R_{c t} \times D^{5} \\
\text { (5) }\end{array}$ \\
\hline \multirow[t]{2}{*}{$\Omega_{\max }$} & Equal & $\begin{array}{l}-8.961^{* * *} \\
(3.149)\end{array}$ & $\begin{array}{l}-0.671 * * * \\
(0.174)\end{array}$ & $\begin{array}{l}-0.556^{* *} \\
(0.240)\end{array}$ & $\begin{array}{l}-0.631 \\
(0.425)\end{array}$ & $\begin{array}{c}0.025 \\
(0.818)\end{array}$ \\
\hline & Expenditure shares & $\begin{array}{l}-12.735^{* * *} \\
(3.820)\end{array}$ & $\begin{array}{l}-0.744^{* * *} \\
(0.238)\end{array}$ & $\begin{array}{l}-0.632 * * \\
(0.314)\end{array}$ & $\begin{array}{l}-0.516 \\
(0.511)\end{array}$ & $\begin{array}{l}-0.007 \\
(0.779)\end{array}$ \\
\hline \multirow[t]{2}{*}{$\Omega_{90}$} & Equal & $\begin{array}{l}-8.817 * * * \\
(2.923)\end{array}$ & $\begin{array}{l}-0.739 * * * \\
(0.188)\end{array}$ & $\begin{array}{l}-0.604 * * * \\
(0.250)\end{array}$ & $\begin{array}{l}-0.688 \\
(0.439)\end{array}$ & $\begin{array}{l}-0.117 \\
(0.846)\end{array}$ \\
\hline & Expenditure shares & $\begin{array}{l}-13.830^{* * *} \\
(3.725)\end{array}$ & $\begin{array}{l}-0.704^{* * *} \\
(0.218)\end{array}$ & $\begin{array}{l}-0.737 * * * \\
(0.275)\end{array}$ & $\begin{array}{l}-0.677 \\
(0.437)\end{array}$ & $\begin{array}{l}-0.047 \\
(0.785)\end{array}$ \\
\hline \multirow[t]{2}{*}{$\Omega_{75}$} & Equal & $\begin{array}{l}-10.160 * * * \\
(3.160)\end{array}$ & $\begin{array}{l}-0.828 * * * \\
(0.194)\end{array}$ & $\begin{array}{l}-0.715^{* * *} \\
(0.257)\end{array}$ & $\begin{array}{l}-0.742 * \\
(0.392)\end{array}$ & $\begin{array}{l}-0.019 \\
(0.822)\end{array}$ \\
\hline & Expenditure shares & $\begin{array}{l}-4.808^{* *} \\
(2.321)\end{array}$ & $\begin{array}{l}-0.430 * * \\
(0.205)\end{array}$ & $\begin{array}{l}-0.312 \\
(0.285)\end{array}$ & $\begin{array}{l}-0.306 \\
(0.343)\end{array}$ & $\begin{array}{c}0.533 \\
(0.689)\end{array}$ \\
\hline
\end{tabular}

Notes: The table reports estimates of specification (4.4). The dependent variable is the average rank of stores where a household shops in a given month. The table reports estimated coefficients on the local seasonallyadjusted unemployment rate. $D^{g}$ is the dummy variable equal to one if a household is in $\mathrm{g}^{\text {th }}$ income quintile and zero otherwise. Each regression has 471,615 observations. Driscoll and Kraay (1998) standard errors are in parentheses. $* * *, * *, *$ denote significance at $0.01,0.05$, and 0.10 levels. 
Table 6. Within category substitution.

\begin{tabular}{lcc}
\hline \hline & $\begin{array}{c}\text { Equal weights } \\
\text { for all stores }\end{array}$ & $\begin{array}{c}\text { Sales shares to } \\
\text { aggregate stores }\end{array}$ \\
\cline { 2 - 3 } & $(1)$ & $(2)$ \\
\hline \hline Substitution within broad categories & $-0.454^{*}$ & $-0.611^{* *}$ \\
Substitution within narrower categories & $(0.251)$ & $(0.265)$ \\
& $-0.377^{*}$ & $-0.475^{*}$ \\
\hline \hline
\end{tabular}

Notes: The table reports estimates of specification (5.2). The dependent variable is the within-category effective inflation rate. The table reports estimated coefficients on the local seasonally-adjusted unemployment rate. Number of observations is 94,851. Driscoll and Kraay (1998) standard errors are in parentheses. ${ }^{* * *}$, **, * denote significance at $0.01,0.05$, and 0.10 levels. 
Figure 1. Correlations between key moments
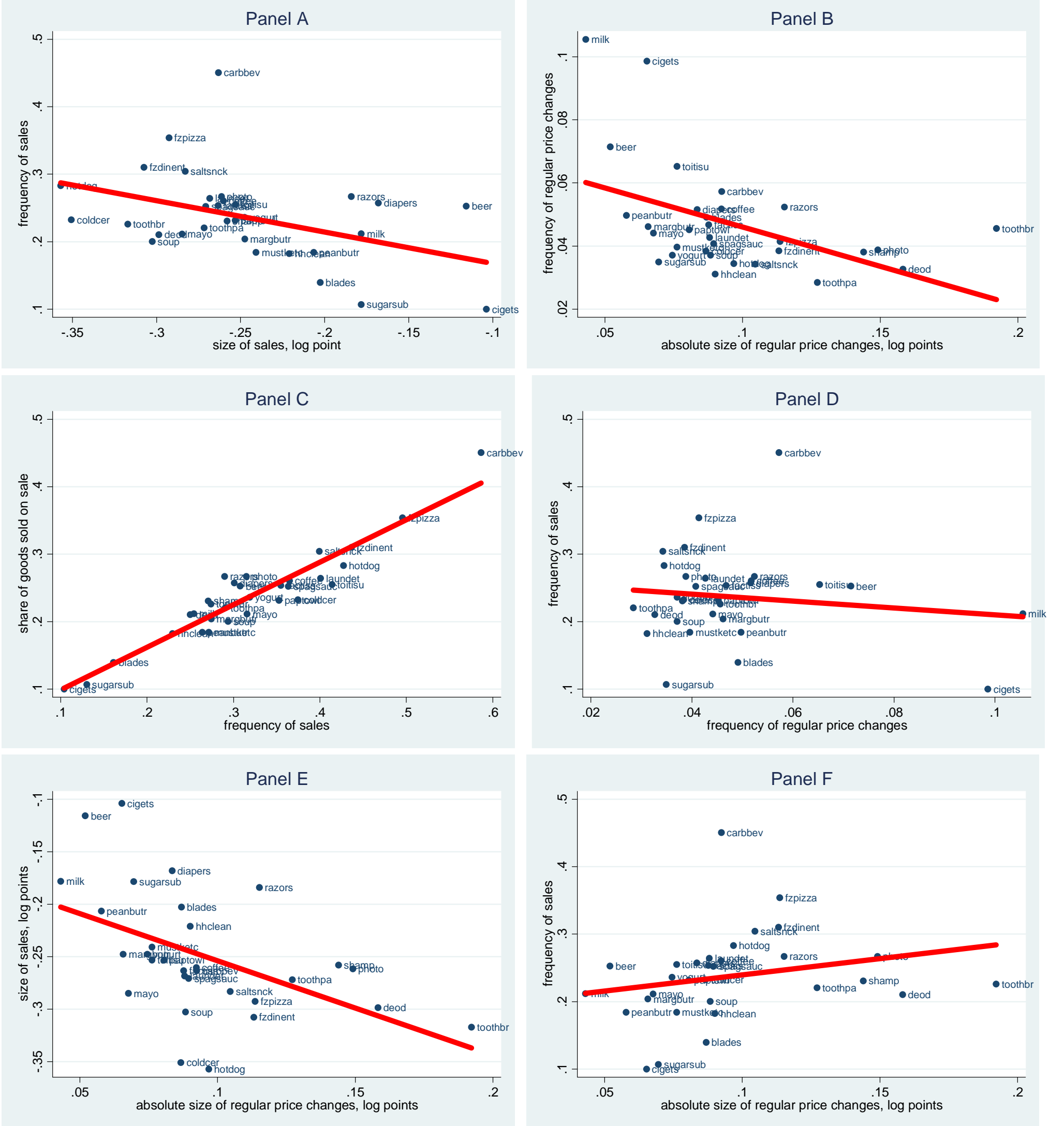

Notes: Figures report average (across time and goods) moments at the category level. Expenditure shares are used as weights to aggregate goods. Red line shows the best fit linear projection. See section 2 for details. 
Figure 2. Economic Conditions and the Reallocation of Consumption Expenditures across Retailers.

Panel A: The Cyclicality of the Gap between the Effective Price Index and the Posted Price Index

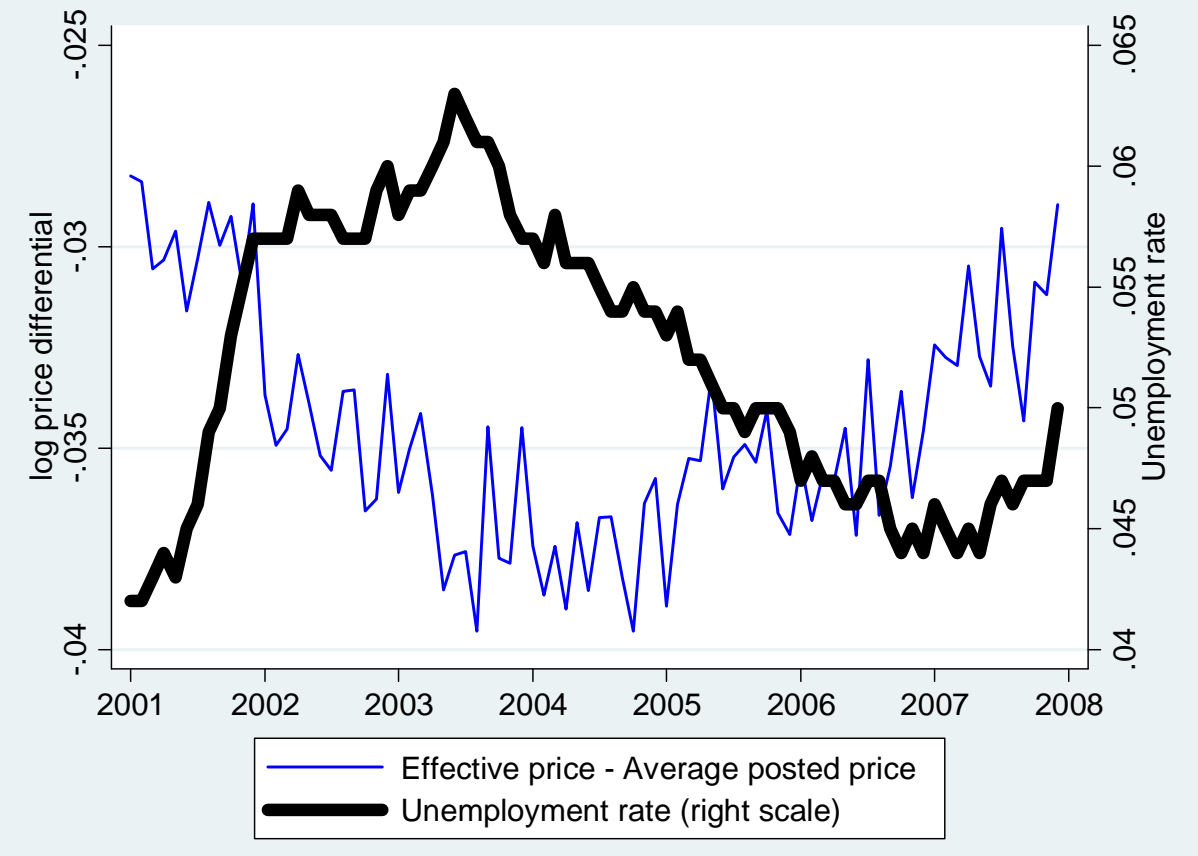

Panel B: The Cyclicality of the Share of Total Retailer Revenues Coming from High-Price Retailers

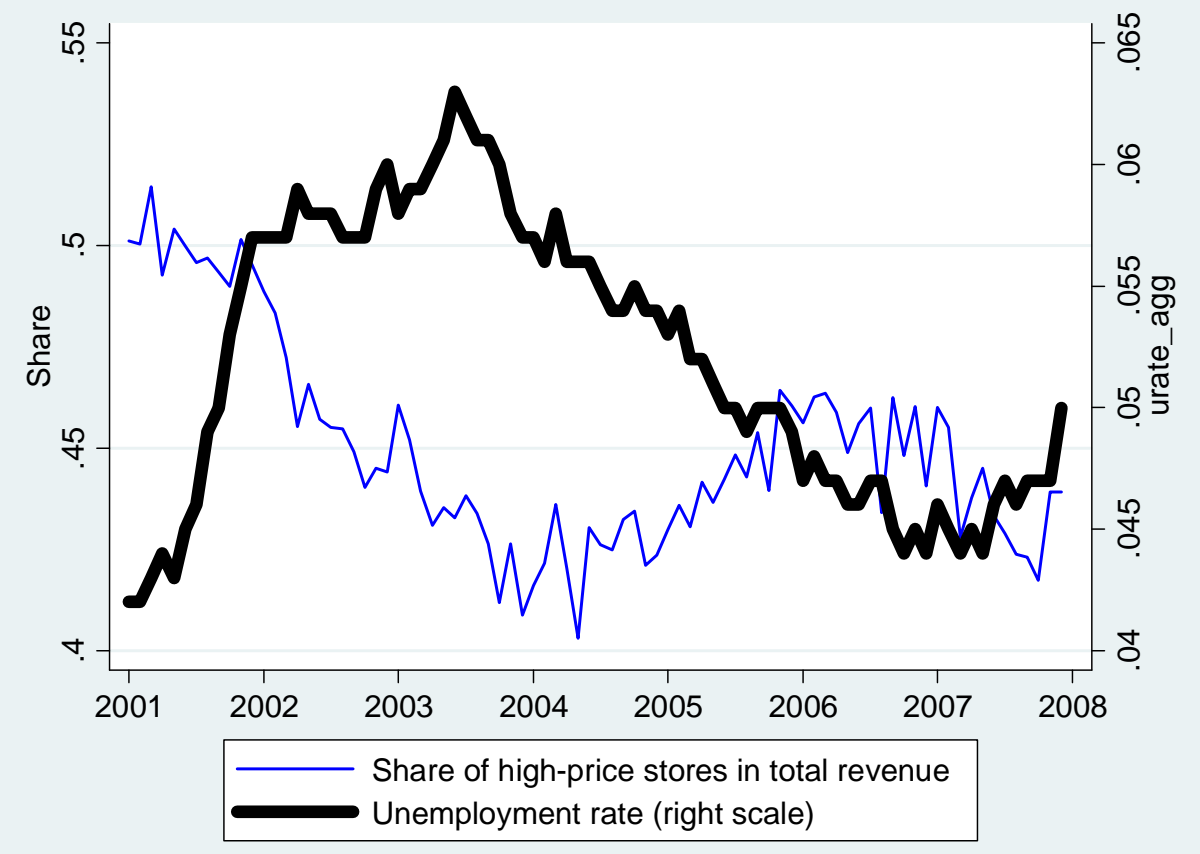

Notes: Panel A plots the difference between the "effective" price index and the "posted" price index. The latter is a fixedexpenditure-weighted average of all UPC prices in each store and metropolitan areas in the data, where weights are average expenditure share of each UPC in each geographic area relative to total household expenditures. The former is the fixedexpenditure-weighted average of average price paid by households for each UPC across all retailers in a metropolitan area. Panel B plots the share of total retailer revenues arising from revenues at high-price retailers in the data. "High-price" retailers are defined as in the text for each metropolitan area. Total share is a fixed expenditure-weighted average across metropolitan areas of shares in each metropolitan area. See section 6.2 for details. 
Figure 3. Correlation between unemployment rate and measures of inflation.

Panel A: Unconditional correlations in the model with endogenous shopping effort and store switching

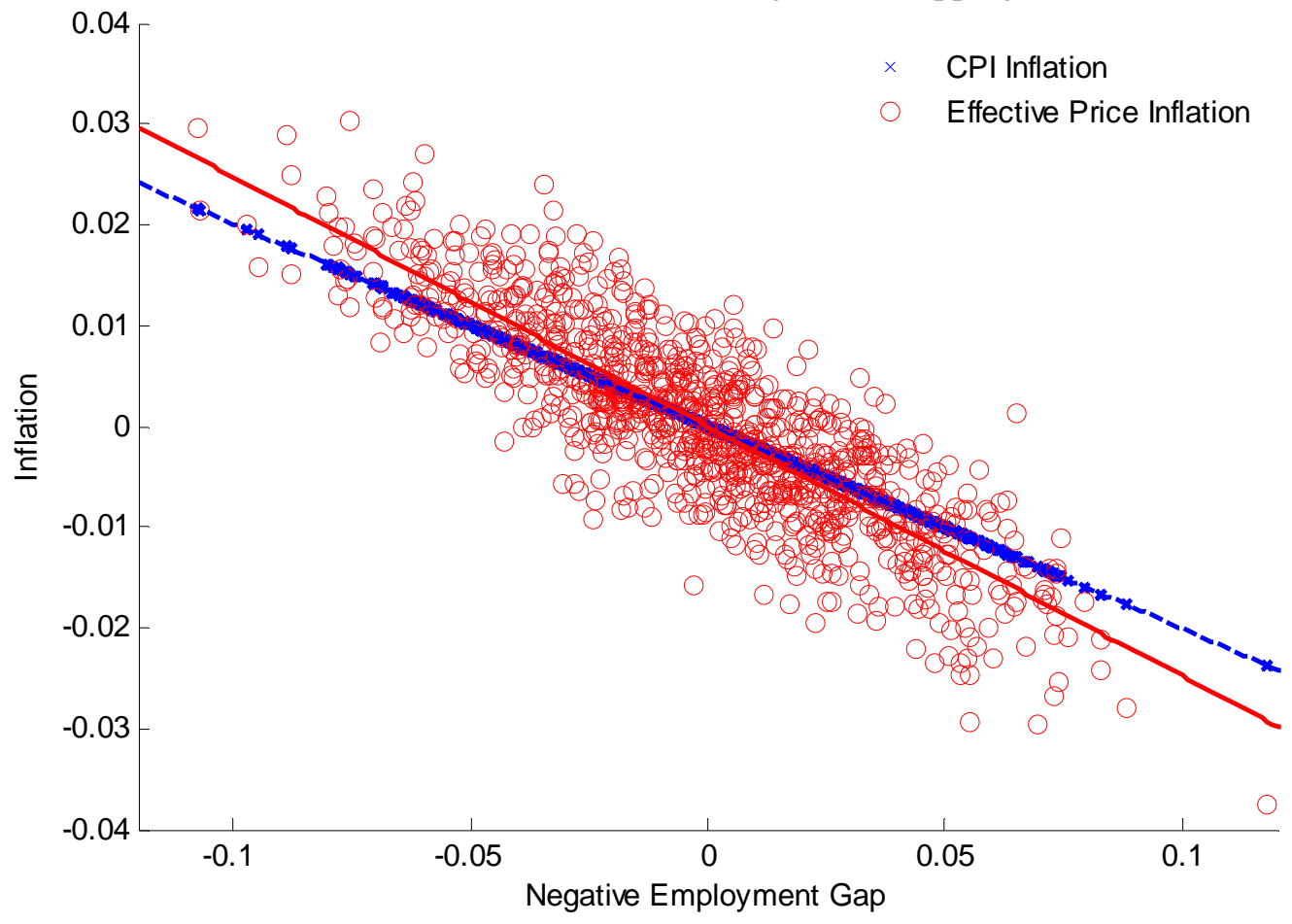

Panel B: Unconditional correlations in the data

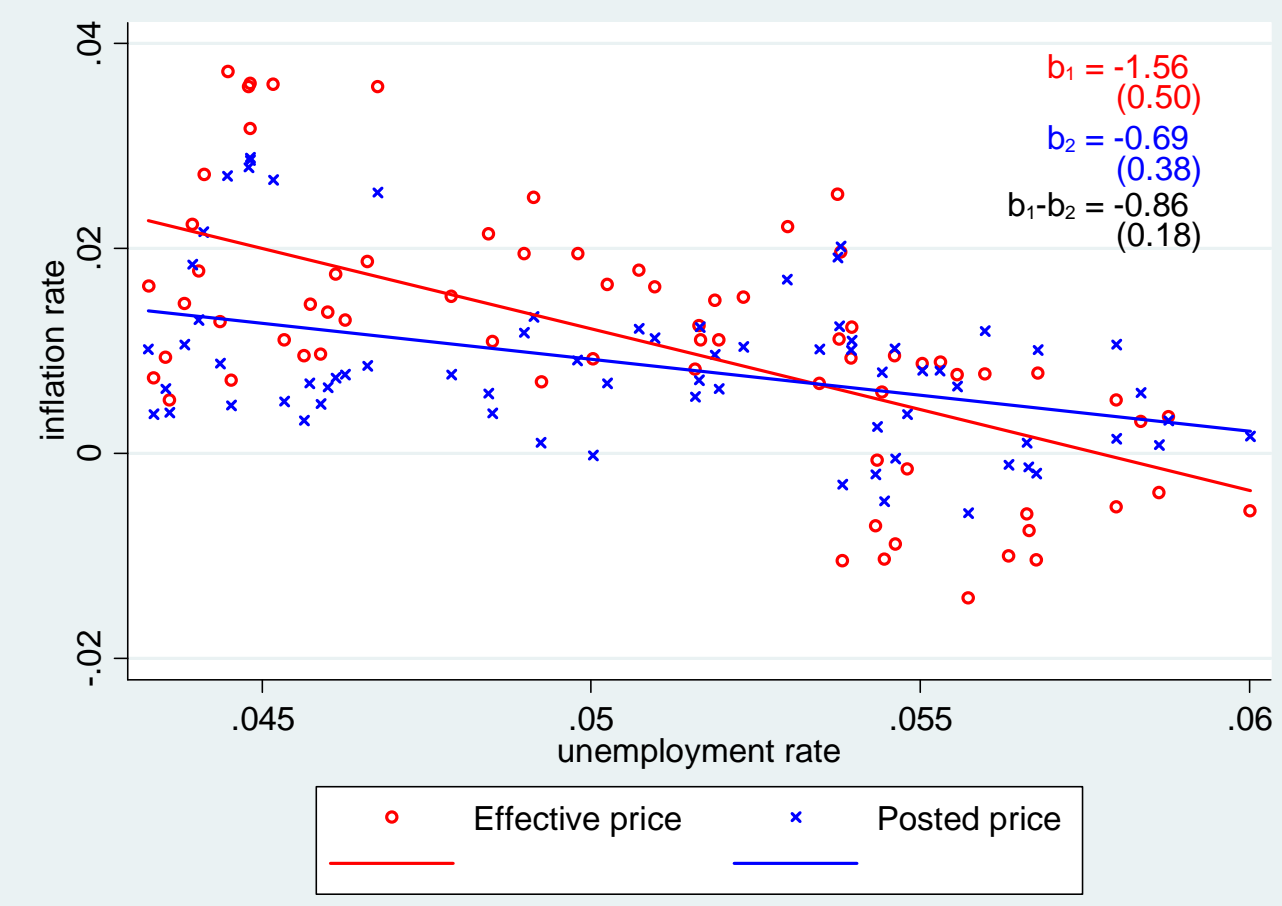

Notes: The top figure plots the unconditional relationship between the negative employment gap $\left(-\check{L}_{t}\right)$ and both posted (CPI) inflation and "effective" price inflation, both annualized, from simulating the model in section 6.1. The solid lines plot the estimated linear relationship between each. The bottom figure presents relationships between the unemployment rate the same two measures of inflation in the data. See section 6.2 for details. 
Figure 4. Business Cycle and Policy Implications of Endogenous Shopping Effort and Store-Switching.

Panel A: Dynamic Responses to Monetary Policy Shock with and without Endogenous Shopping Effort
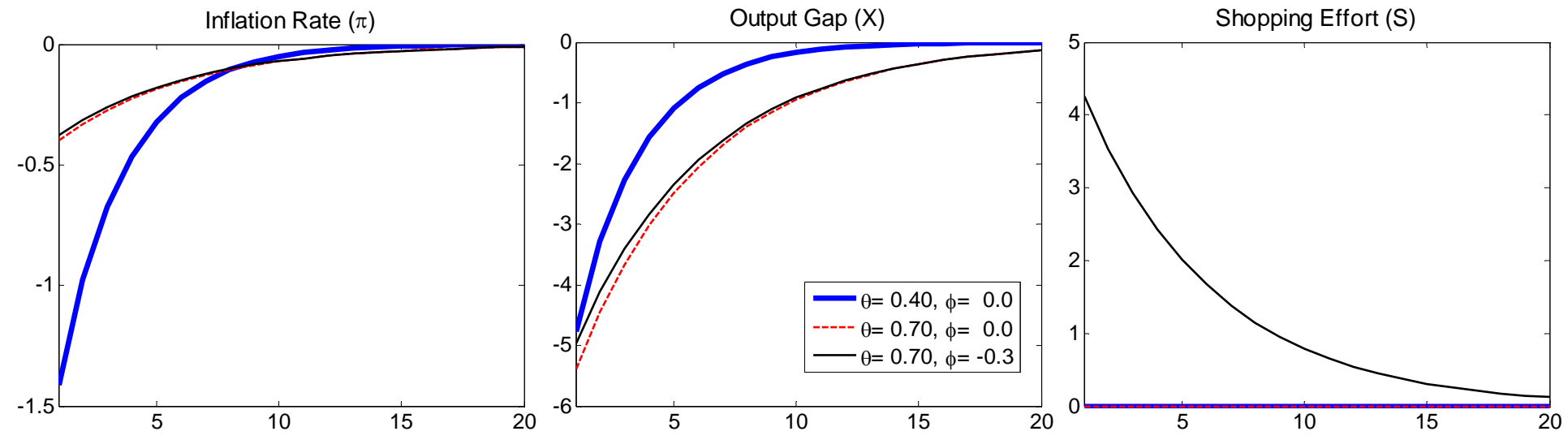

Panel B: Substitution Effects after Monetary Policy Shock $(\phi=-0.3)$
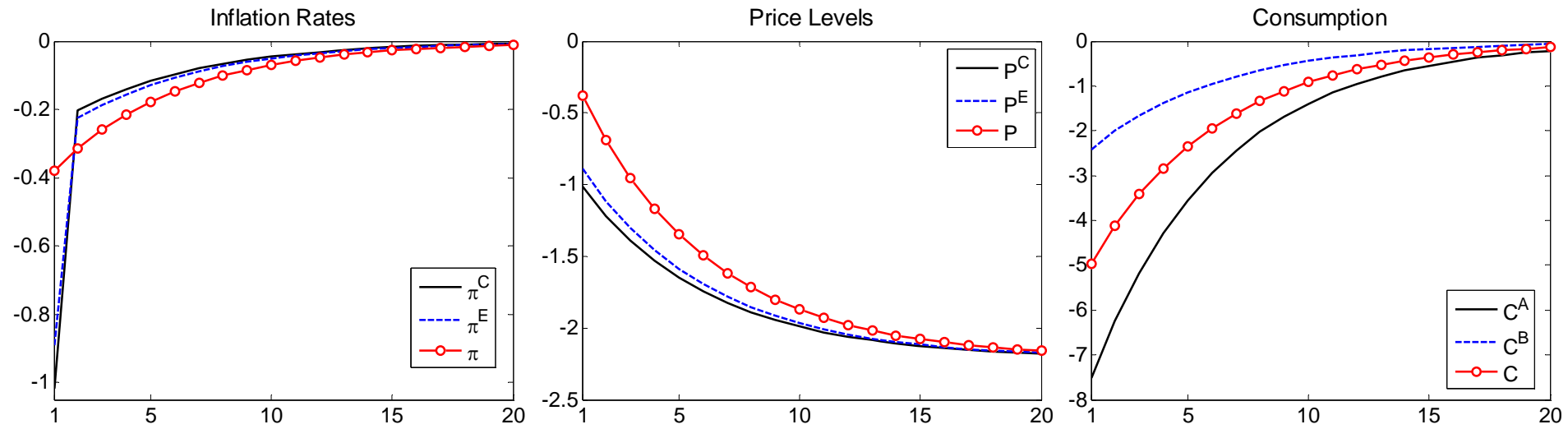

Panel C: Welfare Implications of Endogenous Shopping Effort

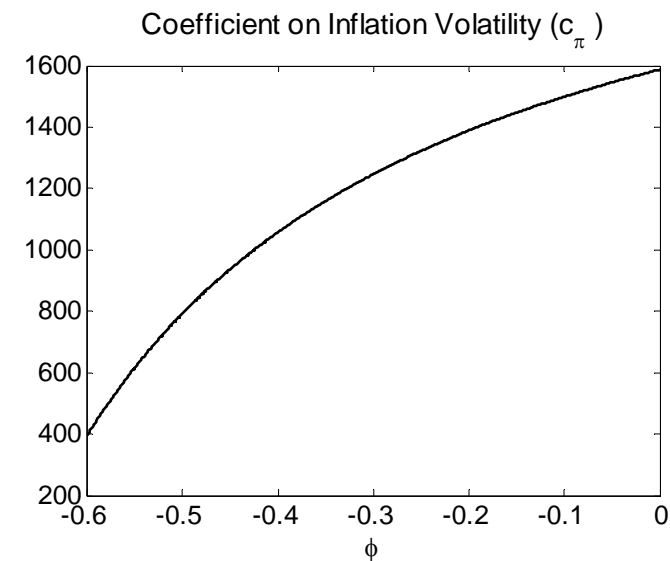

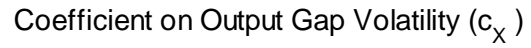

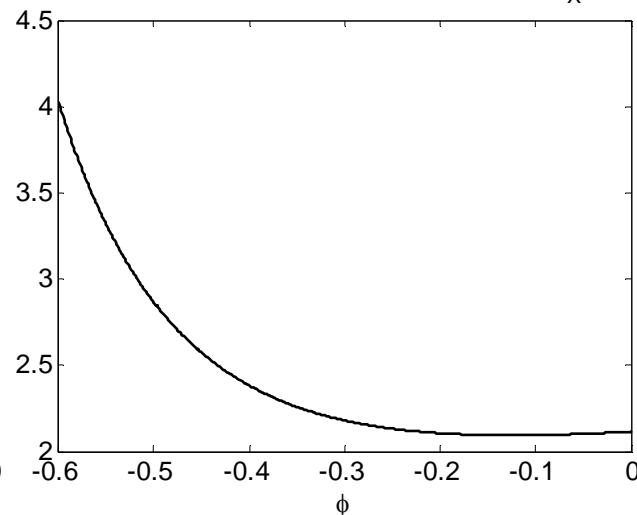

Relative Weight on Output Gap Volatility $\left(c_{x} / c_{\pi}\right.$

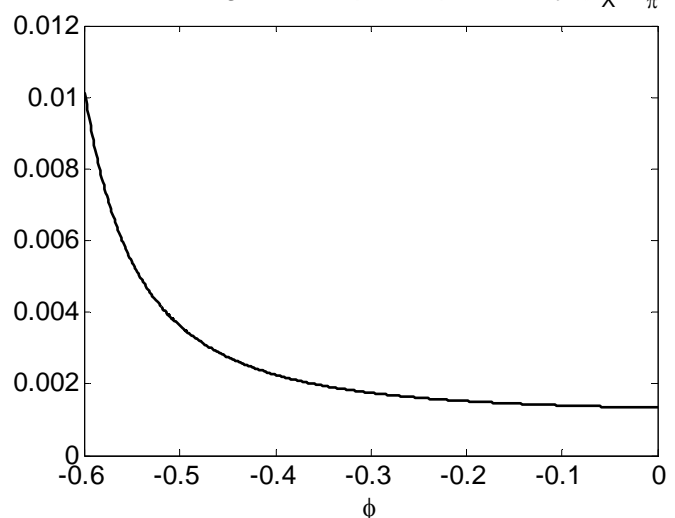

Notes: The top panel displays impulse responses of inflation, output gap and shopping effort to a contractionary monetary policy shock in the model described in section 6.1. $\theta$ is the degree of price stickiness and $\phi$ is the elasticity of iceberg costs to shopping effort. The middle panel plots the impulse responses of inflation rates for final consumption goods $\left(\pi^{C}\right)$, effective prices $\left(\pi^{E}\right)$, and posted prices $(\pi)$ in the left figure, price levels for consumption goods $\left(P^{C}\right)$, effective prices $\left(P^{E}\right)$ and posted prices $(P)$ in the middle figure, and total consumption $(C)$, consumption at the high-price retailer $\left(C^{A}\right)$ and consumption at the low-price retailer $\left(C^{B}\right)$ in the right figure. The bottom panel plots the coefficients on inflation volatility (left) and output gap volatility (middle) from the secondorder approximation to utility in the model of section 6.1 and the right figure plots the ratio of the two. See section 6.3 for details. 
Figure 5. Which Inflation Measure Should Policymakers Target?

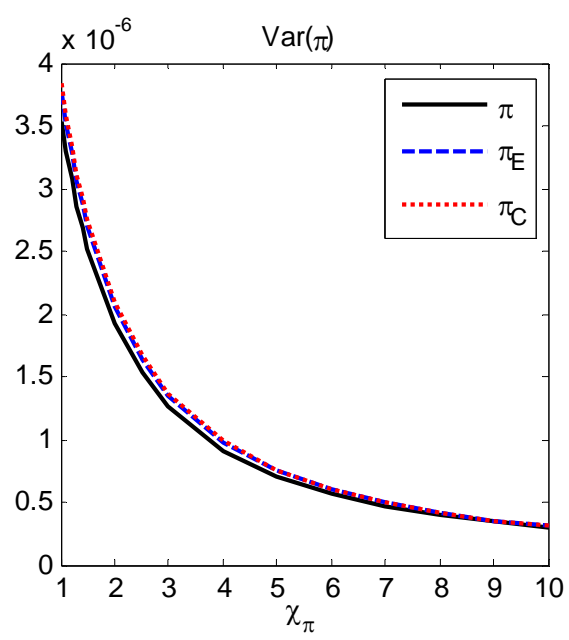

Panel A: Inflation Targeting
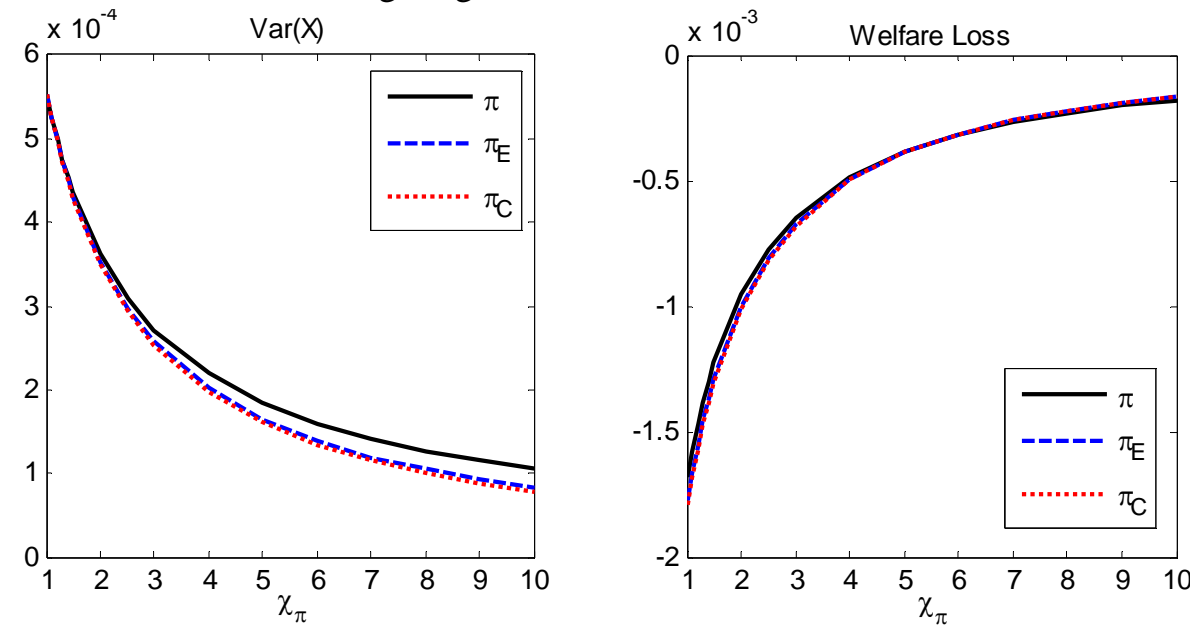

Panel B: Price-Level Targeting
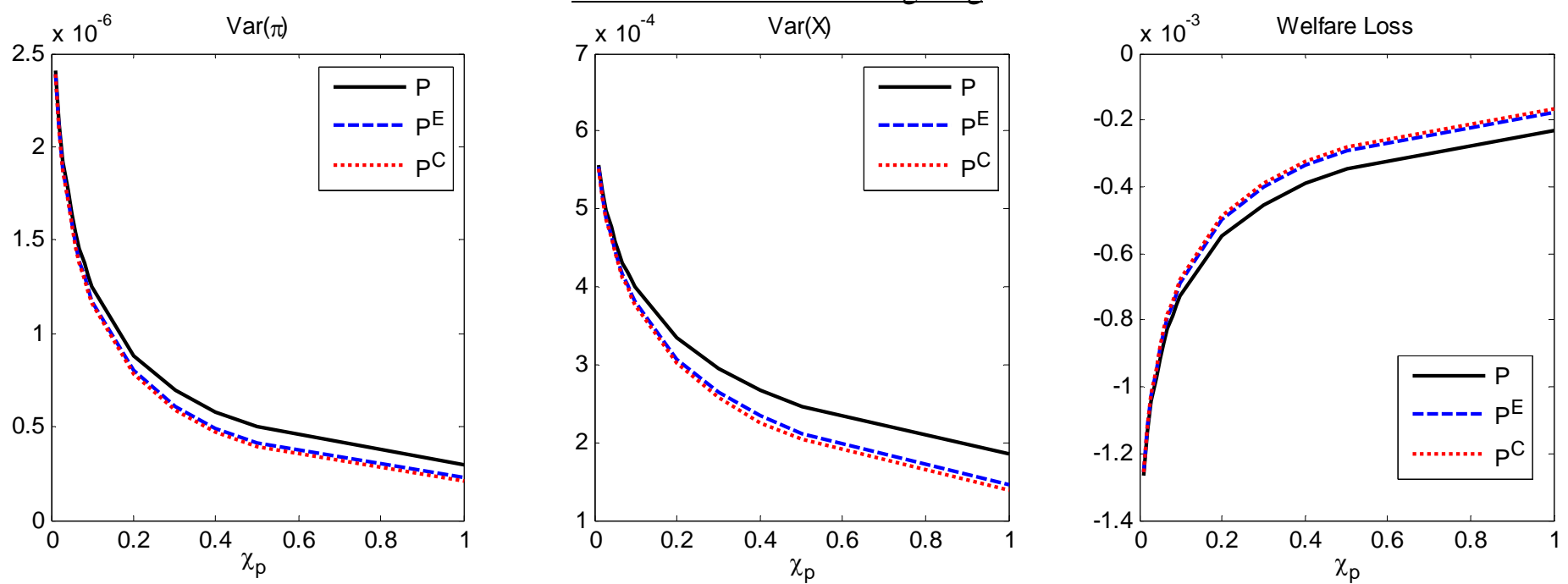

Notes: The top panel displays the variance of inflation (left) and the variance of the output gap (middle) for different longrun responses to inflation by the central bank when the central bank responds to either posted price inflation $(\pi)$, effective price inflation $\left(\pi^{E}\right)$, or inflation of final goods prices $\left(\pi^{C}\right)$. The right panel shows expected utility loss in each case. The bottom panel plots equivalent figures in the case of price-level targeting when the central bank responds to either posted prices ( $P$ ), effective prices $\left(P^{E}\right)$, or final consumption goods prices $\left(P^{C}\right)$. See section 6.3 for details. 


\section{APPENDIX MATERIAL}


APPENDiX A: AdDitional tABLES AND FigURES.

Appendix Table 1. Descriptive statistics by category.

\begin{tabular}{|c|c|c|c|c|c|c|c|c|c|}
\hline \multirow{4}{*}{ Category } & \multicolumn{2}{|c|}{ Sales } & \multirow{4}{*}{ 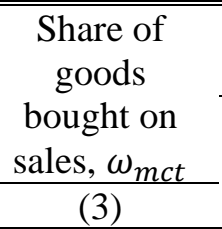 } & \multicolumn{6}{|c|}{ Changes of regular prices } \\
\hline & \multirow[b]{2}{*}{ Frequency } & \multirow[b]{2}{*}{ Size } & & \multicolumn{3}{|c|}{ Frequency } & \multicolumn{3}{|c|}{ Size } \\
\hline & & & & All & Positive & Negative & All & Positive & Negative \\
\hline & (1) & $(2)$ & & (4) & (5) & (6) & (7) & (8) & (9) \\
\hline \multirow[t]{2}{*}{ beer } & 0.152 & -0.122 & 0.171 & 0.052 & 0.034 & 0.017 & 0.028 & 0.077 & -0.063 \\
\hline & (0.069) & $(0.035)$ & (0.077) & $(0.032)$ & $(0.023)$ & $(0.012)$ & $(0.032)$ & (0.030) & (0.025) \\
\hline \multirow[t]{2}{*}{ blades } & 0.144 & -0.267 & 0.160 & 0.051 & 0.036 & 0.016 & 0.032 & 0.119 & -0.165 \\
\hline & (0.038) & $(0.059)$ & $(0.042)$ & $(0.022)$ & $(0.017)$ & $(0.010)$ & $(0.044)$ & $(0.036)$ & $(0.087)$ \\
\hline \multirow[t]{2}{*}{ carbonated beverages } & 0.257 & -0.239 & 0.310 & 0.058 & 0.036 & 0.022 & 0.041 & 0.132 & -0.113 \\
\hline & $(0.055)$ & $(0.039)$ & $(0.063)$ & $(0.022)$ & $(0.015)$ & $(0.009)$ & $(0.024)$ & $(0.028)$ & $(0.030)$ \\
\hline \multirow[t]{2}{*}{ cigarettes } & 0.069 & -0.122 & 0.071 & 0.137 & 0.102 & 0.035 & 0.026 & 0.079 & -0.090 \\
\hline & $(0.046)$ & $(0.051)$ & $(0.047)$ & $(0.073)$ & $(0.069)$ & $(0.020)$ & $(0.035)$ & $(0.032)$ & $(0.039)$ \\
\hline \multirow[t]{2}{*}{ coffee } & 0.203 & -0.237 & 0.236 & 0.053 & 0.035 & 0.018 & 0.037 & 0.126 & -0.119 \\
\hline & (0.069) & $(0.048)$ & $(0.076)$ & $(0.025)$ & $(0.020)$ & (0.009) & $(0.037)$ & (0.039) & $(0.050)$ \\
\hline \multirow[t]{2}{*}{ cold cereals } & 0.210 & -0.314 & 0.278 & 0.038 & 0.027 & 0.012 & 0.045 & 0.112 & -0.092 \\
\hline & $(0.066)$ & $(0.059)$ & $(0.081)$ & $(0.018)$ & $(0.013)$ & $(0.007)$ & $(0.029)$ & $(0.041)$ & $(0.047)$ \\
\hline \multirow{2}{*}{ deodorants } & 0.198 & -0.316 & 0.226 & 0.043 & 0.026 & 0.016 & 0.030 & 0.171 & -0.219 \\
\hline & $(0.053)$ & $(0.055)$ & (0.059) & (0.019) & $(0.013)$ & $(0.010)$ & $(0.055)$ & $(0.048)$ & (0.089) \\
\hline \multirow[t]{2}{*}{ diapers } & 0.242 & -0.185 & 0.269 & 0.058 & 0.030 & 0.027 & 0.008 & 0.100 & -0.107 \\
\hline & $(0.065)$ & (0.039) & $(0.072)$ & $(0.028)$ & $(0.019)$ & $(0.016)$ & $(0.037)$ & (0.033) & (0.053) \\
\hline \multirow[t]{2}{*}{ facial tissue } & 0.219 & -0.265 & 0.279 & 0.043 & 0.027 & 0.016 & 0.040 & 0.116 & -0.093 \\
\hline & $(0.071)$ & $(0.058)$ & $(0.083)$ & $(0.024)$ & $(0.018)$ & $(0.010)$ & $(0.049)$ & $(0.053)$ & $(0.060)$ \\
\hline \multirow{2}{*}{ frozen dinner } & 0.283 & -0.308 & 0.373 & 0.040 & 0.027 & 0.013 & 0.051 & 0.138 & -0.120 \\
\hline & $(0.081)$ & $(0.065)$ & (0.098) & $(0.018)$ & $(0.012)$ & (0.008) & $(0.036)$ & (0.053) & $(0.060)$ \\
\hline \multirow[t]{2}{*}{ frozen pizza } & 0.306 & -0.282 & 0.395 & 0.044 & 0.029 & 0.015 & 0.052 & 0.140 & -0.119 \\
\hline & (0.084) & $(0.050)$ & (0.094) & $(0.021)$ & $(0.014)$ & (0.009) & $(0.033)$ & (0.047) & (0.051) \\
\hline \multirow[t]{2}{*}{ household cleaning } & 0.173 & -0.243 & 0.198 & 0.035 & 0.022 & 0.012 & 0.035 & 0.121 & -0.129 \\
\hline & $(0.062)$ & $(0.054)$ & $(0.071)$ & $(0.017)$ & $(0.013)$ & $(0.009)$ & $(0.052)$ & $(0.050)$ & $(0.084)$ \\
\hline \multirow[t]{2}{*}{ hot dog } & 0.229 & -0.336 & 0.314 & 0.034 & 0.025 & 0.010 & 0.065 & 0.134 & -0.105 \\
\hline & $(0.074)$ & $(0.060)$ & $(0.090)$ & $(0.018)$ & $(0.014)$ & $(0.007)$ & $(0.045)$ & $(0.051)$ & $(0.063)$ \\
\hline \multirow[t]{2}{*}{ laundry and detergents } & 0.233 & -0.272 & 0.307 & 0.044 & 0.028 & 0.016 & 0.037 & 0.118 & -0.104 \\
\hline & $(0.063)$ & $(0.046)$ & $(0.076)$ & $(0.017)$ & $(0.012)$ & $(0.008)$ & $(0.031)$ & $(0.042)$ & $(0.048)$ \\
\hline
\end{tabular}




\begin{tabular}{|c|c|c|c|c|c|c|c|c|c|}
\hline margarine and butter & $\begin{array}{c}0.177 \\
(0.063)\end{array}$ & $\begin{array}{l}-0.256 \\
(0.068)\end{array}$ & $\begin{array}{c}0.229 \\
(0.076)\end{array}$ & $\begin{array}{c}0.041 \\
(0.023)\end{array}$ & $\begin{array}{c}0.029 \\
(0.019)\end{array}$ & $\begin{array}{c}0.012 \\
(0.007)\end{array}$ & $\begin{array}{c}0.042 \\
(0.035)\end{array}$ & $\begin{array}{c}0.091 \\
(0.039)\end{array}$ & $\begin{array}{l}-0.064 \\
(0.040)\end{array}$ \\
\hline mayonnaise & $\begin{array}{c}0.143 \\
(0.055)\end{array}$ & $\begin{array}{l}-0.246 \\
(0.069)\end{array}$ & $\begin{array}{c}0.178 \\
(0.064)\end{array}$ & $\begin{array}{c}0.045 \\
(0.024)\end{array}$ & $\begin{array}{c}0.032 \\
(0.020)\end{array}$ & $\begin{array}{c}0.012 \\
(0.009)\end{array}$ & $\begin{array}{c}0.038 \\
(0.035)\end{array}$ & $\begin{array}{c}0.093 \\
(0.038)\end{array}$ & $\begin{array}{l}-0.083 \\
(0.051)\end{array}$ \\
\hline milk & $\begin{array}{c}0.133 \\
(0.057)\end{array}$ & $\begin{array}{l}-0.181 \\
(0.043)\end{array}$ & $\begin{array}{c}0.156 \\
(0.065)\end{array}$ & $\begin{array}{c}0.055 \\
(0.032)\end{array}$ & $\begin{array}{c}0.038 \\
(0.028)\end{array}$ & $\begin{array}{c}0.017 \\
(0.011)\end{array}$ & $\begin{array}{c}0.029 \\
(0.020)\end{array}$ & $\begin{array}{c}0.071 \\
(0.024)\end{array}$ & $\begin{array}{l}-0.055 \\
(0.024)\end{array}$ \\
\hline mustard and ketchup & $\begin{array}{c}0.152 \\
(0.061)\end{array}$ & $\begin{array}{l}-0.212 \\
(0.056)\end{array}$ & $\begin{array}{c}0.173 \\
(0.067)\end{array}$ & $\begin{array}{c}0.044 \\
(0.020)\end{array}$ & $\begin{array}{c}0.031 \\
(0.016)\end{array}$ & $\begin{array}{c}0.013 \\
(0.009)\end{array}$ & $\begin{array}{c}0.042 \\
(0.046)\end{array}$ & $\begin{array}{c}0.114 \\
(0.037)\end{array}$ & $\begin{array}{l}-0.113 \\
(0.066)\end{array}$ \\
\hline paper towel & $\begin{array}{c}0.204 \\
(0.055)\end{array}$ & $\begin{array}{l}-0.253 \\
(0.050)\end{array}$ & $\begin{array}{c}0.273 \\
(0.065)\end{array}$ & $\begin{array}{c}0.043 \\
(0.022)\end{array}$ & $\begin{array}{c}0.028 \\
(0.017)\end{array}$ & $\begin{array}{c}0.015 \\
(0.009)\end{array}$ & $\begin{array}{c}0.039 \\
(0.035)\end{array}$ & $\begin{array}{c}0.103 \\
(0.040)\end{array}$ & $\begin{array}{l}-0.082 \\
(0.050)\end{array}$ \\
\hline peanut butter & $\begin{array}{c}0.156 \\
(0.060)\end{array}$ & $\begin{array}{l}-0.204 \\
(0.065)\end{array}$ & $\begin{array}{c}0.200 \\
(0.071)\end{array}$ & $\begin{array}{c}0.046 \\
(0.024)\end{array}$ & $\begin{array}{c}0.030 \\
(0.019)\end{array}$ & $\begin{array}{c}0.016 \\
(0.011)\end{array}$ & $\begin{array}{c}0.026 \\
(0.033)\end{array}$ & $\begin{array}{c}0.079 \\
(0.034)\end{array}$ & $\begin{array}{l}-0.065 \\
(0.040)\end{array}$ \\
\hline photo & $\begin{array}{c}0.200 \\
(0.055)\end{array}$ & $\begin{array}{l}-0.285 \\
(0.069)\end{array}$ & $\begin{array}{c}0.221 \\
(0.059)\end{array}$ & $\begin{array}{c}0.046 \\
(0.026)\end{array}$ & $\begin{array}{c}0.025 \\
(0.017)\end{array}$ & $\begin{array}{c}0.021 \\
(0.017)\end{array}$ & $\begin{array}{c}0.004 \\
(0.095)\end{array}$ & $\begin{array}{c}0.171 \\
(0.078)\end{array}$ & $\begin{array}{l}-0.227 \\
(0.131)\end{array}$ \\
\hline razors & $\begin{array}{c}0.226 \\
(0.071)\end{array}$ & $\begin{array}{l}-0.222 \\
(0.069)\end{array}$ & $\begin{array}{c}0.238 \\
(0.074)\end{array}$ & $\begin{array}{c}0.061 \\
(0.034)\end{array}$ & $\begin{array}{c}0.039 \\
(0.026)\end{array}$ & $\begin{array}{c}0.023 \\
(0.020)\end{array}$ & $\begin{array}{c}0.010 \\
(0.076)\end{array}$ & $\begin{array}{c}0.119 \\
(0.059)\end{array}$ & $\begin{array}{l}-0.186 \\
(0.136)\end{array}$ \\
\hline salt snacks & $\begin{array}{c}0.210 \\
(0.052)\end{array}$ & $\begin{array}{l}-0.258 \\
(0.037)\end{array}$ & $\begin{array}{c}0.251 \\
(0.062)\end{array}$ & $\begin{array}{c}0.031 \\
(0.013)\end{array}$ & $\begin{array}{c}0.021 \\
(0.008)\end{array}$ & $\begin{array}{c}0.010 \\
(0.005)\end{array}$ & $\begin{array}{c}0.055 \\
(0.027)\end{array}$ & $\begin{array}{c}0.134 \\
(0.033)\end{array}$ & $\begin{array}{l}-0.110 \\
(0.037)\end{array}$ \\
\hline shampoo & $\begin{array}{c}0.198 \\
(0.044)\end{array}$ & $\begin{array}{l}-0.283 \\
(0.044)\end{array}$ & $\begin{array}{c}0.220 \\
(0.047)\end{array}$ & $\begin{array}{c}0.053 \\
(0.021)\end{array}$ & $\begin{array}{c}0.032 \\
(0.013)\end{array}$ & $\begin{array}{c}0.021 \\
(0.011)\end{array}$ & $\begin{array}{c}0.019 \\
(0.047)\end{array}$ & $\begin{array}{c}0.161 \\
(0.038)\end{array}$ & $\begin{array}{l}-0.213 \\
(0.075)\end{array}$ \\
\hline soup & $\begin{array}{c}0.173 \\
(0.079)\end{array}$ & $\begin{array}{l}-0.296 \\
(0.074)\end{array}$ & $\begin{array}{c}0.225 \\
(0.104)\end{array}$ & $\begin{array}{c}0.044 \\
(0.019)\end{array}$ & $\begin{array}{c}0.031 \\
(0.015)\end{array}$ & $\begin{array}{c}0.012 \\
(0.007)\end{array}$ & $\begin{array}{c}0.047 \\
(0.037)\end{array}$ & $\begin{array}{c}0.122 \\
(0.040)\end{array}$ & $\begin{array}{l}-0.117 \\
(0.060)\end{array}$ \\
\hline spaghetti sauce & $\begin{array}{c}0.211 \\
(0.072)\end{array}$ & $\begin{array}{l}-0.262 \\
(0.064)\end{array}$ & $\begin{array}{c}0.267 \\
(0.085)\end{array}$ & $\begin{array}{c}0.049 \\
(0.023)\end{array}$ & $\begin{array}{c}0.033 \\
(0.016)\end{array}$ & $\begin{array}{c}0.016 \\
(0.010)\end{array}$ & $\begin{array}{c}0.042 \\
(0.039)\end{array}$ & $\begin{array}{c}0.119 \\
(0.042)\end{array}$ & $\begin{array}{l}-0.109 \\
(0.058)\end{array}$ \\
\hline sugar and substitutes & $\begin{array}{c}0.100 \\
(0.052)\end{array}$ & $\begin{array}{l}-0.193 \\
(0.076)\end{array}$ & $\begin{array}{c}0.114 \\
(0.061)\end{array}$ & $\begin{array}{c}0.035 \\
(0.022)\end{array}$ & $\begin{array}{c}0.025 \\
(0.018)\end{array}$ & $\begin{array}{c}0.010 \\
(0.010)\end{array}$ & $\begin{array}{c}0.032 \\
(0.061)\end{array}$ & $\begin{array}{c}0.095 \\
(0.055)\end{array}$ & $\begin{array}{l}-0.099 \\
(0.096)\end{array}$ \\
\hline toilet tissue & $\begin{array}{c}0.208 \\
(0.060)\end{array}$ & $\begin{array}{l}-0.255 \\
(0.048)\end{array}$ & $\begin{array}{c}0.306 \\
(0.074)\end{array}$ & $\begin{array}{c}0.051 \\
(0.024)\end{array}$ & $\begin{array}{c}0.032 \\
(0.019)\end{array}$ & $\begin{array}{c}0.019 \\
(0.009)\end{array}$ & $\begin{array}{c}0.030 \\
(0.029)\end{array}$ & $\begin{array}{c}0.096 \\
(0.036)\end{array}$ & $\begin{array}{l}-0.078 \\
(0.035)\end{array}$ \\
\hline tooth brush & $\begin{array}{c}0.204 \\
(0.058)\end{array}$ & $\begin{array}{l}-0.337 \\
(0.061)\end{array}$ & $\begin{array}{c}0.232 \\
(0.067)\end{array}$ & $\begin{array}{c}0.044 \\
(0.017)\end{array}$ & $\begin{array}{c}0.025 \\
(0.012)\end{array}$ & $\begin{array}{c}0.019 \\
(0.010)\end{array}$ & $\begin{array}{c}0.030 \\
(0.064)\end{array}$ & $\begin{array}{c}0.206 \\
(0.060)\end{array}$ & $\begin{array}{l}-0.256 \\
(0.089)\end{array}$ \\
\hline tooth paste & $\begin{array}{c}0.197 \\
(0.052)\end{array}$ & $\begin{array}{l}-0.287 \\
(0.046)\end{array}$ & $\begin{array}{c}0.233 \\
(0.062)\end{array}$ & $\begin{array}{c}0.039 \\
(0.016)\end{array}$ & $\begin{array}{c}0.024 \\
(0.011)\end{array}$ & $\begin{array}{c}0.015 \\
(0.008)\end{array}$ & $\begin{array}{c}0.037 \\
(0.041)\end{array}$ & $\begin{array}{c}0.153 \\
(0.043)\end{array}$ & $\begin{array}{l}-0.178 \\
(0.073)\end{array}$ \\
\hline yogurt & $\begin{array}{c}0.224 \\
(0.072)\end{array}$ & $\begin{array}{l}-0.254 \\
(0.063)\end{array}$ & $\begin{array}{c}0.291 \\
(0.088)\end{array}$ & $\begin{array}{c}0.036 \\
(0.020)\end{array}$ & $\begin{array}{c}0.024 \\
(0.015)\end{array}$ & $\begin{array}{c}0.012 \\
(0.008)\end{array}$ & $\begin{array}{c}0.037 \\
(0.036)\end{array}$ & $\begin{array}{c}0.098 \\
(0.041)\end{array}$ & $\begin{array}{l}-0.075 \\
(0.043)\end{array}$ \\
\hline
\end{tabular}

Notes: UPCs have equal weights when aggregated to the category level. 
Appendix Table 2. Moments for all (sales and regular) price changes.

\begin{tabular}{|c|c|c|c|c|c|c|}
\hline \multirow{4}{*}{ Category } & \multicolumn{6}{|c|}{ Changes of all prices } \\
\hline & \multicolumn{3}{|c|}{ Frequency } & \multicolumn{3}{|c|}{ Size } \\
\hline & All & Positive & Negative & All & Positive & Negative \\
\hline & $(1)$ & $(2)$ & (3) & (4) & (5) & (6) \\
\hline Total & $\begin{array}{c}0.224 \\
(0.085)\end{array}$ & $\begin{array}{c}0.116 \\
(0.046)\end{array}$ & $\begin{array}{c}0.108 \\
(0.046)\end{array}$ & $\begin{array}{c}0.002 \\
(0.039)\end{array}$ & $\begin{array}{c}0.208 \\
(0.069)\end{array}$ & $\begin{array}{l}-0.223 \\
(0.074)\end{array}$ \\
\hline beer & $\begin{array}{c}0.163 \\
(0.083)\end{array}$ & $\begin{array}{c}0.088 \\
(0.045)\end{array}$ & $\begin{array}{c}0.075 \\
(0.041)\end{array}$ & $\begin{array}{c}0.008 \\
(0.027)\end{array}$ & $\begin{array}{c}0.100 \\
(0.029)\end{array}$ & $\begin{array}{l}-0.104 \\
(0.031)\end{array}$ \\
\hline blades & $\begin{array}{c}0.179 \\
(0.047)\end{array}$ & $\begin{array}{c}0.097 \\
(0.027)\end{array}$ & $\begin{array}{c}0.082 \\
(0.027)\end{array}$ & $\begin{array}{c}0.005 \\
(0.042)\end{array}$ & $\begin{array}{c}0.215 \\
(0.043)\end{array}$ & $\begin{array}{l}-0.251 \\
(0.057)\end{array}$ \\
\hline carbonated beverages & $\begin{array}{c}0.302 \\
(0.072)\end{array}$ & $\begin{array}{c}0.155 \\
(0.039)\end{array}$ & $\begin{array}{c}0.147 \\
(0.036)\end{array}$ & $\begin{array}{c}0.005 \\
(0.019)\end{array}$ & $\begin{array}{c}0.198 \\
(0.035)\end{array}$ & $\begin{array}{l}-0.201 \\
(0.037)\end{array}$ \\
\hline cigarettes & $\begin{array}{c}0.182 \\
(0.083)\end{array}$ & $\begin{array}{c}0.122 \\
(0.073)\end{array}$ & $\begin{array}{c}0.060 \\
(0.032)\end{array}$ & $\begin{array}{c}0.016 \\
(0.036)\end{array}$ & $\begin{array}{c}0.086 \\
(0.032)\end{array}$ & $\begin{array}{l}-0.105 \\
(0.042)\end{array}$ \\
\hline coffee & $\begin{array}{c}0.220 \\
(0.072)\end{array}$ & $\begin{array}{c}0.114 \\
(0.042)\end{array}$ & $\begin{array}{c}0.106 \\
(0.037)\end{array}$ & $\begin{array}{c}0.006 \\
(0.035)\end{array}$ & $\begin{array}{c}0.201 \\
(0.042)\end{array}$ & $\begin{array}{l}-0.209 \\
(0.045)\end{array}$ \\
\hline cold cereals & $\begin{array}{c}0.222 \\
(0.073)\end{array}$ & $\begin{array}{c}0.115 \\
(0.039)\end{array}$ & $\begin{array}{c}0.107 \\
(0.037)\end{array}$ & $\begin{array}{c}0.003 \\
(0.029)\end{array}$ & $\begin{array}{c}0.246 \\
(0.055)\end{array}$ & $\begin{array}{l}-0.263 \\
(0.059)\end{array}$ \\
\hline deodorants & $\begin{array}{c}0.235 \\
(0.065)\end{array}$ & $\begin{array}{c}0.119 \\
(0.034)\end{array}$ & $\begin{array}{c}0.117 \\
(0.036)\end{array}$ & $\begin{array}{c}0.002 \\
(0.041)\end{array}$ & $\begin{array}{c}0.283 \\
(0.048)\end{array}$ & $\begin{array}{l}-0.300 \\
(0.054)\end{array}$ \\
\hline diapers & $\begin{array}{c}0.292 \\
(0.077)\end{array}$ & $\begin{array}{c}0.141 \\
(0.043)\end{array}$ & $\begin{array}{c}0.151 \\
(0.044)\end{array}$ & $\begin{array}{l}-0.010 \\
(0.030)\end{array}$ & $\begin{array}{c}0.161 \\
(0.034)\end{array}$ & $\begin{array}{l}-0.172 \\
(0.039)\end{array}$ \\
\hline facial tissue & $\begin{array}{c}0.241 \\
(0.076)\end{array}$ & $\begin{array}{c}0.121 \\
(0.042)\end{array}$ & $\begin{array}{c}0.120 \\
(0.041)\end{array}$ & $\begin{array}{l}-0.004 \\
(0.041)\end{array}$ & $\begin{array}{c}0.221 \\
(0.052)\end{array}$ & $\begin{array}{l}-0.229 \\
(0.052)\end{array}$ \\
\hline frozen dinner & $\begin{array}{c}0.306 \\
(0.079)\end{array}$ & $\begin{array}{c}0.155 \\
(0.042)\end{array}$ & $\begin{array}{c}0.151 \\
(0.043)\end{array}$ & $\begin{array}{c}0.003 \\
(0.035)\end{array}$ & $\begin{array}{c}0.259 \\
(0.060)\end{array}$ & $\begin{array}{l}-0.266 \\
(0.063)\end{array}$ \\
\hline frozen pizza & $\begin{array}{c}0.336 \\
(0.087)\end{array}$ & $\begin{array}{c}0.171 \\
(0.046)\end{array}$ & $\begin{array}{c}0.166 \\
(0.045)\end{array}$ & $\begin{array}{c}0.003 \\
(0.026)\end{array}$ & $\begin{array}{c}0.238 \\
(0.047)\end{array}$ & $\begin{array}{l}-0.243 \\
(0.050)\end{array}$ \\
\hline household cleaning & $\begin{array}{c}0.173 \\
(0.060)\end{array}$ & $\begin{array}{c}0.087 \\
(0.032)\end{array}$ & $\begin{array}{c}0.086 \\
(0.035)\end{array}$ & $\begin{array}{l}-0.004 \\
(0.048)\end{array}$ & $\begin{array}{c}0.207 \\
(0.042)\end{array}$ & $\begin{array}{l}-0.225 \\
(0.052)\end{array}$ \\
\hline hot dog & $\begin{array}{c}0.277 \\
(0.079)\end{array}$ & $\begin{array}{c}0.143 \\
(0.043)\end{array}$ & $\begin{array}{c}0.133 \\
(0.042)\end{array}$ & $\begin{array}{c}0.009 \\
(0.045)\end{array}$ & $\begin{array}{c}0.281 \\
(0.058)\end{array}$ & $\begin{array}{l}-0.292 \\
(0.062)\end{array}$ \\
\hline laundry and detergents & $\begin{array}{c}0.263 \\
(0.072)\end{array}$ & $\begin{array}{c}0.133 \\
(0.039)\end{array}$ & $\begin{array}{c}0.130 \\
(0.037)\end{array}$ & $\begin{array}{c}0.003 \\
(0.027)\end{array}$ & $\begin{array}{c}0.229 \\
(0.041)\end{array}$ & $\begin{array}{l}-0.236 \\
(0.043)\end{array}$ \\
\hline margarine and butter & $\begin{array}{c}0.206 \\
(0.065)\end{array}$ & $\begin{array}{c}0.108 \\
(0.038)\end{array}$ & $\begin{array}{c}0.099 \\
(0.035)\end{array}$ & $\begin{array}{c}0.005 \\
(0.038)\end{array}$ & $\begin{array}{c}0.205 \\
(0.061)\end{array}$ & $\begin{array}{l}-0.217 \\
(0.064)\end{array}$ \\
\hline mayonnaise & $\begin{array}{c}0.170 \\
(0.062)\end{array}$ & $\begin{array}{c}0.092 \\
(0.036)\end{array}$ & $\begin{array}{c}0.078 \\
(0.033)\end{array}$ & $\begin{array}{c}0.007 \\
(0.044)\end{array}$ & $\begin{array}{c}0.185 \\
(0.053)\end{array}$ & $\begin{array}{l}-0.207 \\
(0.062)\end{array}$ \\
\hline milk & $\begin{array}{c}0.180 \\
(0.070)\end{array}$ & $\begin{array}{c}0.097 \\
(0.042)\end{array}$ & $\begin{array}{c}0.083 \\
(0.036)\end{array}$ & $\begin{array}{c}0.006 \\
(0.023)\end{array}$ & $\begin{array}{c}0.139 \\
(0.037)\end{array}$ & $\begin{array}{l}-0.149 \\
(0.041)\end{array}$ \\
\hline mustard and ketchup & $\begin{array}{c}0.147 \\
(0.055)\end{array}$ & $\begin{array}{c}0.080 \\
(0.032)\end{array}$ & $\begin{array}{c}0.067 \\
(0.031)\end{array}$ & $\begin{array}{c}0.008 \\
(0.044)\end{array}$ & $\begin{array}{c}0.167 \\
(0.041)\end{array}$ & $\begin{array}{l}-0.187 \\
(0.053)\end{array}$ \\
\hline paper towel & $\begin{array}{c}0.231 \\
(0.064)\end{array}$ & $\begin{array}{c}0.118 \\
(0.037)\end{array}$ & $\begin{array}{c}0.113 \\
(0.033)\end{array}$ & $\begin{array}{c}0.002 \\
(0.028)\end{array}$ & $\begin{array}{c}0.205 \\
(0.046)\end{array}$ & $\begin{array}{l}-0.213 \\
(0.047)\end{array}$ \\
\hline peanut butter & $\begin{array}{c}0.180 \\
(0.063)\end{array}$ & $\begin{array}{c}0.094 \\
(0.036)\end{array}$ & $\begin{array}{c}0.086 \\
(0.034)\end{array}$ & $\begin{array}{c}0.004 \\
(0.038)\end{array}$ & $\begin{array}{c}0.157 \\
(0.051)\end{array}$ & $\begin{array}{l}-0.167 \\
(0.057)\end{array}$ \\
\hline photo & $\begin{array}{c}0.219 \\
(0.057)\end{array}$ & $\begin{array}{c}0.107 \\
(0.032)\end{array}$ & $\begin{array}{c}0.112 \\
(0.037)\end{array}$ & $\begin{array}{l}-0.015 \\
(0.061)\end{array}$ & $\begin{array}{c}0.253 \\
(0.055)\end{array}$ & $\begin{array}{l}-0.276 \\
(0.070)\end{array}$ \\
\hline
\end{tabular}




\begin{tabular}{lcccccl} 
razors & 0.238 & 0.124 & 0.114 & -0.009 & 0.180 & -0.222 \\
& $(0.077)$ & $(0.046)$ & $(0.049)$ & $(0.060)$ & $(0.052)$ & $(0.072)$ \\
salt snacks & 0.210 & 0.107 & 0.103 & 0.002 & 0.216 & -0.224 \\
& $(0.061)$ & $(0.032)$ & $(0.031)$ & $(0.021)$ & $(0.036)$ & $(0.038)$ \\
shampoo & 0.232 & 0.117 & 0.115 & -0.006 & 0.249 & -0.273 \\
& $(0.058)$ & $(0.030)$ & $(0.033)$ & $(0.034)$ & $(0.036)$ & $(0.044)$ \\
soup & 0.197 & 0.105 & 0.092 & 0.009 & 0.235 & -0.254 \\
& $(0.081)$ & $(0.043)$ & $(0.044)$ & $(0.052)$ & $(0.063)$ & $(0.068)$ \\
spaghetti sauce & 0.232 & 0.121 & 0.111 & 0.007 & 0.217 & -0.227 \\
& $(0.070)$ & $(0.038)$ & $(0.038)$ & $(0.037)$ & $(0.055)$ & $(0.060)$ \\
sugar and substitutes & 0.115 & 0.061 & 0.053 & 0.004 & 0.151 & -0.174 \\
& $(0.056)$ & $(0.032)$ & $(0.031)$ & $(0.055)$ & $(0.056)$ & $(0.071)$ \\
toilet tissue & 0.256 & 0.131 & 0.125 & 0.000 & 0.205 & -0.215 \\
& $(0.071)$ & $(0.040)$ & $(0.036)$ & $(0.026)$ & $(0.044)$ & $(0.045)$ \\
tooth brush & 0.231 & 0.114 & 0.117 & -0.003 & 0.307 & -0.326 \\
& $(0.068)$ & $(0.036)$ & $(0.038)$ & $(0.048)$ & $(0.054)$ & $(0.059)$ \\
tooth paste & 0.220 & 0.111 & 0.109 & 0.000 & 0.255 & -0.269 \\
& $(0.064)$ & $(0.034)$ & $(0.035)$ & $(0.033)$ & $(0.040)$ & $(0.045)$ \\
\hline yogurt & 0.273 & 0.138 & 0.135 & 0.002 & 0.207 & -0.212 \\
& $(0.079)$ & $(0.043)$ & $(0.041)$ & $(0.031)$ & $(0.062)$ & $(0.064)$ \\
\hline \hline
\end{tabular}

Notes: UPCs have equal weights when aggregated to the category level. 
Appendix Table 3. Alternative standard errors.

\begin{tabular}{|c|c|c|c|c|}
\hline \multirow{3}{*}{ Dependent variable } & \multirow{2}{*}{$\begin{array}{l}\text { Equal weights to } \\
\text { all UPCs } \\
\text { Point estimate }\end{array}$} & \multicolumn{3}{|c|}{ Standard errors } \\
\hline & & $\begin{array}{l}\text { Driscoll- } \\
\text { Kraay }\end{array}$ & $\begin{array}{l}\text { Cluster by } \\
\text { category/city }\end{array}$ & $\begin{array}{l}\text { Cluster by } \\
\text { month }\end{array}$ \\
\hline & $(1)$ & $(2)$ & $(3)$ & $(4)$ \\
\hline \multicolumn{5}{|l|}{ Sales } \\
\hline Frequency & -0.365 & $(0.120)^{* * *}$ & $(0.085) * * *$ & $(0.076) * * *$ \\
\hline Size & 0.256 & $(0.120)^{* *}$ & $(0.084)^{* * *}$ & $(0.070)^{* * *}$ \\
\hline Share of goods bought on sales & -0.461 & $(0.133)^{* * *}$ & $(0.098)^{* * *}$ & $(0.082)^{* * *}$ \\
\hline \multicolumn{5}{|l|}{ Changes of regular prices } \\
\hline \multicolumn{5}{|l|}{ Frequency } \\
\hline All & -0.100 & $(0.044)^{* *}$ & $(0.027)^{* * *}$ & $(0.033)^{* * *}$ \\
\hline Positive & -0.053 & $(0.032)^{*}$ & $(0.020)^{* * *}$ & $(0.026)^{* *}$ \\
\hline Negative & -0.047 & $(0.019)^{* * *}$ & $(0.014)^{* * *}$ & $(0.013)^{* * *}$ \\
\hline \multicolumn{5}{|l|}{ Size } \\
\hline All & -0.095 & $(0.062)$ & $(0.042)^{* *}$ & $(0.053) *$ \\
\hline Positive & -0.155 & $(0.092) *$ & $(0.064)^{* * *}$ & $(0.056)^{* * *}$ \\
\hline Negative & -0.004 & $(0.129)$ & $(0.093)$ & $(0.082)$ \\
\hline Inflation of posted prices & 0.007 & $(0.034)$ & $(0.024)$ & $(0.020)$ \\
\hline Inflation of effective prices & -0.206 & $(0.045)^{* * *}$ & $(0.045)^{* * *}$ & $(0.027)^{* * *}$ \\
\hline
\end{tabular}

Notes: The table shows the baseline point estimate (column 1) and standard error (column 2) which correspond to results presented in column 3 of Table 1 . Columns 3 and 4 show alternative estimates of standard errors associated with column (1). Column (3) clusters standard errors by city and category (1550 clusters) which allows for arbitrary collation of errors across time. Column (4) clusters standard errors by month (84 clusters) which allow for arbitrary cross-sectional correlation. $* * *, * * *$ indicates statistical significance at 1,5 and 10 percent. 
Appendix Table 4. Cyclical Behavior of Price Changes at the Category Level.

\begin{tabular}{|c|c|c|c|c|c|c|c|c|c|c|c|}
\hline \multirow{4}{*}{ Category } & \multicolumn{2}{|c|}{ Sales } & \multirow{4}{*}{$\begin{array}{l}\text { Share of } \\
\text { goods } \\
\text { bought on } \\
\text { sales, } \\
\omega_{m c t} \\
(3)\end{array}$} & \multicolumn{6}{|c|}{ "Changes of regular prices } & \multicolumn{2}{|c|}{ Inflation } \\
\hline & \multirow[b]{2}{*}{ Frequency } & \multirow[b]{2}{*}{ Size } & & \multicolumn{3}{|c|}{ Frequency } & \multicolumn{3}{|c|}{ Size } & \multirow[b]{2}{*}{$\begin{array}{l}\text { posted } \\
\text { prices }\end{array}$} & \multirow[b]{2}{*}{$\begin{array}{c}\text { effective } \\
\text { prices }\end{array}$} \\
\hline & & & & All & Positive & Negative & All & Positive & Negative & & \\
\hline & $(1)$ & $(2)$ & & (4) & (5) & (6) & $(7)$ & $(8)$ & (9) & $(10)$ & $(11)$ \\
\hline \multirow[t]{2}{*}{ beer } & $-0.440 * * *$ & -0.100 & 0.008 & $-0.460 * * *$ & $-0.307 * * *$ & $-0.153 *$ & -0.037 & 0.073 & -0.036 & -0.024 & -0.059 \\
\hline & $(0.184)$ & $(0.159)$ & $(0.218)$ & $(0.176)$ & $(0.102)$ & $(0.084)$ & $(0.077)$ & $(0.086)$ & $(0.046)$ & $(0.070)$ & $(0.101)$ \\
\hline blades & $-0.493 * * *$ & $0.284^{*}$ & $-0.614 * * *$ & -0.105 & -0.004 & $-0.101^{* *}$ & 0.007 & -0.121 & -0.403 & 0.036 & 0.126 \\
\hline \multirow[t]{2}{*}{ carbonated beverages } & -0.048 & 0.001 & 0.219 & $-0.368 * * *$ & $-0.246 * * *$ & -0.122 & -0.054 & 0.004 & 0.053 & 0.137 & $-0.530 * * *$ \\
\hline & $(0.248)$ & $(0.231)$ & $(0.271)$ & $(0.140)$ & $(0.071)$ & $(0.075)$ & $(0.092)$ & $(0.095)$ & $(0.095)$ & $(0.118)$ & $(0.155)$ \\
\hline \multirow{2}{*}{ cigarettes } & 0.119 & $0.339 *$ & -0.008 & 0.273 & 0.195 & 0.078 & 0.096 & -0.092 & 0.103 & -0.001 & 0.226 \\
\hline & $(0.346)$ & (0.193) & $(0.396)$ & $(0.224)$ & $(0.199)$ & $(0.086)$ & $(0.116)$ & $(0.158)$ & $(0.103)$ & $(0.133)$ & $(0.198)$ \\
\hline \multirow[t]{2}{*}{ coffee } & $-1.262 * * *$ & 0.080 & $-1.466 * * *$ & 0.130 & 0.091 & 0.039 & -0.007 & -0.213 & 0.281 & 0.209 & $-0.658 * * *$ \\
\hline & $(0.397)$ & $(0.210)$ & $(0.403)$ & $(0.110)$ & $(0.087)$ & $(0.042)$ & $(0.117)$ & $(0.179)$ & $(0.186)$ & $(0.162)$ & $(0.263)$ \\
\hline \multirow[t]{2}{*}{ cold cereals } & 0.120 & -0.240 & -0.274 & $-0.219 * *$ & $-0.173^{* * *}$ & -0.046 & 0.199 & $0.456 *$ & $-0.369 *$ & $-0.289 * * *$ & $-0.688 * * *$ \\
\hline & $(0.262)$ & $(0.326)$ & $(0.315)$ & $(0.097)$ & $(0.056)$ & $(0.050)$ & $(0.174)$ & $(0.239)$ & (0.198) & $(0.086)$ & $(0.089)$ \\
\hline deodorants & $(0.244)$ & $(0.245)$ & $(0.268)$ & $(0.086)$ & $(0.068)$ & $(0.029)$ & $(0.139)$ & $(0.171)$ & $(0.319)$ & $(0.048)$ & $(0.115)$ \\
\hline \multirow[t]{2}{*}{ diapers } & $0.601 * *$ & $-0.550 * * *$ & $0.792 * * *$ & $-0.419 * * *$ & $-0.226 * * *$ & $-0.193 * * *$ & $0.269 * *$ & $0.569 * * *$ & $-0.384 * *$ & -0.085 & $-0.414 * * *$ \\
\hline & $(0.267)$ & $(0.212)$ & $(0.336)$ & $(0.118)$ & $(0.074)$ & $(0.070)$ & $(0.131)$ & $(0.151)$ & $(0.199)$ & $(0.094)$ & (0.109) \\
\hline \multirow[t]{2}{*}{ facial tissue } & $-1.014^{* * *}$ & -0.318 & $-1.024 * * *$ & -0.154 & -0.114 & -0.041 & -0.086 & -0.091 & 0.148 & $-0.655^{* * *}$ & $-0.539 * *$ \\
\hline & $(0.302)$ & $(0.302)$ & $(0.376)$ & $(0.176)$ & $(0.122)$ & $(0.067)$ & $(0.263)$ & $(0.237)$ & (0.169) & $(0.173)$ & $(0.250)$ \\
\hline \multirow[t]{2}{*}{ frozen dinner } & -0.577 & -0.338 & -0.660 & $-0.160 *$ & -0.035 & $-0.126 * * *$ & $0.296^{*}$ & 0.195 & -0.113 & -0.031 & $-0.316 * * *$ \\
\hline & $(0.370)$ & $(0.253)$ & $(0.424)$ & $(0.090)$ & $(0.050)$ & $(0.047)$ & $(0.166)$ & $(0.185)$ & $(0.184)$ & $(0.097)$ & $(0.091)$ \\
\hline \multirow[t]{2}{*}{ frozen pizza } & 0.237 & -0.468 & 0.643 & $-0.606^{* * *}$ & $-0.328 * * *$ & $-0.278 * * *$ & $0.331 * * *$ & $0.579 * * *$ & -0.210 & 0.031 & 0.085 \\
\hline & $(0.487)$ & $(0.338)$ & $(0.566)$ & $(0.141)$ & $(0.085)$ & $(0.063)$ & $(0.128)$ & $(0.178)$ & $(0.176)$ & $(0.154)$ & $(0.101)$ \\
\hline \multirow[t]{2}{*}{ household cleaning } & $-0.799 * * *$ & $0.789 * * *$ & $-1.149 * * *$ & 0.097 & 0.041 & $0.055^{* *}$ & -0.040 & -0.127 & $0.832 * * *$ & -0.020 & $0.313^{*}$ \\
\hline & $(0.234)$ & $(0.247)$ & $(0.252)$ & $(0.085)$ & $(0.066)$ & $(0.028)$ & $(0.098)$ & $(0.152)$ & $(0.244)$ & $(0.076)$ & $(0.171)$ \\
\hline \multirow[t]{2}{*}{ hot dog } & -0.496 & $1.617^{* * *}$ & $-1.381 * * *$ & $0.208^{*}$ & $0.153 *$ & 0.054 & -0.122 & $-0.639 * *$ & 0.168 & $0.270^{* *}$ & $-0.395 *$ \\
\hline & $(0.406)$ & $(0.274)$ & $(0.419)$ & $(0.111)$ & $(0.083)$ & $(0.050)$ & $(0.263)$ & $(0.331)$ & $(0.298)$ & $(0.132)$ & $(0.209)$ \\
\hline \multirow[t]{2}{*}{ laundry \& detergents } & $-0.681 * * *$ & -0.200 & $-0.749 * * *$ & $-0.187^{*}$ & -0.089 & $-0.097 * * *$ & 0.064 & 0.064 & 0.193 & $0.159 * *$ & $-0.563 * * *$ \\
\hline & $(0.212)$ & $(0.216)$ & $(0.275)$ & $(0.100)$ & $(0.071)$ & $(0.040)$ & $(0.121)$ & $(0.160)$ & $(0.188)$ & $(0.071)$ & $(0.152)$ \\
\hline margarine and butter & $-0.944 * * *$ & $1.046^{* * *}$ & $-1.248 * * *$ & $-0.248 * *$ & $-0.210 * * *$ & -0.037 & $-0.257 *$ & -0.192 & -0.056 & $-0.286 * * *$ & $-0.939 * * *$ \\
\hline & $(0.274)$ & $(0.353)$ & $(0.351)$ & $(0.106)$ & $(0.081)$ & $(0.048)$ & $(0.140)$ & $(0.155)$ & $(0.137)$ & $(0.102)$ & $(0.172)$ \\
\hline mayonnaise & $-1.111 * * *$ & 0.115 & $-1.976 * * *$ & -0.054 & -0.154 & $0.100 * *$ & $-0.260 *$ & $-0.266^{*}$ & 0.198 & $-0.189 *$ & -0.077 \\
\hline
\end{tabular}




\begin{tabular}{|c|c|c|c|c|c|c|c|c|c|c|c|}
\hline milk & $\begin{array}{c}0.665 \\
(0.658)\end{array}$ & $\begin{array}{c}0.200 \\
(0.282)\end{array}$ & $\begin{array}{c}0.188 \\
(0.732)\end{array}$ & $\begin{array}{c}0.080 \\
(0.278)\end{array}$ & $\begin{array}{c}0.126 \\
(0.175)\end{array}$ & $\begin{array}{l}-0.046 \\
(0.156)\end{array}$ & $\begin{array}{l}-0.164 * * \\
(0.078)\end{array}$ & $\begin{array}{l}-0.245^{* *} \\
(0.119)\end{array}$ & $\begin{array}{l}-0.004 \\
(0.095)\end{array}$ & $\begin{array}{c}0.288^{*} \\
(0.170)\end{array}$ & $\begin{array}{c}0.142 \\
(0.228)\end{array}$ \\
\hline mustard and ketchup & $\begin{array}{l}-0.692^{* * *} \\
(0.218)\end{array}$ & $\begin{array}{c}0.116 \\
(0.365)\end{array}$ & $\begin{array}{l}-1.260 * * * \\
(0.297)\end{array}$ & $\begin{array}{l}-0.200^{* *} \\
(0.095)\end{array}$ & $\begin{array}{l}-0.125^{*} \\
(0.067)\end{array}$ & $\begin{array}{l}-0.075^{*} \\
(0.040)\end{array}$ & $\begin{array}{c}0.046 \\
(0.152)\end{array}$ & $\begin{array}{c}0.110 \\
(0.155)\end{array}$ & $\begin{array}{l}-0.117 \\
(0.208)\end{array}$ & $\begin{array}{l}-0.152^{* *} \\
(0.065)\end{array}$ & $\begin{array}{l}-0.319 * * \\
(0.160)\end{array}$ \\
\hline paper towel & $\begin{array}{l}-0.898 * * * \\
(0.250)\end{array}$ & $\begin{array}{l}-0.511 * * * \\
(0.199)\end{array}$ & $\begin{array}{l}-0.566^{* *} \\
(0.259)\end{array}$ & $\begin{array}{l}-0.395^{* * *} \\
(0.145)\end{array}$ & $\begin{array}{l}-0.193^{*} \\
(0.104)\end{array}$ & $\begin{array}{l}-0.201^{* * *} \\
(0.052)\end{array}$ & $\begin{array}{c}0.198 \\
(0.144)\end{array}$ & $\begin{array}{c}0.205 \\
(0.202)\end{array}$ & $\begin{array}{c}0.022 \\
(0.165)\end{array}$ & $\begin{array}{c}0.198 * \\
(0.111)\end{array}$ & $\begin{array}{l}-0.107 \\
(0.137)\end{array}$ \\
\hline peanut butter & $\begin{array}{l}-0.536^{* * *} \\
(0.224)\end{array}$ & $\begin{array}{c}0.477 \\
(0.396)\end{array}$ & $\begin{array}{l}-0.902 * * * \\
(0.323)\end{array}$ & $\begin{array}{l}0.310^{* *} \\
(0.139)\end{array}$ & $\begin{array}{c}0.130 \\
(0.096)\end{array}$ & $\begin{array}{l}0.180^{* * *} \\
(0.060)\end{array}$ & $\begin{array}{l}-0.276^{* * *} \\
(0.095)\end{array}$ & $\begin{array}{l}-0.406^{* * *} \\
(0.143)\end{array}$ & $\begin{array}{c}0.186^{*} \\
(0.101)\end{array}$ & $\begin{array}{l}-0.129 \\
(0.098)\end{array}$ & $\begin{array}{l}-0.281 \\
(0.224)\end{array}$ \\
\hline photo & $\begin{array}{l}-0.545^{*} \\
(0.303)\end{array}$ & $\begin{array}{l}-0.023 \\
(0.237)\end{array}$ & $\begin{array}{l}-0.555 \\
(0.345)\end{array}$ & $\begin{array}{c}0.075 \\
(0.128)\end{array}$ & $\begin{array}{c}0.027 \\
(0.091)\end{array}$ & $\begin{array}{c}0.048 \\
(0.060)\end{array}$ & $\begin{array}{l}-0.624^{* * *} \\
(0.262)\end{array}$ & $\begin{array}{c}0.109 \\
(0.327)\end{array}$ & $\begin{array}{l}-0.832^{* * *} \\
(0.339)\end{array}$ & $\begin{array}{c}0.036 \\
(0.105)\end{array}$ & $\begin{array}{l}-0.718^{* * *} \\
(0.282)\end{array}$ \\
\hline razors & $\begin{array}{l}-0.217 \\
(0.324)\end{array}$ & $\begin{array}{l}0.593^{* * *} \\
(0.205)\end{array}$ & $\begin{array}{l}-0.325 \\
(0.374)\end{array}$ & $\begin{array}{c}0.071 \\
(0.118)\end{array}$ & $\begin{array}{c}0.044 \\
(0.086)\end{array}$ & $\begin{array}{c}0.027 \\
(0.053)\end{array}$ & $\begin{array}{l}-0.147 \\
(0.205)\end{array}$ & $\begin{array}{l}-0.190 \\
(0.254)\end{array}$ & $\begin{array}{c}0.347 \\
(0.367)\end{array}$ & $\begin{array}{l}-0.024 \\
(0.119)\end{array}$ & $\begin{array}{c}0.006 \\
(0.174)\end{array}$ \\
\hline salt snacks & $\begin{array}{l}-0.689 * * * \\
(0.232)\end{array}$ & $\begin{array}{l}-0.503 * \\
(0.292)\end{array}$ & $\begin{array}{l}-0.525^{* *} \\
(0.260)\end{array}$ & $\begin{array}{l}-0.360^{* * *} \\
(0.101)\end{array}$ & $\begin{array}{l}-0.183^{* * *} \\
(0.053)\end{array}$ & $\begin{array}{l}-0.177^{* * *} \\
(0.054)\end{array}$ & $\begin{array}{c}0.292 \\
(0.187)\end{array}$ & $\begin{array}{l}0.623^{* * *} \\
(0.179)\end{array}$ & $\begin{array}{l}-0.743^{* * *} \\
(0.154)\end{array}$ & $\begin{array}{l}-0.031 \\
(0.063)\end{array}$ & $\begin{array}{l}-0.363^{* * *} \\
(0.137)\end{array}$ \\
\hline shampoo & $\begin{array}{c}0.353^{*} \\
(0.199)\end{array}$ & $\begin{array}{c}0.113 \\
(0.190)\end{array}$ & $\begin{array}{c}0.196 \\
(0.219)\end{array}$ & $\begin{array}{c}0.057 \\
(0.077)\end{array}$ & $\begin{array}{c}0.048 \\
(0.060)\end{array}$ & $\begin{array}{c}0.009 \\
(0.033)\end{array}$ & $\begin{array}{c}0.098 \\
(0.158)\end{array}$ & $\begin{array}{l}-0.026 \\
(0.187)\end{array}$ & $\begin{array}{c}0.022 \\
(0.237)\end{array}$ & $\begin{array}{c}0.035 \\
(0.056)\end{array}$ & $\begin{array}{l}-0.262 * * \\
(0.122)\end{array}$ \\
\hline soup & $\begin{array}{l}-0.866 * * * \\
(0.236)\end{array}$ & $\begin{array}{c}0.551 * \\
(0.312)\end{array}$ & $\begin{array}{l}-1.509 * * * \\
(0.330)\end{array}$ & $\begin{array}{l}-0.046 \\
(0.103)\end{array}$ & $\begin{array}{l}-0.059 \\
(0.080)\end{array}$ & $\begin{array}{c}0.013 \\
(0.037)\end{array}$ & $\begin{array}{l}-0.186 \\
(0.138)\end{array}$ & $\begin{array}{l}-0.559 * * * \\
(0.203)\end{array}$ & $\begin{array}{l}0.554^{* * *} \\
(0.146)\end{array}$ & $\begin{array}{c}-0.162 * \\
(0.092)\end{array}$ & $\begin{array}{c}-0.214 * \\
(0.116)\end{array}$ \\
\hline spaghetti sauce & $\begin{array}{l}-0.563 \\
(0.354)\end{array}$ & $\begin{array}{c}0.673^{* *} \\
(0.306)\end{array}$ & $\begin{array}{l}-0.862 * * * \\
(0.360)\end{array}$ & $\begin{array}{l}-0.087 \\
(0.128)\end{array}$ & $\begin{array}{l}-0.059 \\
(0.086)\end{array}$ & $\begin{array}{l}-0.028 \\
(0.055)\end{array}$ & $\begin{array}{l}-0.077 \\
(0.167)\end{array}$ & $\begin{array}{l}-0.128 \\
(0.165)\end{array}$ & $\begin{array}{l}-0.018 \\
(0.151)\end{array}$ & $\begin{array}{l}-0.171 \\
(0.131)\end{array}$ & $\begin{array}{l}-0.552 * * \\
(0.277)\end{array}$ \\
\hline sugar and substitutes & $\begin{array}{l}-0.827 * * * \\
(0.333)\end{array}$ & $\begin{array}{l}0.914 * * * \\
(0.334)\end{array}$ & $\begin{array}{l}-0.611 \\
(0.388)\end{array}$ & $\begin{array}{c}0.029 \\
(0.081)\end{array}$ & $\begin{array}{l}-0.025 \\
(0.067)\end{array}$ & $\begin{array}{c}0.054 \\
(0.047)\end{array}$ & $\begin{array}{c}0.012 \\
(0.205)\end{array}$ & $\begin{array}{l}-0.481^{* *} \\
(0.212)\end{array}$ & $\begin{array}{c}0.410 \\
(0.378)\end{array}$ & $\begin{array}{l}0.158^{* *} \\
(0.082)\end{array}$ & $\begin{array}{l}0.256^{* * *} \\
(0.098)\end{array}$ \\
\hline toilet tissue & $\begin{array}{l}-0.612 * * * \\
(0.252)\end{array}$ & $\begin{array}{l}-0.587^{* * *} \\
(0.151)\end{array}$ & $\begin{array}{l}-0.586^{* *} \\
(0.299)\end{array}$ & $\begin{array}{l}-0.098 \\
(0.157)\end{array}$ & $\begin{array}{l}-0.086 \\
(0.097)\end{array}$ & $\begin{array}{l}-0.012 \\
(0.073)\end{array}$ & $\begin{array}{c}0.126 \\
(0.101)\end{array}$ & $\begin{array}{l}0.351^{* *} \\
(0.157)\end{array}$ & $\begin{array}{l}-0.299 * * \\
(0.131)\end{array}$ & $\begin{array}{c}0.060 \\
(0.116)\end{array}$ & $\begin{array}{l}-0.658 * * * \\
(0.158)\end{array}$ \\
\hline tooth brush & $\begin{array}{l}0.529 * * \\
(0.229)\end{array}$ & $\begin{array}{l}0.515^{* * *} \\
(0.214)\end{array}$ & $\begin{array}{l}0.541^{* *} \\
(0.238)\end{array}$ & $\begin{array}{c}0.183^{*} \\
(0.104)\end{array}$ & $\begin{array}{l}0.153^{* *} \\
(0.070)\end{array}$ & $\begin{array}{c}0.030 \\
(0.044)\end{array}$ & $\begin{array}{c}0.034 \\
(0.223)\end{array}$ & $\begin{array}{l}-0.144 \\
(0.166)\end{array}$ & $\begin{array}{c}0.114 \\
(0.283)\end{array}$ & $\begin{array}{l}-0.041 \\
(0.053)\end{array}$ & $\begin{array}{l}-0.193 \\
(0.162)\end{array}$ \\
\hline tooth paste & $\begin{array}{l}-0.076 \\
(0.190)\end{array}$ & $\begin{array}{l}0.565^{* * *} \\
(0.218)\end{array}$ & $\begin{array}{l}-0.301 \\
(0.227)\end{array}$ & $\begin{array}{l}-0.015 \\
(0.077)\end{array}$ & $\begin{array}{c}0.014 \\
(0.057)\end{array}$ & $\begin{array}{l}-0.029 \\
(0.028)\end{array}$ & $\begin{array}{c}0.239 \\
(0.148)\end{array}$ & $\begin{array}{c}0.079 \\
(0.157)\end{array}$ & $\begin{array}{l}-0.263 \\
(0.239)\end{array}$ & $\begin{array}{c}0.004 \\
(0.059)\end{array}$ & $\begin{array}{c}0.148 \\
(0.104)\end{array}$ \\
\hline yogurt & $\begin{array}{l}-1.342^{* * *} \\
(0.317) \\
\end{array}$ & $\begin{array}{l}-0.319 \\
(0.271) \\
\end{array}$ & $\begin{array}{l}-1.455^{* * *} \\
(0.417) \\
\end{array}$ & $\begin{array}{l}-0.341^{* * *} \\
(0.091) \\
\end{array}$ & $\begin{array}{l}-0.204^{* * *} \\
(0.069) \\
\end{array}$ & $\begin{array}{l}-0.137 * * * \\
(0.048) \\
\end{array}$ & $\begin{array}{c}0.010 \\
(0.118) \\
\end{array}$ & $\begin{array}{c}0.143 \\
(0.148) \\
\end{array}$ & $\begin{array}{l}-0.213^{* * *} \\
(0.086) \\
\end{array}$ & $\begin{array}{l}-0.265^{* * *} \\
(0.105) \\
\end{array}$ & $\begin{array}{l}-0.238 \\
(0.201) \\
\end{array}$ \\
\hline
\end{tabular}

Notes: City-specific weights are used to aggregate across UPCs (corresponds to column 4 in Table 2). 
Appendix Table 5. Cyclicality of pricing moments by store rank, alternative aggregation across UPCs.

\begin{tabular}{|c|c|c|c|c|c|c|}
\hline \multirow[t]{2}{*}{ "Dependent variable } & \multicolumn{2}{|c|}{ "UPC rank sample: $\Omega_{\max }$} & \multicolumn{2}{|c|}{ "UPC rank sample: $\Omega_{90}$} & \multicolumn{2}{|c|}{ "UPC rank sample: $\Omega_{75}$} \\
\hline & $\begin{array}{l}\text { UR } \\
(1) \\
\end{array}$ & $\begin{array}{c}\text { UR } \times \text { rank } \\
(2) \\
\end{array}$ & $\begin{array}{l}\text { UR } \\
(4) \\
\end{array}$ & $\begin{array}{c}\text { UR } \times \text { rank } \\
(5) \\
\end{array}$ & $\begin{array}{l}\text { UR } \\
(7) \\
\end{array}$ & $\begin{array}{c}\text { UR } \times \text { rank } \\
(8) \\
\end{array}$ \\
\hline \multicolumn{7}{|l|}{ Sales } \\
\hline Frequency & $\begin{array}{l}-0.069 \\
(0.141)\end{array}$ & $\begin{array}{l}-1.213 * * * \\
(0.143)\end{array}$ & $\begin{array}{l}0.015 \\
(0.140)\end{array}$ & $\begin{array}{l}-1.368 * * * \\
(0.154)\end{array}$ & $\begin{array}{l}0.085 \\
(0.142)\end{array}$ & $\begin{array}{l}-1.503 * * * \\
(0.157)\end{array}$ \\
\hline Size & $\begin{array}{l}0.175^{*} \\
(0.092)\end{array}$ & $\begin{array}{l}-0.197 \\
(0.141)\end{array}$ & $\begin{array}{l}0.208^{* *} \\
(0.091)\end{array}$ & $\begin{array}{l}-0.259 \\
(0.166)\end{array}$ & $\begin{array}{l}0.217^{* * *} \\
(0.091)\end{array}$ & $\begin{array}{l}-0.276 \\
(0.183)\end{array}$ \\
\hline $\begin{array}{l}\text { Share of goods bought on } \\
\text { sales, } \omega_{m c t}\end{array}$ & $\begin{array}{l}0.225 \\
(0.163)\end{array}$ & $\begin{array}{l}-1.677 * * * \\
(0.210)\end{array}$ & $\begin{array}{l}0.332 * * \\
(0.168)\end{array}$ & $\begin{array}{l}-1.874 * * * \\
(0.227)\end{array}$ & $\begin{array}{l}0.412 * * * \\
(0.170)\end{array}$ & $\begin{array}{l}-2.030 * * * \\
(0.235)\end{array}$ \\
\hline $\begin{array}{l}\text { Growth rate of revenue } \\
\text { (month on month) }\end{array}$ & $\begin{array}{l}0.351 \\
(0.226)\end{array}$ & $\begin{array}{l}-0.779 * * * \\
(0.088)\end{array}$ & $\begin{array}{l}0.379^{*} \\
(0.221)\end{array}$ & $\begin{array}{l}-0.825^{* * *} \\
(0.088)\end{array}$ & $\begin{array}{l}0.414^{*} \\
(0.223)\end{array}$ & $\begin{array}{l}-0.893 * * * \\
(0.098)\end{array}$ \\
\hline \multicolumn{7}{|l|}{ Changes of regular prices } \\
\hline All & $\begin{array}{l}-0.024 \\
(0.072)\end{array}$ & $\begin{array}{l}-0.129 * * * \\
(0.043)\end{array}$ & $\begin{array}{l}-0.013 \\
(0.074)\end{array}$ & $\begin{array}{l}-0.151^{* * *} \\
(0.050)\end{array}$ & $\begin{array}{l}-0.005 \\
(0.074)\end{array}$ & $\begin{array}{l}-0.168 * * * \\
(0.053)\end{array}$ \\
\hline Positive & $\begin{array}{l}-0.008 \\
(0.048)\end{array}$ & $\begin{array}{l}-0.036 \\
(0.029)\end{array}$ & $\begin{array}{l}-0.002 \\
(0.049)\end{array}$ & $\begin{array}{l}-0.047 \\
(0.034)\end{array}$ & $\begin{array}{l}0.005 \\
(0.049)\end{array}$ & $\begin{array}{l}-0.060 * \\
(0.036)\end{array}$ \\
\hline Negative & $\begin{array}{l}-0.017 \\
(0.029)\end{array}$ & $\begin{array}{l}-0.093^{* * *} \\
(0.016)\end{array}$ & $\begin{array}{l}-0.011 \\
(0.030)\end{array}$ & $\begin{array}{l}-0.104 * * * \\
(0.019)\end{array}$ & $\begin{array}{l}-0.009 \\
(0.030)\end{array}$ & $\begin{array}{l}-0.108 * * * \\
(0.020)\end{array}$ \\
\hline \multicolumn{7}{|l|}{ Size } \\
\hline All & $\begin{array}{l}-0.098 * \\
(0.055)\end{array}$ & $\begin{array}{l}0.043 \\
(0.036)\end{array}$ & $\begin{array}{l}-0.110 * * \\
(0.055)\end{array}$ & $\begin{array}{l}0.066^{*} \\
(0.038)\end{array}$ & $\begin{array}{l}-0.110^{*} \\
(0.058)\end{array}$ & $\begin{array}{l}0.067 \\
(0.042)\end{array}$ \\
\hline Positive & $\begin{array}{l}-0.165^{*} \\
(0.090)\end{array}$ & $\begin{array}{l}-0.118 * * * \\
(0.035)\end{array}$ & $\begin{array}{l}-0.172 * \\
(0.093)\end{array}$ & $\begin{array}{l}-0.105^{* * *} \\
(0.040)\end{array}$ & $\begin{array}{l}-0.163^{*} \\
(0.095)\end{array}$ & $\begin{array}{l}-0.122^{* * *} \\
(0.044)\end{array}$ \\
\hline Negative & $\begin{array}{l}0.306^{* * *} \\
(0.078)\end{array}$ & $\begin{array}{l}-0.032 \\
(0.053)\end{array}$ & $\begin{array}{l}0.313^{* * * *} \\
(0.083)\end{array}$ & $\begin{array}{l}-0.046 \\
(0.067)\end{array}$ & $\begin{array}{l}0.296 * * * \\
(0.088)\end{array}$ & $\begin{array}{l}-0.015 \\
(0.078)\end{array}$ \\
\hline
\end{tabular}

Notes: This table corresponds to Table 3 in the text. The difference is that equal weights are used to aggregate ranks across UPCs. See the note to Table 3. 
Appendix Table 6. Use Price Differentials to Construct Relative Price Ranks of Stores: Store-Level Results.

\begin{tabular}{|c|c|c|c|c|c|c|}
\hline \multirow[t]{2}{*}{ "Dependent variable } & \multicolumn{2}{|c|}{ "UPC rank sample: $\Omega_{\max }$} & \multicolumn{2}{|c|}{ "UPC rank sample: $\Omega_{90}$} & \multicolumn{2}{|c|}{ "UPC rank sample: $\Omega_{75}$} \\
\hline & $\begin{array}{l}\text { UR } \\
(1) \\
\end{array}$ & $\begin{array}{l}\text { UR } \times \text { rank } \\
(2) \\
\end{array}$ & $\begin{array}{l}\text { UR } \\
(4) \\
\end{array}$ & $\begin{array}{c}\text { UR } \times \text { rank } \\
(5)\end{array}$ & $\begin{array}{l}\text { UR } \\
(7) \\
\end{array}$ & $\begin{array}{l}\text { UR } \times \text { rank } \\
(8) \\
\end{array}$ \\
\hline \multicolumn{7}{|l|}{ Sales } \\
\hline Frequency & $\begin{array}{l}-0.864 * * * \\
(0.189)\end{array}$ & $\begin{array}{l}-8.285^{* * *} \\
(0.785)\end{array}$ & $\begin{array}{l}-0.811^{* * *} \\
(0.202)\end{array}$ & $\begin{array}{l}-12.074 * * * \\
(1.050)\end{array}$ & $\begin{array}{l}-0.876 * * * \\
(0.216)\end{array}$ & $\begin{array}{l}-15.767 * * * \\
(1.068)\end{array}$ \\
\hline Size & $\begin{array}{l}-0.014 \\
(0.134)\end{array}$ & $\begin{array}{l}-0.533 \\
(0.672)\end{array}$ & $\begin{array}{l}-0.009 \\
(0.133)\end{array}$ & $\begin{array}{l}-0.298 \\
(0.972)\end{array}$ & $\begin{array}{l}-0.012 \\
(0.137)\end{array}$ & $\begin{array}{l}-0.554 \\
(1.262)\end{array}$ \\
\hline $\begin{array}{l}\text { Share of goods bought on } \\
\text { sales, } \omega_{m c t}\end{array}$ & $\begin{array}{l}-0.755^{* * *} \\
(0.178)\end{array}$ & $\begin{array}{l}-9.907 * * * \\
(1.021)\end{array}$ & $\begin{array}{l}-0.693^{* * *} \\
(0.193)\end{array}$ & $\begin{array}{l}-14.067 * * * \\
(1.323)\end{array}$ & $\begin{array}{l}-0.764 * * * \\
(0.205)\end{array}$ & $\begin{array}{l}-17.678^{* * *} \\
(1.396)\end{array}$ \\
\hline Growth rate of revenue & $\begin{array}{l}0.055 \\
(0.233)\end{array}$ & $\begin{array}{l}-0.239 * * * \\
(0.084)\end{array}$ & $\begin{array}{l}0.171 \\
(0.228)\end{array}$ & $\begin{array}{l}-0.424^{* * *} \\
(0.075)\end{array}$ & $\begin{array}{l}0.237 \\
(0.218)\end{array}$ & $\begin{array}{l}-0.541 * * * \\
(0.079)\end{array}$ \\
\hline \multicolumn{7}{|l|}{$\begin{array}{l}\text { Changes of regular prices } \\
\text { Frequency }\end{array}$} \\
\hline All & $\begin{array}{l}-0.072 \\
(0.084)\end{array}$ & $\begin{array}{l}-0.898 * * * \\
(0.223)\end{array}$ & $\begin{array}{l}-0.067 \\
(0.084)\end{array}$ & $\begin{array}{l}-0.998 * * * \\
(0.369)\end{array}$ & $\begin{array}{l}-0.073 \\
(0.085)\end{array}$ & $\begin{array}{l}-1.310^{* * *} \\
(0.514)\end{array}$ \\
\hline Positive & $\begin{array}{l}-0.029 \\
(0.049)\end{array}$ & $\begin{array}{l}-0.419 * * * \\
(0.149)\end{array}$ & $\begin{array}{l}-0.027 \\
(0.049)\end{array}$ & $\begin{array}{l}-0.394 \\
(0.239)\end{array}$ & $\begin{array}{l}-0.030 \\
(0.049)\end{array}$ & $\begin{array}{l}-0.638^{*} \\
(0.338)\end{array}$ \\
\hline Negative & $\begin{array}{l}-0.043 \\
(0.039)\end{array}$ & $\begin{array}{l}-0.479 * * * \\
(0.091)\end{array}$ & $\begin{array}{l}-0.040 \\
(0.039)\end{array}$ & $\begin{array}{l}-0.604^{* * *} \\
(0.144)\end{array}$ & $\begin{array}{l}-0.043 \\
(0.039)\end{array}$ & $\begin{array}{l}-0.672^{* * *} \\
(0.194)\end{array}$ \\
\hline \multicolumn{7}{|l|}{ Size } \\
\hline All & $\begin{array}{l}-0.103^{* *} \\
(0.050)\end{array}$ & $\begin{array}{l}-0.026 \\
(0.206)\end{array}$ & $\begin{array}{l}-0.103^{* *} \\
(0.050)\end{array}$ & $\begin{array}{l}0.165 \\
(0.262)\end{array}$ & $\begin{array}{l}-0.103^{* *} \\
(0.050)\end{array}$ & $\begin{array}{l}-0.016 \\
(0.297)\end{array}$ \\
\hline Positive & $\begin{array}{l}-0.198 * * * \\
(0.083)\end{array}$ & $\begin{array}{l}-0.253 \\
(0.182)\end{array}$ & $\begin{array}{l}-0.196 * * * \\
(0.084)\end{array}$ & $\begin{array}{l}-0.626 * * * \\
(0.230)\end{array}$ & $\begin{array}{l}-0.200 * * * \\
(0.084)\end{array}$ & $\begin{array}{l}-0.747 * * * \\
(0.204)\end{array}$ \\
\hline Negative & $\begin{array}{l}0.286^{* * *} \\
(0.069)\end{array}$ & $\begin{array}{l}-0.361 \\
(0.245)\end{array}$ & $\begin{array}{l}0.289 * * * \\
(0.070)\end{array}$ & $\begin{array}{l}-0.334 \\
(0.362)\end{array}$ & $\begin{array}{l}0.286 * * * \\
(0.070)\end{array}$ & $\begin{array}{l}-0.624 \\
(0.421)\end{array}$ \\
\hline
\end{tabular}

Notes: The table corresponds to Table 3 in the paper. The rank of the store is calculated using the percent deviation of a given UPC's price in a given store from the median price of the UPC in a given market and month. These percent deviations are aggregated across UPCs using equal weights or expenditure shares. This table is constructed using equal weights. Driscoll and Kraay (1998) standard errors are in parentheses. ***, **, * denote significance at $0.01,0.05$, and 0.10 levels. See text and the note for Table 3 for further details. 
Appendix Table 7. Use Price Differentials to Construct Relative Price Ranks of Stores: HouseholdLevel Results.

\begin{tabular}{ccc}
\hline \hline $\begin{array}{c}\text { Sample of UPCs } \\
\text { used in ranking } \\
\text { stores }\end{array}$ & Equal weights to all goods & $\begin{array}{c}\text { Goods are weighted by } \\
\text { expenditure shares }\end{array}$ \\
\cline { 2 - 3 }$\Omega_{\max }$ & $(1)$ & $(2)$ \\
& $-0.994^{* * *}$ & -0.611 \\
$\Omega_{90}$ & $(0.354)$ & $(0.575)$ \\
& $-0.790^{* *}$ & -0.548 \\
& $(0.358)$ & $(0.588)$ \\
$\Omega_{75}$ & $-0.561^{* *}$ & -0.567 \\
& $(0.292)$ & $(0.555)$ \\
\hline \hline
\end{tabular}

Notes: The table corresponds to Table 4 in the paper. The rank of the store is calculated using the percent deviation of a given UPC's price in a given store from the median price of the UPC in a given market and month. These percent deviations are aggregated across UPCs using equal weights (column 1) or expenditure shares (column 2). Driscoll and Kraay (1998) standard errors are in parentheses. ***, **, * denote significance at $0.01,0.05$, and 0.10 levels. See text and the note for Table 4 for further details. 
Appendix Figure 1. Sensitivity of Output Gap Response to Contractionary Monetary Policy Shock
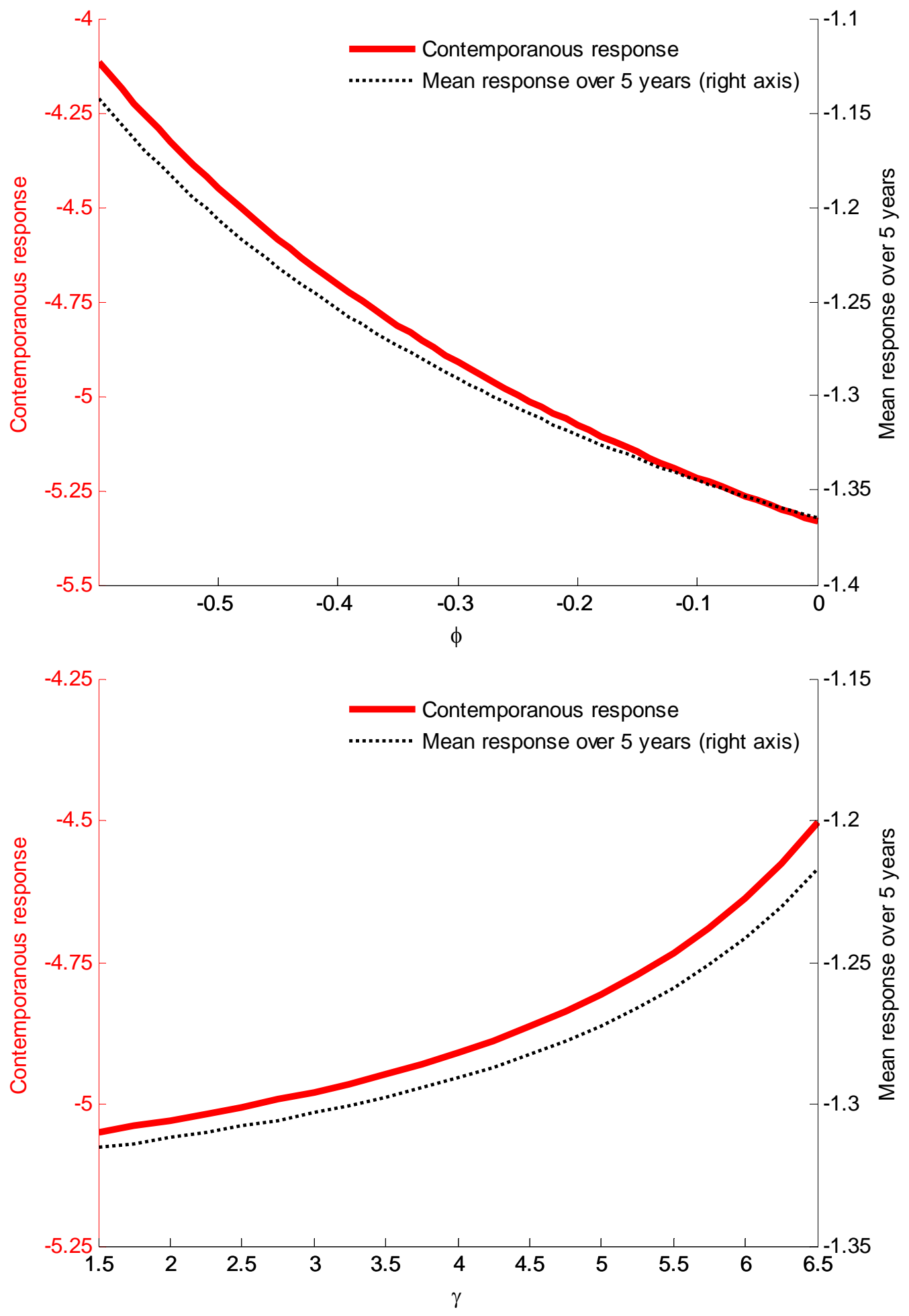

Notes: This figure shows the sensitivity of output gap response to a nominal shock as a function of two parameters $\phi$ (elasticity of iceberg cost with respect to shopping effort) and $\gamma$ (elasticity of substitution across stores). The mean response is the average response of output gap over 20 periods. 


\section{Appendix B: A Model of Store-Switching and Pro-Cyclical Sales}

In this section, we introduce a simple model of sales that allows us to understand how the frequency and depth of sales can be pro-cyclical as well as rationalize why stores may have different level of prices. We use Lal and Rao (1997) which provides a popular model of sales. In Lal and Rao (1997), there are two possible pricing strategies defined by the frequency of sales the retailer chooses to implement. The first type of pricing strategy is having no sales at all times while offering the lowest (regular) price in the market at all times. Such pricing strategy is called "every day low prices" or EDLP pricing. The second type of pricing strategy introduces temporary price cuts or sales for certain periods while maintaining the regular price at other times. Such pricing strategy is called "HiLo" or promotional pricing. To assess the cyclical patterns of sales, we incorporate a setting where there are two types of retailers, EDLP and HiLo, in the economy. While we assume the coexistence of the HiLo (high-price) and EDLP (low-price) retailers, Lal and Rao (1997) show that the coexistence of the EDLP and HiLo retailers is a unique Nash equilibrium.

The two stores compete over two different types of consumers: bargain hunters and loyal (or time constrained) consumers. These consumers differ in their transportation costs and in whether they observe sales prices. Bargain hunters have low transportation costs and always observe all prices, hence they buy a single unit from the store that offers the lowest cost that period (including transportation cost). Loyal consumers have higher transportation costs and do not observe current prices. As a result, they buy a single unit from the retailer which offers the lowest price (net of transportation costs) in expectation.

The purpose of our model is twofold: first, to describe the equilibrium pricing strategies in the given environment; second, to understand how optimal pricing strategies correlate with the changes in the economic conditions.

\section{Setup}

The setup of the model builds on Lal and Rao (1997). We abstract from various extensions considered in Lal and Rao (1997) to focus on the core properties relevant for our analysis.

\section{Stores}

There are two types of retailers that provide the same good: (1) Hi-Lo Retailer and (2) Every-day-lowprices (EDLP) retailer. The HiLo retailer periodically sets a low discount price to attract "bargain hunters” (or consumers who would prefer to search for price discounts and buy goods at a lower price). The other type of retailer maintains the 'every day low price' (hereafter, EDLP) pricing strategy. The EDLP retailer sets a constant price to appeal to the "loyal/time-constrained" consumers, who have high opportunity cost and do not shop opportunistically. The rationale is based upon the idea that retailers use different pricing strategies to segment the market and maximize their profits, and consumers self-select based on their shopping preferences.

Both retailers sell exactly the same goods. However, the pricing strategies for each retailer differ: the EDLP offers low prices on any given good and it does not have sales. Denote the size of this basket discount at the EDLP store with $\delta$. The HiLo store offers occasional sales (or promotions) for certain length of time, while keeping the price at a pre-discounted (regular) price at other times. During the times of sales, the difference between the regular price and the sales price is $D$. We assume that the frequency of promotions is equal to $1 / 2$ so that sales happen every other period. ${ }^{24}$

There is a price level $R$ ("regular price") of the good that is recommended by the manufacturer. The price $R$ is fixed and taken as given by all agents in the economy. Without loss of generality, we follow Lal and Rao (1997) and assume that the stores have zero marginal cost of getting a good from a manufacturer.

We assume that there are two stores located on a unit interval with EDLP store located at 0 and with HiLo store located at 1.

\footnotetext{
${ }^{24}$ One can readily extend the model to the case where the HiLo randomizes sales with frequency $f$.
} 


\section{Buyers}

As mentioned above, there are two types of buyers: bargain hunters and loyal consumers. Bargain hunters buy any given good in the store that offer the cheapest price. On the other hand, loyal consumers buy any given good in the "closest" retailer, since they have high opportunity cost of searching. Buyers are uniformly distributed on the [0,1] interval. The cost of travel distance ' $x$ ' to a store is given by $x /\left(2 t_{B H}\right)$ and $x /\left(2 t_{L C}\right)$ for bargain hunters and loyal consumers. One may reasonably assume that $t_{B H}>t_{L C}$. Each buyer can purchase only one unit of good. We assume that the share of bargain hunters in total population is $\lambda$. To capture variation in the price sensitivity of consumers over the business cycle, we will vary $\lambda$ so that high values of $\lambda$ could be interpreted as recession times.

\section{Demand}

\section{Decision where to buy}

Loyal customers choose the store which offers the lowers cost (travel + price of a good). The marginal buyer at local $q$ is indifferent between EDLP and HiLo:

$$
\frac{q}{2 t_{L C}}+(R-\delta)=\frac{(1-q)}{2 t_{L C}}+\frac{1}{2}(R-D)+\frac{1}{2} R
$$

where $\frac{q}{2 t_{L C}}+(R-\delta)$ is the total cost of shopping in EDLP, $\frac{(1-q)}{2 t_{L C}}+\frac{1}{2}(R-D)+\frac{1}{2} R$ is the total cost of shopping in HiLo and $\frac{1}{2}(R-D)+\frac{1}{2} R$ is the expected prices paid by a loyal consumer in the HiLo store. Hence,

$$
q=\frac{1}{2}+t_{L C}\left(\delta-\frac{1}{2} D\right)
$$

The choice of bargain hunters depends on whether there is a sale in HiLo or not. With the sale in place, the marginal bargain hunter at location $s$ satisfies:

$$
\frac{s}{2 t_{B H}}+(R-\delta)=\frac{(1-s)}{2 t_{B H}}+(R-D) \Rightarrow s=\frac{1}{2}+t_{B H}(\delta-D) .
$$

Without a sale, the marginal bargain hunter at location $k$ satisfies:

$$
\frac{k}{2 t_{B H}}+(R-\delta)=\frac{(1-k)}{2 t_{B H}}+R \Rightarrow k=\frac{1}{2}+t_{B H} \delta<s
$$

\section{Demand levels}

The demand for the HiLo store with a sale is given by

$$
Q_{S}=\lambda(1-s)+(1-\lambda)(1-q)=\frac{1}{2}-\left(\lambda t_{B H}+(1-\lambda) t_{L C}\right) \delta+\left(\lambda t_{B H}+\frac{1}{2}(1-\lambda) t_{L C}\right) D .
$$

The demand for the HiLo store without a sale is given by

$$
Q_{N S}=\lambda(1-k)+(1-\lambda)(1-q)=\frac{1}{2}-\left(\lambda t_{B H}+(1-\lambda) t_{L C}\right) \delta+\frac{1}{2}(1-\lambda) t_{L C} D<Q_{S} .
$$

The (expected) demand for the EDLP store is given by

$$
Q_{E}=\frac{1}{2} \lambda(s+k)+(1-\lambda) q=\frac{1}{2}+\left(\lambda t_{B H}+(1-\lambda) t_{L C}\right) \delta-\frac{1}{2}\left(\lambda t_{B H}+(1-\lambda) t_{L C}\right) D .
$$

\section{Profits}

The expected profit for the HiLo store is given by

$$
\pi_{H i L o}=\frac{1}{2} Q_{S}(R-D)+\frac{1}{2} Q_{N S} R=\frac{1}{2} R\left\{1-2\left(\lambda t_{B H}+(1-\lambda) t_{L C}\right) \delta+\left(\lambda t_{B H}+(1-\lambda) t_{L C}\right) D\right\}-\frac{1}{2} Q_{S} D .
$$

The expected profit for the EDLP store is given by

$$
\pi_{E D L P}=Q_{E}(R-\delta) .
$$




\section{Optimality conditions}

The first-order conditions with respect to $\delta$ and $D$ for HiLo and EDLP respectively are:

$$
\begin{gathered}
\frac{\partial \pi_{E D L P}}{\partial \delta}=-\frac{1}{2}+R\left(\lambda t_{B H}+(1-\lambda) t_{L C}\right)-2 \delta\left(\lambda t_{B H}+(1-\lambda) t_{L C}\right)+\frac{1}{2} D\left(\lambda t_{B H}+(1-\lambda) t_{L C}\right)=0 \\
\frac{\partial \pi_{H i L O}}{\partial D}=-\frac{1}{2}\left\{R\left(\lambda t_{B H}+(1-\lambda) t_{L C}\right)-\frac{1}{2}+\delta\left(\lambda t_{B H}+(1-\lambda) t_{L C}\right)-2 D\left(\lambda t_{B H}+\frac{1}{2}(1-\lambda) t_{L C}\right)\right\}=0
\end{gathered}
$$

Solving for $D^{*}$ and $\delta^{*}$, we can find that

$$
\begin{gathered}
D^{*}=3 \frac{2 R\left(\lambda t_{B H}+(1-\lambda) t_{L C}\right)-1}{7 \lambda t_{B H}+3(1-\lambda) t_{L C}}, \\
\delta^{*}=\frac{\left(3(1-\lambda) t_{L C}+5 \lambda t_{B H}\right) \times\left(2 R\left(\lambda t_{B H}+(1-\lambda) t_{L C}\right)-1\right)}{2 \times\left((1-\lambda) t_{L C}+\lambda t_{B H}\right) \times\left(7 \lambda t_{B H}+3(1-\lambda) t_{L C}\right)}=\frac{3(1-\lambda) t_{L C}+5 \lambda t_{B H}}{6 \times\left((1-\lambda) t_{L C}+\lambda t_{B H}\right)} D^{*}<D^{*} .
\end{gathered}
$$

In order for $0<\delta^{*}<D^{*}<R$ to hold, the following conditions should hold

$$
\frac{1}{2\left(\lambda t_{B H}+(1-\lambda) t_{L C}\right)}<R<\frac{3}{3(1-\lambda) t_{L C}-\lambda t_{B H}} .
$$

\section{Comparative statics}

Here, we check how the optimal size of discount is related to underlying economic conditions. We capture the state of economic conditions in the share of bargain hunters in the economy. We want to know how the optimal size of discounts depend on the share of bargain hunters:

$$
\frac{\partial D^{*}}{\partial \lambda}=\frac{-21 t_{B H}\left(R t_{L C}-1\right)-3 R t_{B H} t_{L C}-9 t_{L C}}{\left(7 \lambda t_{B H}+3(1-\lambda) t_{L C}\right)^{2}}
$$

If $t_{L C}=1$ (which could be just a normalization), $\frac{\partial D^{*}}{\partial \lambda}<0$ which means that the size of sales in the HiLo store decreases as there are more bargain hunters.

$$
\frac{\partial \delta^{*}}{\partial \lambda}=\frac{\partial D^{*}}{\partial \lambda} \times \frac{3(1-\lambda) t_{L C}+5 \lambda t_{B H}}{6 \times\left((1-\lambda) t_{L C}+\lambda t_{B H}\right)}+D^{*} \times \frac{t_{L C} t_{B H}}{3 \times\left((1-\lambda) t_{L C}+\lambda t_{B H}\right)^{2}}
$$

The second term in $\frac{\partial \delta^{*}}{\partial \lambda}$ is unambiguously positive and thus the sign of $\frac{\partial \delta^{*}}{\partial \lambda}$ depends on the relative sizes of the first and second terms. However, because $\frac{3(1-\lambda) t_{L C}+5 \lambda t_{B H}}{6 \times\left((1-\lambda) t_{L C}+\lambda t_{B H}\right)}<1$ and the second term is positive, it is clear that $\frac{\partial D^{*}}{\partial \lambda}<\frac{\partial \delta^{*}}{\partial \lambda}$. One may interpret this result as suggesting that the size of the discount in the EDLP store is less sensitive to changes in the business conditions. 


\section{APPENDIX C: SECOND ORDER APPROXIMATION TO UTILITY WITH ENDOGENOUS SHOPPING EFFORT AND STORE-SWITCHING}

The second-order approximation to utility is:

$$
\begin{aligned}
U_{t}= & \log C_{t}+\log \left(1-L_{t}-S_{t}\right) \\
\approx & \log \bar{C}+\frac{1}{\bar{C}}\left(C_{t}-\bar{C}\right)-\frac{1}{2}\left(\frac{1}{\bar{C}}\right)^{2}\left(C_{t}-\bar{C}\right)^{2}+\log (1-\bar{L}-\bar{S})+\frac{-1}{1-\bar{L}-\bar{S}}\left(L_{t}-\bar{L}\right)+\frac{-1}{1-\bar{L}-\bar{S}}\left(S_{t}-\bar{S}\right)- \\
& \frac{1}{2}\left(\frac{1}{1-\bar{L}-\bar{S}}\right)^{2}\left(L_{t}-\bar{L}\right)^{2}-\frac{1}{2}\left(\frac{1}{1-\bar{L}-\bar{S}}\right)^{2}\left(S_{t}-\bar{S}\right)^{2}-\left(\frac{1}{1-\bar{L}-\bar{S}}\right)^{2}\left(L_{t}-\bar{L}\right)\left(S_{t}-\bar{S}\right)+\text { h.o.t. } \\
= & \text { t.i.p. }+\left(\check{C}_{t}+\frac{1}{2} \check{C}_{t}^{2}\right)-\frac{1}{2} \check{C}_{t}^{2}-\eta_{L}\left(\check{L}_{t}+\frac{1}{2} \breve{L}_{t}^{2}\right)-\eta_{S}\left(\check{S}_{t}+\frac{1}{2} \check{S}_{t}^{2}\right)-\frac{1}{2} \eta_{L}^{2} \check{L}_{t}^{2}-\frac{1}{2} \eta_{S}^{2} \check{S}_{t}^{2}-\eta_{L} \eta_{S}\left(\check{L}_{t}+\right. \\
& \left.\quad \frac{1}{2} \check{L}_{t}^{2}\right)\left(\check{S}_{t}+\frac{1}{2} \check{S}_{t}^{2}\right)+\text { h. o.t. } \\
= & \text { t.i.p. }+\check{C}_{t}-\eta_{L} \check{L}_{t}-\frac{1}{2} \eta_{L}\left(1+\eta_{L}\right) \check{L}_{t}^{2}-\eta_{S} \check{S}_{t}-\frac{1}{2} \eta_{S}\left(1+\eta_{S}\right) \check{S}_{t}^{2}-\bar{L} \eta_{S} \check{L}_{t} \check{S}_{t}+\text { h.o.t. }
\end{aligned}
$$

where $\eta_{L} \equiv \frac{\bar{L}}{1-\bar{L}-\bar{S}}=\left(\frac{\sigma-1}{\sigma}\right)\left(\frac{\alpha}{\mu}\right), \eta_{S} \equiv \frac{\bar{S}}{1-\bar{L}-\bar{S}}=-\frac{\phi}{2}$ when $\bar{\tau}=\mu$, and following Woodford (2003), $X_{t}-\bar{X}=\bar{X}\left(\check{X}_{t}+\frac{1}{2} \check{X}_{t}^{2}\right)$.

From the derivation of the model in the text with $\bar{\tau}=\mu$, we have $\check{Y}_{t}=\check{X}_{t}+\check{Z}_{t}$ and $\check{S}_{t}=$ $\frac{\alpha}{\mu}\left(\frac{\sigma-1}{\sigma}\right) \frac{1}{\phi-1-\frac{1}{2} \gamma \phi} \check{L}_{t}$. Given the production function $Y_{t}(i)=Z_{t} N_{t}(i)^{\alpha}$, it follows that

$$
\begin{gathered}
\Rightarrow N_{t}=\int_{0}^{1} N_{t}(i) d i=\int_{0}^{1}\left(\frac{Y_{t}(i)}{Z_{t}}\right)^{1 / \alpha} d i=\left(\frac{Y_{t}}{Z_{t}}\right)^{1 / \alpha} \int_{0}^{1}\left(\frac{Y_{t}(i)}{Y_{t}}\right)^{1 / \alpha} d i=\left(\frac{Y_{t}}{Z_{t}}\right)^{1 / \alpha} \int_{0}^{1}\left(\frac{P_{t}(i)}{P_{t}}\right)^{-\sigma / \alpha} d i \\
\Rightarrow Y_{t}=Z_{t} N_{t}^{\alpha}\left\{\int_{0}^{1}\left(\frac{P_{t}(i)}{P_{t}}\right)^{-\frac{\sigma}{\alpha}} d i\right\}^{-\alpha} \\
\Rightarrow \check{Y}_{t}=\check{Z}_{t}+\alpha \breve{N}_{t}-d_{t}
\end{gathered}
$$

where $d_{t} \equiv \alpha \log \left\{\int_{0}^{1}\left(\frac{P_{t}(i)}{P_{t}}\right)^{-\frac{\sigma}{\alpha}} d i\right\}$. From the labor market clearing conditions, we have $N_{t}=L_{t} \Rightarrow \breve{N}_{t}=$ $\check{L}_{t}$. It follows that

$$
\check{L}_{t}=\breve{N}_{t}=\frac{1}{\alpha}\left(\check{Y}_{t}-\check{Z}_{t}+d_{t}\right)=\frac{1}{\alpha} \check{X}_{t}+\frac{1}{\alpha} d_{t}
$$

Also, one can show (see Gali 2008) that $d_{t}=\alpha \log \left\{\int_{0}^{1}\left(\frac{P_{t}(i)}{P_{t}}\right)^{-\frac{\sigma}{\alpha}} d i\right\} \approx \frac{1}{2} \frac{\sigma}{\Theta} \operatorname{var}_{i}\left(\log \left(P_{t}(i)\right)\right)$. Define $\Delta_{t} \equiv \operatorname{var}_{i}\left(\log \left(P_{t}(i)\right)\right)$. Woodford (2003) shows that

$$
\Delta_{t}=\theta \Delta_{t-1}+\frac{\theta}{1-\theta} \pi_{t}^{2}+h o t
$$

Hence, $E\left(\Delta_{t}\right)=\frac{\theta}{(1-\theta)^{2}} E\left(\pi_{t}^{2}\right)$. Thus, $E\left(d_{t}\right) \approx \frac{1}{2} \frac{\sigma}{\Theta} \frac{\theta}{(1-\theta)^{2}} E\left(\pi_{t}^{2}\right)$. 
Finally, for the link between consumption and output, given $C_{t}=\left(C_{A, t}^{\frac{\gamma-1}{\gamma}}+C_{B, t}^{\frac{\gamma-1}{\gamma}}\right)^{\gamma /(\gamma-1)},\left(C_{A, t}+\right.$ $\left.C_{B, t}\right)=Y_{t}$, and $\frac{C_{A, t}}{C_{B, t}}=\left\{\frac{\tau_{t}}{\mu}\right\}^{\gamma}$, we have $C_{t}=Y_{t} \Phi_{t}$ where $\Phi_{t} \equiv\left(\left(\frac{\tau_{t}}{\mu}\right)^{\gamma-1}+1\right)^{\frac{\gamma}{\gamma-1}} /\left\{\left(\frac{\tau_{t}}{\mu}\right)^{\gamma}+1\right\}$. So

$$
\begin{gathered}
C_{t}-\bar{C}=\bar{\Phi}\left(Y_{t}-\bar{Y}\right)+\left.\bar{Y} \frac{\partial \Phi_{t}}{\partial \tau_{t}}\right|_{\tau_{t}=\bar{\tau}}\left(\tau_{t}-\bar{\tau}\right)+0\left(Y_{t}-\bar{Y}\right)^{2}+\left.\frac{1}{2} \bar{Y} \frac{\partial^{2} \Phi_{t}}{\partial \tau_{t}^{2}}\right|_{\tau_{t}=\bar{\tau}}\left(\tau_{t}-\bar{\tau}\right)^{2} \\
+\left.\frac{\partial \Phi_{t}}{\partial \tau_{t}}\right|_{\tau_{t}=\bar{\tau}}\left(\tau_{t}-\bar{\tau}\right)\left(Y_{t}-\bar{Y}\right)
\end{gathered}
$$

Note that steady-state levels with $\bar{\tau}=\mu$ are given by $\bar{\Phi}=2^{\frac{1}{\gamma-1}},\left.\frac{\partial \Phi_{t}}{\partial \tau_{t}}\right|_{\tau_{t}=\bar{\tau}}=0$, and $\left.\frac{\partial^{2} \Phi_{t}}{\partial \tau_{t}^{2}}\right|_{\tau_{t}=\bar{\tau}}=-\frac{\gamma}{\mu^{2}} \frac{\bar{\Phi}}{4}$, so

$$
\begin{gathered}
C_{t}-\bar{C}=\bar{\Phi} \bar{Y} \check{Y}_{t}+0+0-\frac{1}{8} \gamma \bar{\Phi} \bar{Y} \check{\tau}_{t}^{2} \\
\Rightarrow \check{C}_{t}=\check{Y}_{t}-\frac{1}{8} \gamma \check{\tau}_{t}^{2}=\check{Y}_{t}-\frac{1}{8} \gamma \phi^{2} \check{S}_{t}^{2}=\check{X}_{t}+\check{Z}_{t}-\frac{1}{8} \gamma \phi^{2} \zeta^{2} \check{X}_{t}^{2}
\end{gathered}
$$

Now substituting into our approximation to utility yields

$$
\begin{aligned}
& U_{t}=\log C_{t}+\log \left(1-L_{t}-S_{t}\right) \\
& \approx \text { t.i.p. }+\check{C}_{t}-\eta_{L} \breve{L}_{t}-\frac{1}{2} \eta_{L}\left(1+\eta_{L}\right) \check{L}_{t}^{2}-\eta_{S} \check{S}_{t}-\frac{1}{2} \eta_{S}\left(1+\eta_{S}\right) \check{S}_{t}^{2}-\eta_{L} \eta_{S} \check{L}_{t} \check{S}_{t}+\text { h.o.t. } \\
& =\text { t.i.p. }+\left(\check{X}_{t}-\check{Z}_{t}+-\frac{1}{8} \gamma \phi^{2} \zeta^{2} \check{X}_{t}^{2}\right)-\left(\frac{\sigma-1}{\sigma}\right)\left(\frac{\alpha}{\mu}\right)\left(\frac{\check{X}_{t}}{\alpha}+\frac{d_{t}}{\alpha}+\frac{1}{2}\left\{\frac{\check{X}_{t}}{\alpha}+\frac{d_{t}}{\alpha}\right\}^{2}\right)+\frac{\phi}{2}\left(\zeta \check{X}_{t}+\zeta d_{t}+\right. \\
& \left.\frac{1}{2}\left\{\zeta \breve{X}_{t}+\zeta d_{t}\right\}^{2}\right)-\frac{1}{2}\left(\left(\frac{\sigma-1}{\sigma}\right)\left(\frac{\alpha}{\mu}\right)\right)^{2}\left\{\frac{\check{X}_{t}}{\alpha}+\frac{d_{t}}{\alpha}\right\}^{2}-\frac{1}{2}\left(\frac{\phi}{2}\right)^{2}\left\{\zeta \breve{X}_{t}+\zeta d_{t}\right\}^{2}- \\
& \left(\frac{\sigma-1}{\sigma}\right)\left(\frac{\alpha}{\mu}\right) \frac{-\phi}{2}\left\{\frac{\check{X}_{t}}{\alpha}+\frac{d_{t}}{\alpha}\right\}\left\{\zeta \breve{X}_{t}+\zeta d_{t}\right\}+\text { h.o.t. } \\
& =\text { t.i.p. }+\left[1-\left(\frac{\sigma-1}{\sigma}\right)\left(\frac{1}{\mu}\right)^{\frac{1}{2} \phi(1-\gamma)-1} \frac{1}{\phi-\frac{1}{2} \phi \gamma-1}\right] \check{X}_{t}+\left[-\left(\frac{\sigma-1}{\sigma}\right)\left(\frac{1}{\mu}\right) \frac{\frac{1}{2} \phi(1-\gamma)-1}{\phi-\frac{1}{2} \phi \gamma-1}\right] d_{t} \\
& -\frac{1}{2}\left(\frac{\sigma-1}{\sigma}\right)\left(\frac{1}{\mu}\right)\left[\frac{1}{\alpha}+\frac{1}{4} \gamma \phi^{2}\left(\frac{\sigma-1}{\sigma}\right)\left(\frac{1}{\mu}\right) \frac{1}{\left(\phi-\frac{1}{2} \phi \gamma-1\right)^{2}}-\frac{\phi}{2}\left(\frac{\sigma-1}{\sigma}\right)\left(\frac{1}{\mu}\right) \frac{1}{\left(\phi-\frac{1}{2} \phi \gamma-1\right)^{2}}\right] \check{X}_{t}^{2} \\
& -\frac{1}{2}\left\{\left(\frac{\sigma-1}{\sigma}\right)\left(\frac{1}{\mu}\right) \frac{\frac{1}{2} \phi(1-\gamma)-1}{\phi-\frac{1}{2} \phi \gamma-1}\right\}^{2} \check{X}_{t}^{2}+\text { h.o.t. }
\end{aligned}
$$

Therefore expected utility is

$$
\begin{aligned}
& E U_{t} \approx-\frac{1}{2}\left\{\left(\frac{\sigma-1}{\sigma \mu}\right) \frac{\frac{1}{2} \phi(1-\gamma)-1}{\phi-\frac{1}{2} \phi \gamma-1} \frac{\sigma}{\Theta} \frac{\theta}{(1-\theta)^{2}}\right\} E\left(\pi_{t}^{2}\right) \\
& -\frac{1}{2}\left\{\left(\frac{\sigma-1}{\sigma \mu}\right)\left[\frac{1}{\alpha}+\frac{1}{4} \gamma \phi^{2}\left(\frac{\sigma-1}{\sigma \mu}\right) \frac{1}{\left(\phi-\frac{1}{2} \phi \gamma-1\right)^{2}}-\frac{\phi}{2}\left(\frac{\sigma-1}{\sigma \mu}\right) \frac{1}{\left(\phi-\frac{1}{2} \phi \gamma-1\right)^{2}}\right]+\left\{\left(\frac{\sigma-1}{\sigma \mu}\right) \frac{\frac{1}{2} \phi(1-\gamma)-1}{\phi-\frac{1}{2} \phi \gamma-1}\right\}^{2}\right\} E\left(\check{X}_{t}^{2}\right) \\
& + \text { t.i.p. +h.o.t. }
\end{aligned}
$$

which after rearranging yields the expression in the text. 


\section{ApPendix D: Construction Of Data Moments}

This appendix describes how we constructed moments for the empirical analysis in sections II through IV.

Frequency of sales. The IRI data set provides a flag to indicate whether a given good was on sale in a given store in a given week. In addition to this flag, we use filters as in Nakamura and Steinsson (2008). Specifically, if a price is reduced temporarily (up to three weeks) and then returns to the level observed before the price cut, we identify this episode as a sale. When we apply this filter, we use two approaches to identify a price spell. In the first approach (approach "A"), we treat missing values as interrupting price spells. In other words, if a price was $\$ 4$ for two weeks, then price was missing for a week, and then again observed at $\$ 4$ for another three weeks, we treat the data as reporting two price spells with durations of two and three weeks. In the second approach (approach "B”), missing values do not interrupt price spells if the price is the same before and after periods of missing values. For example, in the previous example, approach " $\mathrm{B}$ " yields one price spell with the duration of five weeks. To identify the incidence of sales, we use the union of sales flags that we obtain from the IRI data set directly and from applying approaches " $A$ " and "B". In the end, using approaches " $A$ " and " $B$ " does not materially change the incidence of sales identified by the sales flag provided in the IRI data set. The frequency of sales is computed at the weekly frequency as the fraction of weeks in a month when a good is identified by the sales flag as being on sale.

Size of sales. The size of the sale is computed as the (log) difference between the sales price (the incidence of a sale is identified by the sales flag) and the price preceding the sale. Since one may have more than one sale in a month, we take the average size of sales in a month.

Share of goods sold on sale. The share of goods sold on sale for a given good in a given city (or store) in a given month is calculated as the following ratio. The numerator is the number of units sold during episodes identified as sales by the sales flag. The denominator is the total number of sold units.

Frequency of regular price changes. A price change in a given week is identified as regular if the following criteria are satisfied: i) the sales flag does not identify this week as a period when a good is on sale; ii) the sales flag does not identify the preceding week as a period when a good is on sale; iii) the price change is larger than one cent or one percent in absolute value (or more than 0.5 percent for prices larger than \$5). The last criterion removes small price changes which could arise from rounding errors and the like. Again, we use approaches " $\mathrm{A}$ " and " $\mathrm{B}$ " to identify the price in the preceding period. The incidence of regular price changes is the union of incidents identified by " $\mathrm{A}$ " and " $\mathrm{B}$ ". The frequency of regular price changes is computed at the weekly frequency as the fraction of weeks in a month when a good is identified as having a regular price change.

Size of regular price change. The size of the regular price change is computed as the (log) difference between the price in the period identified as having a regular price change and the price in the preceding period (using approach "A" and "B" to identify the preceding period). Since one may have more than one regular price change in a month, we take the average size of regular price changes in a month.

Weighting. To aggregate across goods to the category level, we employ three weighting schemes: $i$ ) equal weights; ii) expenditure shares for a given city and year ("city specific”); iii) cross-city expenditure shares for a given year (“common”). The city-specific expenditure share weights are calculated as 


$$
\omega_{m c t j}=\frac{\sum_{s} T R_{m s c t j}}{\sum_{k} \sum_{s} T R_{m s c t k}}
$$

and the common expenditure share weights are calculated as

$$
\omega_{c t j}=\frac{\sum_{m} \sum_{s} T R_{m s c t j}}{\sum_{m} \sum_{k} \sum_{s} T R_{m s c t k}}
$$

where $m, s, c, t$, and $j$ index markets, stores, product categories, time, and UPC, and $T R_{m s c t}$ is the revenue from selling good $j$ in the year covering month $t$.

To aggregate across goods and categories to the store level, we employ two weighting schemes: $i$ ) equal weights; ii) expenditure shares for a given store, good and year. The expenditure share weights are calculated as

$$
\omega_{m s c t j}=\frac{T R_{m s c t j}}{\sum_{k} \sum_{l} T R_{m s l t k}}
$$

where $T R_{m s c t j}$ is the revenue from selling good $j$ in the year covering month $t$. 